\title{
Friendship features associated with college students' friendship maintenance and dissolution following problems
}

\author{
Rebecca A. Owens \\ West Virginia University
}

Follow this and additional works at: https://researchrepository.wvu.edu/etd

\section{Recommended Citation}

Owens, Rebecca A., "Friendship features associated with college students' friendship maintenance and dissolution following problems" (2003). Graduate Theses, Dissertations, and Problem Reports. 1832. https://researchrepository.wvu.edu/etd/1832

This Dissertation is protected by copyright and/or related rights. It has been brought to you by the The Research Repository @ WVU with permission from the rights-holder(s). You are free to use this Dissertation in any way that is permitted by the copyright and related rights legislation that applies to your use. For other uses you must obtain permission from the rights-holder(s) directly, unless additional rights are indicated by a Creative Commons license in the record and/ or on the work itself. This Dissertation has been accepted for inclusion in WVU Graduate Theses, Dissertations, and Problem Reports collection by an authorized administrator of The Research Repository @ WVU. For more information, please contact researchrepository@mail.wvu.edu. 
Friendship Features Associated with College Students' Friendship Maintenance and Dissolution Following Problems

\title{
Rebecca A. Owens
}

\author{
Dissertation submitted to the \\ Eberly College of Arts and Sciences \\ in partial fulfillment of the requirements \\ for the degree of \\ Doctor of Philosophy \\ in \\ Psychology
}

JoNell Strough, Ph.D., Chair Katherine Karraker, Ph.D. B. Kent Parker, Ph.D. Michelle Sandrey, Ph.D. Matthew Scullin, Ph.D.

Department of Psychology

Morgantown, West Virginia 2003

Keywords: Friendship, Problems, Friendship Dissolution, College Students 


\begin{abstract}
Friendship Features Associated with College Students' Friendship Maintenance and Dissolution Following Problems
\end{abstract}

\title{
Rebecca A. Owens
}

This study examined the association between friendship features (i.e., support and resources, trust, similarity, common experiences, commitment, intimate communication, balance of costs and rewards, personal characteristics and behaviors, length of friendship, amount of time spent with friend, closeness of the friendship, and expected ease of finding a new friend) and friendship outcomes (maintenance vs. dissolution and overall quality) following college students' problems with their pre-college and college friends. Reported causes of college students' pre-college and college friendship problems and friendship dissolution were examined. In addition, links between experiencing problems with friends and adjustment were explored. Friendship features and problems were assessed through several written questionnaires. Precollege friendships were more susceptible to problems and dissolution than were college friendships. Expected ease of finding a new friend predicted friendship quality, maintenance, and dissolution for pre-college and college friends. Commitment and length of friendship predicted friendship quality for both types of friends, and the balance of costs and rewards predicted outcomes for college friends. College students did not identify the same causes of friendship problems and endings; a lack of common experiences was most likely to be mentioned as causing actual friendship dissolution but unlikely to be identified as causing friendship problems. When asked to indicate how often various specific events contributed to friendship problems and dissolution, students indicated that many events were more frequent and more important in their pre-college friendships. Students who indicated that they frequently experienced many problems with their friends also reported higher levels of loneliness and homesickness and lower levels of social support. Links between adjustment measures and frequency of specific types of friendship problems were identified. For example, students who frequently had problems associated with similarity reported using alcohol infrequently and had relatively high grade point averages. Results generally suggest that college students' friendship outcomes are similar to outcomes of other types of relationships. Implications for college personnel are discussed. 


\section{Acknowledgements}

I would like to thank JoNell Strough for serving as the chair of my committee. I also thank the members of my dissertation committee, Katherine Karraker, Kent Parker, Michelle Sandrey, and Matthew Scullin, for their comments and suggestions. In addition, I thank Paulette Southerly and Jennifer Napierkowski for their help with data collection, data entry, coding, and other tasks. Finally, I appreciate the instructors who allowed me to recruit participants from their classes. 
Table of Contents

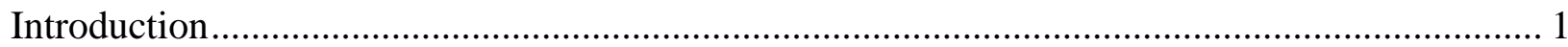

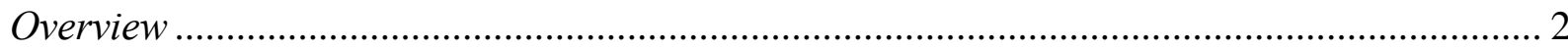

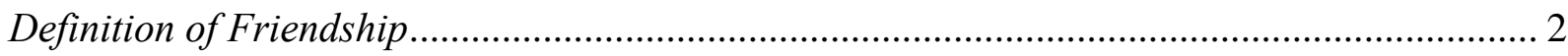

Developmental Changes in Friendships ...................................................................... 3

Friendship, Adjustment, and Well Being ................................................................. 5

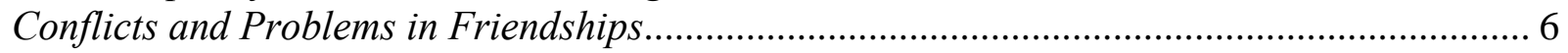

Pre-college and College Friends ........................................................................................ 7

Friendship Features Associated with Friendship Dissolution and Maintenance ...................... 7

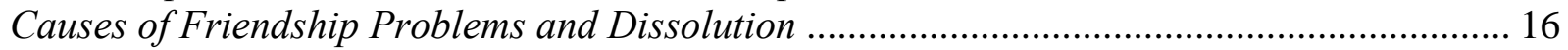

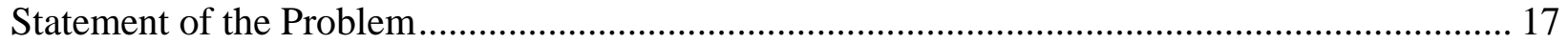

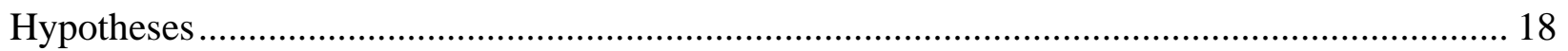

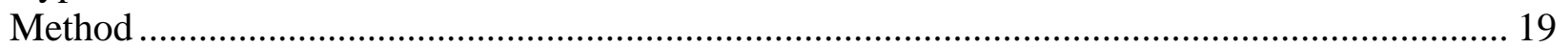

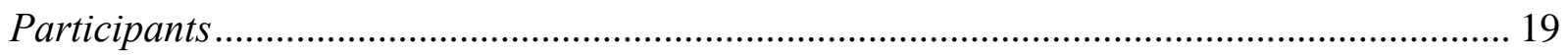

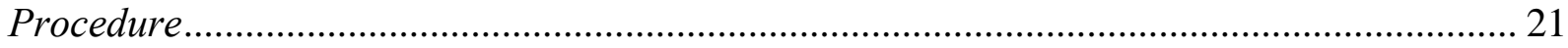

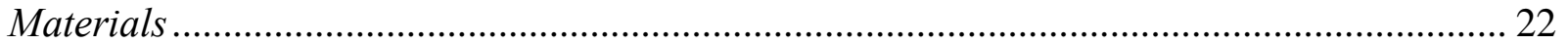

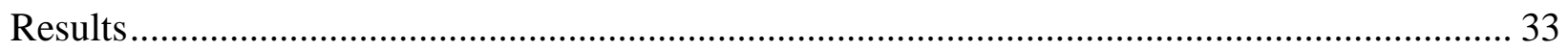

Descriptive Information .......................................................................................... 33

Friendship Maintenance, Dissolution, and Quality Following Problem Occurrence............. 35

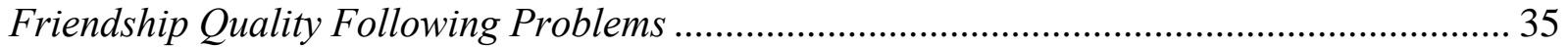

Friendship Maintenance or Dissolution Following Problems ............................................. 37

Causes of Friendship Dissolution ................................................................................... 39

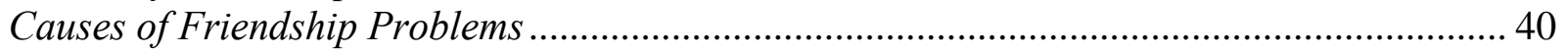

Pre-college and College Causes of Problems and Endings ............................................... 41

Gender Comparisons of Friendship Problems and Endings .............................................. 41

Prevalence of Friendship Problems................................................................................. 41

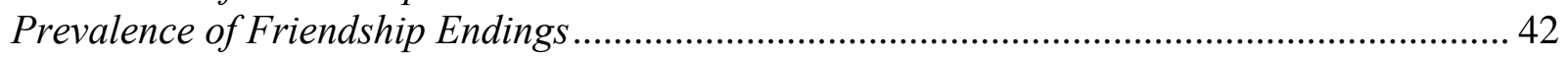

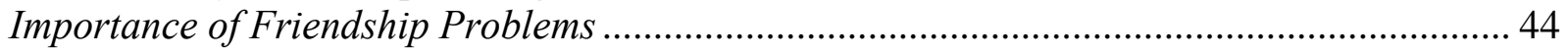

Importance of Events for Ending Friendships ............................................................. 45

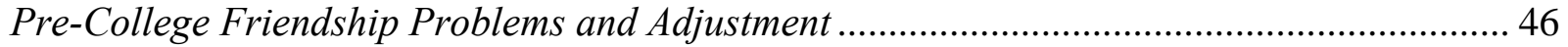

College Friendship Problems and Adjustment Measures .................................................. 50

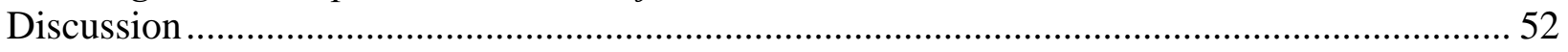

Friendship Quality Following Problems ...................................................................... 53

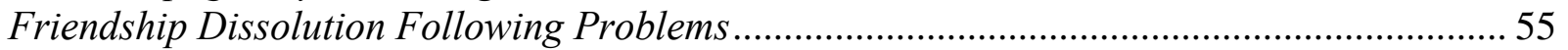

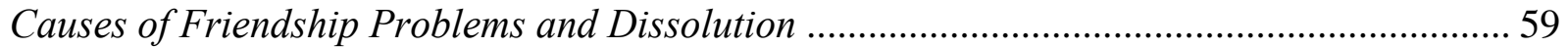

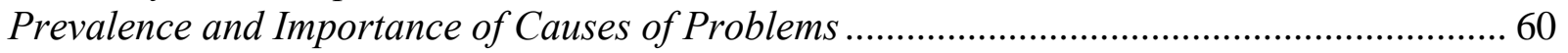

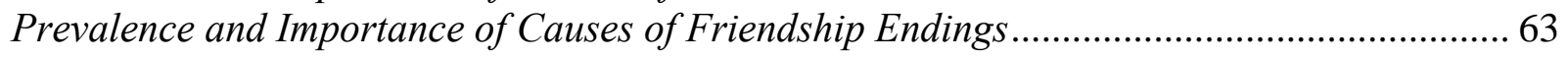

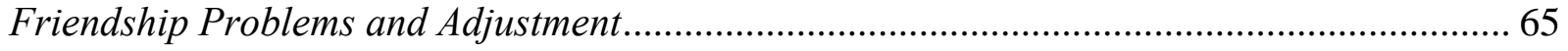

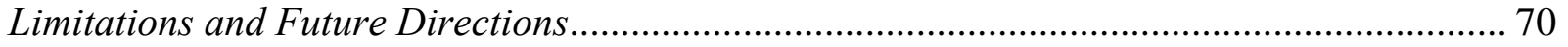

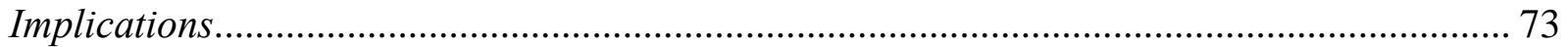

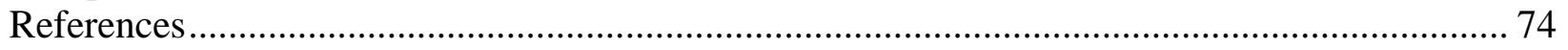

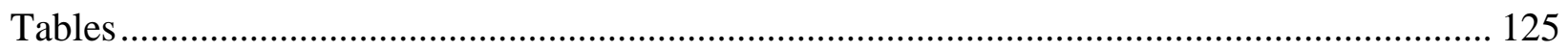

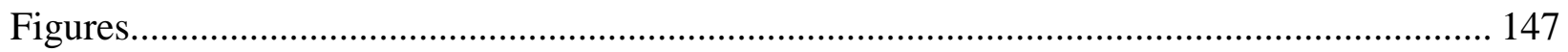




\section{List of Tables}

Table 1. Descriptive Statistics for Friendship Features Before Friendship Problems.... .125

Table 2. Cronbach's Alpha Levels for Event Prevalence and Importance Scales....

Table 3. Descriptive Information for Problems with Friends

Table 4. Descriptive Information for Friendship Endings

Table 5. Standardized and Unstandardized Regression Weights for Model Predicting PreCollege Friendship Quality From FriendshipFeatures.

Table 6. Standardized and Unstandardized Regression Weights for Model Predicting College Friendship Quality From Friendship Features

Table 7. Logistic Regression Analysis Predicting Pre-College Friendship Dissolution from 11 Friendship Features.

Table 8. Logistic Regression Analysis Predicting College Friendship Dissolution from 11 Friendship Features

Table 9. Means and (Standard Errors) for Friendship Type x Problem Frequency $x$ Gender MANOVA

Table 10. Means and (Standard Errors) for Results of Friendship Type x Ending Event Frequency $x$ Gender MANOVA.

Table 11. Means and (Standard Errors) for Results of Friendship Type x Problem Importance $x$ Gender Repeated Measures ANOVAs

Table 12. Means and (Standard Deviations) for Results of Friendship Type x Importance of Ending Event $x$ Gender MANOVA.....

Table 13. Intercorrelations Among Ratings of Problem Frequency. .143

Table 14. Intercorrelations Among Adjustment Items.... 
Friendship Features vi

Table 15. Intercorrelations Among Coping Strategies.................................145

Table 16. Correlations of Coping Strategies and Adjustment Measures.......................146 
Friendship Features vii

\section{List of Figures}

Figure 1. Percentage of reported causes of problems and causes of friendship dissolution for pre-college and college friends....................................... 148

Figure 2. Males' and Females' mean ratings of the frequency of causes of friendship

dissolution............................................................. 149 
Friendship Features Associated with College Students' Friendship Maintenance and Dissolution Following Problems

The purpose of the present study was to investigate the factors that are important to the maintenance and dissolution of friendships during the college years. Particular emphasis is placed on the problems college students experience with their friends. The transition to college represents a significant change in relationships with peers. College students often spend the majority of their time with peers, especially if they do not live with their parents. As a result, friends made in college likely provide important support for students. Research suggests that friendships are associated with well being and adjustment (e.g., Brissette, Scheier, \& Carver, 2002; Dwyer \& Cummings, 2001; Hussong, Hicks, Levy, \& Curran, 2001). For example, students who have close friends tend to have higher levels of academic achievement and are less likely to abuse alcohol as compared to other students. If individuals do benefit from having friends, then it is valuable to understand what makes friendships last and what predicts their failure. Most friendship research is centered on the formation and qualities of friendships (e.g., Hays, 1985) rather than on the factors associated with the maintenance and dissolution of friendships. However, it is particularly important to consider friendship maintenance, dissolution, and quality following problems, because problems represent times when decisions often are made about whether or not to maintain a friendship. It is likely that many features of friendships contribute to whether friendships will dissolve following problems, and differences in the impact of particular features likely exist between pre-college friends (i.e., friends that were made prior to beginning college) and college friends (i.e., friends that were made during the college years). Consideration of the association between specific friendship features and friendship outcomes is necessary to provide a more comprehensive picture of friendship dissolution. Additional 
information about the causes of friendship problems and friendship dissolution is needed to help to illustrate complex friendship processes of college students.

\section{Overview}

The following review of the literature will consider a number of issues. First, friendship will be defined. Developmental changes in friendships, particularly during the transition to college, will be discussed. The benefits of having friends in terms of the potential links between friendship problems and adjustment and well being also will be explored. In addition, literature suggesting that conflicts are normal parts of friendships and that problems are contexts in which decisions about friendships are made will be reviewed. Friendship features that may be associated with friendship maintenance or dissolution following problems will be discussed. Finally, the importance of considering causes of friendship problems and friendship dissolution separately will be explored.

\section{Definition of Friendship}

In daily life, college students often spend time in environments where they are naturally together. For example, when they go to school or work, they often spend time interacting with peers. Within groups of peers, some members get to know each other well and form friendships. According to Auhagen (1996), friendships are informal social relationships between two people. In addition, friendships are mutual relationships, are voluntary relationships, occur over time (i.e., they have past and future components), include positive emotions, include no overt sexuality, and have some value to the friends (Auhagen). In friendship relationships, the actions of one member of a pair depend on the actions of the other member (Wright \& Keple, 1981).

Other characteristics (also known as features or factors) also are typically present in friendships. For example, Auhagen's (1996) review of the literature suggests that friendships 
differ in terms of frequency, content, and quality of interactions, self-disclosure, and closeness of the friendship. Furthermore, individuals enter friendships because they tend to enjoy each other's company; friends also share reciprocal affection (Rubin, Bukowski, \& Parker, 1998). People who are friends generally work to resolve conflicts when they occur and are faithful to each other (Newcomb \& Bagwell, 1995).

\section{Developmental Changes in Friendships}

During and beyond adolescence, individuals' expectations about friends change and the dynamics of friendships also change (e.g., Newcomb \& Bagwell, 1995; Rubin et al., 1998;

Selman \& Schultz, 1990). For example, younger adolescents may end friendships if their friends make new friends (see Owens \& Strough, 2002), but older adolescents are more likely to recognize that it is important for their friends to also have other relationships (Selman \& Schultz). This issue is particularly significant when individuals begin college.

The transition to college is both an exciting and an anxiety-provoking experience (Paul \& Kelleher, 1995). New college students often experience loneliness and social anxiety as they enter into a new environment (Larose \& Boivin, 1998) and may also experience psychological disturbances and absent-mindedness (Fisher \& Hood, 1987). The beginning of college also represents a significant shift in the dynamics of friendships. During the transition, individuals face the possibility of new friendship development and possible pre-college friendship loss at the same time (Paul \& Kelleher).

When individuals enter college, they meet new people and begin to establish new groups of friends. Meeting new people and forming new social networks are important developmental tasks for college students (Strough, Swenson, Owens, \& Pickard, 2002). Prior to beginning college, individuals likely have existing social networks; high school students attend school in a 
familiar environment and typically have known their friends for several years. For adolescents, friendships provide opportunities to maintain a sense of belonging to a group, which is a fundamental motivation of humans (Baumeister \& Leary, 1995). Prior to college, individuals value personal relationships with general groups of peers; a common problem early adolescents identify is feeling excluded from the peer group (Owens \& Strough, 2002). It is likely that college students also will strive to be members of peer social groups, because the transition to college is a time when group membership is important (e.g., Paul \& Kelleher, 1995).

In addition to concerns with the general peer group, college students also are concerned with their friendships. The college environment typically requires significant changes in precollege friendship circles, and college students face the task of making new friends. Research suggests that it takes new college students a long time to form friendships at school. Specifically, after being in college for 10 weeks, many students do not identify college friends as being part of their social networks (Paul \& Brier, 2001; Paul \& Kelleher, 1995). Making new friends is one indicator of social adjustment in college. Although college students cite making friends as an important task (Strough et al., 2002), much of the adjustment research has focused on academic adjustment (Paul \& Kelleher) rather than on social adjustment during the transition to college (Paul \& Brier; Paul \& Kelleher). Additional information regarding social adjustment for college students is needed.

Before college, individuals are likely to have made decisions about which friendships to keep and which to terminate (Aboud \& Mendelson, 1996). Upon entering college, individuals need to make similar decisions (e.g., Paul \& Kelleher, 1995). However, in college, students may focus on different components of friendships in deciding whether or not to maintain friendships, because friends may fill different roles in college as compared to high school friends. Such 
decisions are important in light of college students' increased reliance on peers. Part of the transition to college includes facing issues related to alcohol, roommates, sex, and newfound freedom. Friends likely play an important role in determining how individuals handle such issues (e.g., Hussong et al., 2001). Therefore, it is important to focus research attention on the role of college students' friends in predicting students' adjustment.

Friendship, Adjustment, and Well Being

As they adjust to a new and unfamiliar lifestyle, college students benefit from having friendships. People who have close relationships tend to be healthier (House, Landis, \& Umberson, 1988; Uchino, Uno, \& Holt-Lunstad, 1999), have a greater sense of purpose, and have more of a sense of belonging to a group (Baumeister \& Leary, 1995) as compared to individuals without close relationships. College friendships are associated with relatively high levels of perceived social support, effective coping with stress (Dwyer \& Cummings, 2001), and lower perceived levels of stress (Lakey \& Heller, 1988). Specifically, friends may provide instrumental support (e.g., lending money) or emotional support (e.g., help in coping with a bad day) (Fehr, 1999). In addition, college women who report satisfaction with their friendships also report lower levels of loneliness as compared to women with less satisfying friendships (Ponzetti \& Cate, 1988), and college students who have friendships are less likely to experience psychological disturbances as a result of loneliness (Fisher \& Hood, 1987).

College students who have friendships also may have academic benefits. For example, during college, individuals who have social support networks are more likely to seek help from their teachers when they are experiencing academic difficulties as compared to students without supportive networks (Larose, Bernier, Soucy \& Duchesne, 1999). The researchers suggest that friends may encourage students to seek needed help. 
Alcohol use also may be related to friendship. Hussong et al. (2001) found that college students who had intimate friendships were less likely to use alcohol to cope with feelings of sadness and hostility as compared to students without intimate friendships. Students may learn more effective coping strategies such as discussing problems with others when they participate in activities with others (Paul \& Kelleher, 1995). In general, coping with stress effectively may be associated with few friendship problems. On the other hand, students who experience many problems with their friends may not effectively handle stressful situations.

\section{Conflicts and Problems in Friendships}

In addition to the benefits associated with friendships, conflicts and everyday problems are part of the friendship experience. As friendships become closer, conflict becomes practically inevitable; friends discover their differences and recognize that friendships include costs as well as benefits (Hays, 1985). Conflicts can have several effects on friendships. Conflict resolution may lead to strengthening of the friendship, but conflicts also may lead to termination of the relationship (Weinstock \& Bond, 2000). Thus, problems in friendships represent times when friendships may or may not continue (Weinstock \& Bond).

The outcome of a friendship (i.e., maintenance or dissolution) following problems depends on several factors, including the understanding each friend has about conflict and friendship (Weinstock \& Bond, 2000). That is, some friends may assume that the relationship will continue and will work toward relationship maintenance, but others may evaluate the friendship and decide to end it when a problem develops. Because daily hassles and problems with friends are related to physical and mental health problems (Dwyer \& Cummings, 2001) and because problems can represent a turning point in friendships (Weinstock \& Bond), it is necessary to further explore the role of problems in predicting friendship outcomes. 


\section{Pre-college and College Friends}

One's pre-college friends and college friends will necessarily differ. Most importantly, pre-college friendships will be longer in duration as compared to college friendships. As a result, pre-college friends will have longer shared histories than will college friends. Previous research suggests that relationships that are longer in duration tend to be more stable as compared to shorter relationships (Owens \& Strough, 2002; Simpson, 1987). Over the course of long-lasting friendships, individuals likely share a variety of experiences, both positive and negative. Although pre-college friends may have shared greater numbers of experiences, college friends typically share different types of experiences than do pre-college friends. For example, college friends help each other with adjusting to new situations, and college friends often live together. Although pre-college and college friendships necessarily differ in length, it is important to consider how the two types of friendships differ in terms of additional factors.

\section{Friendship Features Associated with Friendship Dissolution and Maintenance}

Often it is assumed that friendships dissolve as a result of conflicts with friends. However, friendships end for other reasons as well. In one investigation, Azmitia, Lippman, and Ittel (1999) found that adolescents reported that best friends were likely to break-up if they experienced conflict, untrustworthiness, exclusion, unhelpfulness, or diverging interests. Azmitia et al. also found that friendships may deteriorate if an individual's friend forms new friendships, has bad personal qualities, violates rules, or no longer lives near the adolescent. The most common reason that early adolescents report as causing their friendship endings is a lack of common experiences (i.e., not doing things together) (Owens \& Strough, 2002). College students' friendships may dissolve for similar reasons. Furthermore, Fehr (1999) suggests that 
going away to college, moving to a new area, developing a serious illness, marriage, and other factors may contribute to the dissolution of young adults' friendships.

Although some information about friendship dissolution is available, little specific information is known about college students' friendship dissolution. Because few studies of friendship dissolution have been conducted, it is useful to draw from studies of friendship maintenance in predicting which friendship features are associated with friendship dissolution. It is presumed that a lack of friendship maintenance-related features is associated with friendship dissolution. Some of the main features related to friendship maintenance are outlined in the following section.

Support and Resources. By early adulthood, individuals begin to make the transition from relying on parents for support to also relying on peers for support (e.g., Bogat, Caldwell, Rogasch, \& Kriegler, 1985; Helsen, Vollegergh, \& Meeus, 2000; Scholte, van Lieshout, \& van Aken, 2001). Helsen et al. found that, in general, perceived peer support increases between the ages of 12 and 24. Peer support likely increases in importance as college students experience a lack of daily contact with their parents. Although college students use their parents as primary sources of general support, college students also rely on their friends for support (Bogat et al.). In particular, college friends provide support regarding specific problems encountered in daily life. They may rely on their friends for support with household tasks, academic demands, family relationships, and other daily activities. Parents may, on the other hand, provide general support such as encouragement to pursue career goals; parents may receive phone calls from students who simply want to be reassured that "everything will be all right."

Individuals may terminate friendships when they do not feel that their friends are supportive (e.g., Hays, 1985). Important specific areas of support may, however, be different for 
different types of friends. For example, pre-college friends may provide general support, and college friends may provide support with specific daily problems. Feeling supported in some way by friends is likely to be important to the maintenance of both pre-college and college friendships. When friends experience problems, they may terminate their friendships if they feel unsupported.

Trust. Another important feature of friendships is trust (Azmitia et al., 1999; Jones, 1991; Rawlins \& Holl, 1989; Selman \& Schultz, 1990). For example, Jones (1991) found that trust in one's friends is one of the main predictors of friendship satisfaction for college students. That is, when college students form new friendships, they value trust in those relationships. It is likely that longer-lasting pre-college friendships include a component of trust and that pre-college friends have resolved trust-related problems. Therefore, it is likely that college students will experience friendship dissolution with friends they do not trust following problems in their college friendships more often than they will experience friendship dissolution in untrusting relationships with their pre-college friends.

Similarity. Researchers argue that friends tend to be like each other in many ways (e.g., Akers, Jones, \& Coyl, 1998; Henderson \& Furnham, 1982; Newcomb \& Bagwell, 1995; Tolson \& Urberg, 1993). For example, friends share similar interests, personalities, self-concepts, levels of aggression (Newcomb \& Bagwell, 1995), levels of delinquency, frequency of substance use, mutual friends (Akers et al.; Urberg, Degirmencioglu, \& Tolson, 1998), and activity choices (Akers et al.; Newcomb \& Bagwell; Werner \& Parmelee, 1979).

Individuals also are more likely to form friendships with people who share their values (Hill \& Stull, 1981; Lea \& Duck, 1982; Newcomb \& Bagwell, 1995; Stensrud, 1986). Lea and Duck found that individuals who had been friends for between 4 and 6 months reported 
similarity in values. However, individuals who had been friends for 12 or more months did not show additional similarity in values. Other research (e.g., Clements, Cordova, Markman, \& Laurenceau, 1997) suggests that similarity leads people to begin relationships but does not lead to the maintenance of relationships. Thus, similarity may be a more important feature in new friendships as compared to well-established friendships, assuming the degree of similarity between the friends remains constant. Therefore, it is likely that friendships that formed in college would be more likely to dissolve following problems if friends are not similar to each other. The maintenance of pre-college friendships following problems may not depend as heavily on similarities. An exception to this idea is the possibility that individuals will change in terms of values and activity preferences as they make the transition to college. Friends who believed that they were similar in the past but perceive that they are no longer similar may terminate their friendships with dissimilar individuals.

Shared History. The type of experiences friends have shared also may play a role in friendship outcomes. Longer friendships offer opportunities for accumulated experiences (e.g., Fehr, 1999). Some of the experiences are likely to be particularly meaningful. Meaningful experiences may have a significant impact on the friends' development, and individuals likely value the experiences in such long-lasting friendships. For example, in Devlin's (1996) report about an optional pre-college orientation wilderness survival program, program participants indicated that they maintained their friendships with each other during their college years more than did non-participants. Therefore, the significance or impact of common experiences may be associated with friendship stability.

College students who have shared significant or intense experiences with their friends may be more likely to maintain friendships after problems occur as compared to students who 
have not shared meaningful experiences with their friends. Specifically, pre-college friendships are likely to dissolve following problems if the friends do not have significant or intense shared histories. Because college friends may not have had the opportunity to share as many significant past experiences, shared history is likely not as important in predicting post-problem college friendship outcomes.

Current Common Experiences. Sharing current common experiences also may enhance friendships. Engaging in mutually interesting activities is a strong predictor of making friends and maintaining friendships in college (Stensrud, 1986; Werner \& Parmelee, 1979). Fehr (1999) suggests that friendships are often more stable when friends live close to each other and have the opportunity to share experiences. Simply spending time together may be associated with friendship outcomes following problems. Spending time with individuals is associated with liking those individuals (Hill \& Stull, 1981), and romantic partners who spend little time together are likely to experience relationship dissolution (Felmlee, Sprecher, \& Bassin, 1990).

Friends who do not spend a lot of time together may not maintain their friendships (e.g., Felmlee et al., 1990). This suggests that pre-college friendships may end following problems because the friends do not currently share many common experiences. On the other hand, precollege friends may not need to have current common experiences to maintain friendships, because they have a shared history of experiences. A lack of current common experiences is particularly likely to predict friendship outcomes for college friendships; in the absence of long shared histories, college friends rely on exposure to maintain friendships.

Commitment. Friends of many ages (Fehr, 1999) identify commitment as being crucial to friendship stability. Commitment can be defined as the general perception that the friendship will be maintained (Winn, Crawford, \& Fischer, 1991) and the general assumption that one's friend is 
a better friend than would be alternative friends (Rusbult, 1980). Friendships are likely to continue when friends are committed to each other, and relationships seem likely to end when at least one friend is not committed to the friendship.

Because moving away to college leads to difficulty in friendship maintenance (Fehr, 1999), commitment is likely to be especially important in predicting the maintenance or dissolution of pre-college friendships. Commitment to friendships is necessary in order for precollege friends to keep in touch while they are separated, especially if problems occur in friendships. Individuals who are not interested in maintaining their friendships would, on the other hand, be less likely to attempt to resolve problems. College friendships may be less likely to dissolve if friends are not committed to the relationship, because it may be relatively easier to maintain relationships that include regular face-to-face interactions.

Communication. Being able to communicate well with friends is important to friends of various ages. Childhood friends are better able to resolve conflicts if they can communicate their objectives (e.g., Hartup, French, Laursen, Johnston \& Ogawa, 1993). Conflict resolution likely remains important for individuals at other ages. One aspect of communication that is particularly important to friendships is intimacy. Self-disclosure, a component of intimacy, is related to friendship satisfaction for college students (Jones, 1991). In a longitudinal study of first-year college student friendship development, intimacy increased as friendships became more intense (Hays, 1985). Furthermore, friendships that did not become intense did not include as much intimacy. In a study of roommates, individuals who were friends before living together shared more intimacy as compared to individuals who were not friends before living together (Hill \& Stull, 1981). 
The research outlined above suggests that communication, including intimate communication, in friendships is associated with greater relationship satisfaction. It is likely that friendships will be maintained more often if intimate communication is present in the relationship. College students may be more likely to terminate friendships with both pre-college friends and college friends following problems when communication is lacking.

Balance of Costs and Rewards. In friendships, individuals typically expect to both put effort into the relationship and to derive benefit from the relationship. Friends tend to be more satisfied when the costs of maintaining the relationship do not outweigh the benefits of the friendship (Rusbult, 1980) and may become angry when friendships are more costly than beneficial (Winn et al., 1991). In an investigation of previously unacquainted college roommates, those who were satisfied with their relationships with their roommates reported that friendship with their roommates became more rewarding (i.e., less costly) as the relationships progressed (Berg, 1984).

Thus, individuals whose efforts in a friendship exceed the benefits of the friendship are likely to experience friendship dissolution. This is likely to be the case for both pre-college and college friends. That is, when problems occur in friendships, individuals may decide that it is not worth maintaining costly friendships.

Personal Characteristics and Behaviors. A variety of personal characteristics are related to the desirability of particular college friendships. For example, a study of college students' perceptions of their friendships suggested that individuals were more satisfied with their friendships when they enjoyed the excitement their friends provided (Jones, 1991). In addition, previous work suggests an association between liking the type of person one's friend is and friendship maintenance during early adolescence (Owens \& Strough, 2002). 
When problems occur in friendships, individuals are not likely to remain friends with individuals whose personal characteristics they do not like much in the first place. Pre-college friendships likely are particularly vulnerable to dissolution if one friend disapproves of the other's personal characteristics. The separation due to the transition to college may offer individuals the opportunity to end friendships with individuals who have undesirable traits or behaviors. In addition, as individuals change during their transitions to college, their friends' personal characteristics and behaviors may become more or less appealing. College friendships may be less likely to end even if friends' characteristics are disliked, because individuals may feel that they do not have better options and because individuals rely on peers for support during the transition to college. That is, college students may settle for friends who may not have particularly attractive personal characteristics.

Expected Ease of Making a New Friend. Research shows that early adolescents who believe that making new friends would be easy are less likely to maintain existing friendships when problems occur (Owens \& Strough, 2002). Little other research has addressed the issue of expectations in terms of making new friends, however romantic relationships may dissolve when partners expect that they could easily find a new partner (Simpson, 1987). It is likely that college students' friendships will dissolve following problems if individuals feel that they could easily make new friends. Similar outcomes are likely for both pre-college friends and college friends. If problems occur in either type of friendship, individuals may feel that it is not worth maintaining the friendships if new friends could be made easily. Instead, new friends may be sought.

Gender Differences. It is possible that males and females differ in terms of the friendship features that predict friendship outcomes. Evidence suggests that males and females differ in terms of friendship features. For example, females report that they receive greater levels of social 
support from friends as compared to males (Dwyer \& Cummings, 2001; Jones, 1991).

Furthermore, adolescent and college females often report experiencing more intimacy in their friendships (Field, Lang, Yando, \& Bendell, 1995; Grabill \& Kerns, 2000; Hartup, 1993; Hays, 1985; Raja, McGee, \& Stanton, 1992) and spend more time together as compared to males (Hartup). Females are more likely to demonstrate casual affection with their close friends than are males, and males tend to form friendships based on shared activities (Hays). In spite of differences in males' and females' friendship experiences, previous research on gender differences in friendship features and outcomes indicates that males and females experience friendship maintenance and dissolution for similar reasons. Specifically, Owens and Strough (2002) found that friendship features associated with friendship maintenance and dissolution were similar for early adolescent males and females. Although friendship features may differ for males and females, the causes of relationship problems and dissolution might be the same.

Summary. Previous research suggests that a variety of friendship features are associated with the maintenance of college students' friends. College students typically experience friendships as positive when they include support and resources, trust, similarity, shared histories, current common experiences, commitment, intimate communication, a balance of costs and rewards, and desirable personal characteristics. Friendships lacking such features may dissolve following friendship problems. Problems represent contexts in which decisions about maintaining friendships occur. Pre-college friendships are particularly likely to dissolve following problems when the friendships include a lack of shared history, a lack of commitment, or disapproval of a friend's personal characteristics. Similarity, trust, and current common experiences are likely to be particularly important predictors of friendship outcomes following college friends' problems. It also should be noted that friendships that are maintained following 
problems may not be high quality relationships. That is, individuals may remain friends but not experience the friendship positively after problems occur or may experience a decline in their friendship quality following problems.

\section{Causes of Friendship Problems and Dissolution}

In addition to exploring the associations between friendship features and friendship outcomes following problems, it is important to consider the specific causes of problems and reasons for ending friendships. Although some friendships end as a result of conflicts, many friendships end gradually and without conflicts (Sprecher \& Fehr, 1998). A friendship also may end if one friend no longer wishes to maintain the friendship (Sprecher \& Fehr). For example, friendships may dissolve if friends gradually stop making attempts to keep in touch with each other when they go away to college. Also, problems often occur in maintained friendships. For example, friends may experience a temporary hassle and later resolve the problem. Thus, causes of friendship problems and friendship dissolution need to be considered separately. In addition, because little research has examined the topic, more information is needed to estimate the prevalence and importance of various specific causes of friendship problems and friendship endings as well as the relationship between problems and adjustment.

Previous research (Owens \& Strough, 2002) suggests that early adolescent friends experience problems and dissolution for different reasons. Specifically, friends reported that many problems were caused by feelings of exclusion from a group of peers and by issues related to a friend's personal characteristics. On the other hand, a lack of common experiences was the most common reported cause of friendship dissolution. Additional research is needed to determine if college students experience similar causes of friendship problems and friendship dissolution. Differences between causes of problems and causes of friendship dissolution for pre- 
college and college friends also are important to consider. Such information could be used to inform those who help college students with the transition from high school to college. Previous investigations have not addressed these issues.

\section{Statement of the Problem}

Friends are important parts of college students' lives, and problems often occur in friendships. When problems occur, individuals make decisions about whether to maintain or dissolve friendships. Previous research has illustrated features of friendships that are associated with friendship maintenance. However, it is not known whether a lack of friendship features associated with relationship maintenance (e.g., similar interests; common experiences) predicts friendship outcomes (e.g., dissolution or low quality) following college students' friendship problems. The current investigation seeks to identify associations among pre-problem friendship features and post-problem friendship outcomes.

Potential differences in the associations for pre-college and college friendships also are considered. The distinction is important in terms of determining whether different types of friendships include the same basic friendship processes. Specifically, the current study includes an exploration of the frequency with which various types of events contribute to friendship problems and dissolution for pre-college and college friendships. This information contributes to an understanding of relationship processes for different types of friendships.

In addition, consequences of friendship problems for adjustment are discussed. Previous research indicated that having good friends has benefits for college students, but little is known about the impact of having problems with friends in terms of adjustment. In the current study, potential associations between having problems in friendships and adjustment are explored. 


\section{Hypotheses}

The present investigation addressed one primary question and four secondary questions. The primary purpose of the investigation was to assess the association between friendship features of pre-college and college friends and friendship quality after problem occurrence. It was expected that pre-college friendships characterized by a lack of positive features such as shared history, commitment, and approval of a friend's personal characteristics would be lower in quality following problems. Similarity, trust, and current common experiences were expected to be especially important features in the prediction of post-problem friendship outcomes for college friends. Pre-college and college friends' outcomes (i.e., maintenance, dissolution, and quality) were not expected to differ in terms of support and resources, communication, a balance of costs and rewards, and expected ease of finding a new friend. Gender differences were explored, but no specific gender differences were predicted.

Second, the investigation included an examination of the issues college students identified when asked to explain the reasons for their actual friendship dissolution. It was expected that participants would provide a variety of reasons for friendship dissolution; dissolution was not expected to result only from conflict. Gender differences in causes of friendship dissolution and potential differences between college and pre-college friends were explored, but no specific differences were predicted.

Third, the association between causes of problems with friends and causes of friendship dissolution was explored. It was expected that when participants were asked to explain the reasons for particular friendship problems or friendship dissolution that they would not identify the same reasons for friendship problems and friendship endings. Previous research indicates that causes of friendship dissolution and friendship problems differ for early adolescents (Owens \& 
Strough, 2002). It was expected that a similar pattern would emerge for college students. Differences in the causes of friendship problems and friendship dissolution for pre-college and college friendships also were explored.

Fourth, in addition to exploring specific problems and reasons that college students identified when asked to discuss only one problem with one friend and the circumstances surrounding one ended friendship, this study included an investigation of events college students may or may not have experienced. Through their indications of how often a variety of listed events led to problems or dissolution of friendships, college students provided information about the frequency of events in their pre-college and college friendships. The importance of each event also was considered. Specific predictions were not hypothesized; exploration of this area provided information about which events are the most prevalent in college students' friendships.

Fifth, and finally, links between friendship and adjustment and well being were explored. It was expected that college students who report having fewer significant problems in their friendships also would report lower levels of alcohol abuse, lower levels of loneliness, and higher levels of academic performance as compared to students with more friendship problems. In addition, the possibility that fewer friendship problems would be associated with more use of effective coping strategies was explored.

Method

\section{Participants}

The participants were 241 college students (96 males and 145 females). The mean age of participants was 20.3 years $(S D=3.20$ years $)$. Participants were in their second or third year of college. Most participants $(68.9 \%)$ had never attended another university. This sample was used because second and third year students have had enough time to form college friendships as well 
as to make decisions about which pre-college friendships to maintain. Many participants indicated that they were in dating relationships (59.3\%). Several participants (1.7\%) were married, and $38.8 \%$ reported being single (i.e., not in a relationship). Individuals who were dating or married reported that they had been in their relationships for an average of 19.06 months $(S D=18.07$, range $=1-120)$.

Regarding race, most $(90.9 \%)$ of the participants described themselves as White/Caucasian. Another 5.4\% of participants were Black/African American. Other participants indicated that they were Asian (2.1\%), Hispanic (0.8\%), or Arab $(0.4 \%)$. One participant $(0.4 \%)$ did not indicate a racial group. Many participants (60.2\%) reported that their parents were married. In addition, $21.6 \%$ indicated that their parents were divorced or separated, and $14.5 \%$ reported that their parents were single. Also, $3.3 \%$ had parents who were widowed; $0.4 \%$ reported that both parents were deceased.

Participants' parents generally had obtained high levels of education. Specifically, $46.9 \%$ of fathers and $40.3 \%$ of mothers had earned at least a college degree. Only $2.9 \%$ of fathers and $1.7 \%$ of mothers had not completed high school. Regarding occupation, $50.1 \%$ of fathers and $67.2 \%$ of mothers had white-collar occupations (e.g., professional or specialty). Others had bluecollar occupations (e.g., transportation or factory). The distinction was based on the Occupational Classification System used by the U. S. Census (1987).

Most participants lived in an apartment or house with same-sex students (57.1\%). Many lived in residence halls $(15 \%)$ or in apartments with no roommates (7.1\%). An additional 5.5\% of participants lived with a spouse, boyfriend, or girlfriend. Some participants lived with family members $(7.9 \%)$ or with opposite-sex students whom they were not dating $(5.4 \%)$. The remaining $2.1 \%$ of participants reported other living arrangements. 
The sample included participants from approximately 60 different academic majors. Psychology and pre-psychology majors accounted for $19.1 \%$ of the sample; each other major accounted for less than $10 \%$ of the sample. The average grade point average of the participants was $3.01(S D=0.55$; range $=1.50-4.00)$.

Most participants indicated that their friendship networks had changed since they began college. Participants reported making about 12 new friends in college $(M=11.52 ; S D=6.65$; range $=0-37)$. They also lost an average of 5 friends in college $(M=4.94, S D=4.89$; range $=0$ 19). In addition, participants reported that they attended college with about 6 pre-college friends $(M=5.95, S D=5.52 ;$ range $=0-19)$ and did not attend college with about 12 pre-college friends $(M=12.34, S D=6.56 ;$ range $=0-63)$. Participants reported attending school approximately $21 / 2$ hours from their hometowns $(M=157.20$ minutes; $S D=233.22$ minutes; range $=0-2880$ minutes). In addition, participants reported that they visit their hometowns about 7 times each semester $(M=7.02 ; S D=9.92 ;$ range $=0-105)$.

Informed consent was obtained from college students before they participated in the study. Participants were recruited from undergraduate Psychology courses. Each participant chose to receive extra credit in a course $(n=221)$ or a $\$ 5.00$ cash incentive $(n=20)$ in exchange for participation in the investigation. None of the participants withdrew from the study.

\section{Procedure}

Participants were recruited from undergraduate psychology courses. Individuals who agreed to participate in the project signed up for times to meet with the investigator outside of class. Groups of participants ranging in size from 5 to 30 completed several written questionnaires in classrooms. It took participants between 45 minutes and 2 hours to complete the study. First, participants provided demographic and adjustment information. Next, 
participants responded to items on the Friendship Problems Questionnaire, the Friendship Endings Questionnaire, and the Prevalence of Causes of Problems and Endings Questionnaire. All participants completed the questionnaires twice, once in terms of a college friend and once in terms of a pre-college friend. Half of the participants completed items for college friends first and half completed items for pre-college friends first to control for order effects. For questions about college friendships, participants were asked to describe problems and endings with friends they had met since the beginning of college. It is possible that participants experienced problems and endings with pre-college friends with whom they attended the same college. These issues were not assessed in the current investigation, because the comparison of interest was old versus new friends. College friendships were conceptualized as new friends.

\section{Materials}

Demographic Information. Participants indicated whether they were male or female, their year in school, race, birth date, romantic relationship status (i.e., dating, married, neither), current living arrangement, extracurricular activities, employment status, distance between college and hometown, and frequency of visits to their hometowns (see Appendix A). In addition, participants provided information regarding their parents' marital status, occupations, and educational levels. Participants also listed their pre-college and college friends as a way to estimate the size of their friendship networks. This information was used to generate descriptive information about the participants.

Adjustment Measure. In addition to the demographic information, participants responded to items about their adjustment (See Appendix A). Participants responded to items about feelings of loneliness, feelings of homesickness, feelings of social support, academic support, academic performance, alcohol consumption, and strategies for coping with stress. Each participant 
received a score for each adjustment category. Scores for loneliness, homesickness, social support, and academic support were based on a 5-point scale on which participants indicated how often the items were true $(1=$ never; $5=$ almost always $)$. Social support scores were the mean responses to the questions asking how often the person could count on having someone to talk to and how often they could count on having someone to help them $(\alpha=.74)$; other scores were the individual responses to each item. Academic performance scores were self-reported grade point averages, and alcohol consumption scores were the numeric responses for each item (e.g., typical number of alcoholic drinks consumed at one time). Higher responses indicated more loneliness, more homesickness, more social support, more academic support, better academic performance, and more alcohol consumption.

The strategies participants used to handle stressful events in their lives were assessed as another aspect of adjustment. Strategies for coping with stress were assessed via open-ended responses to the question, "When you are feeling stressed, what are you most likely to do?" Participants listed the ways in which they would most likely deal with stress. Scores for coping strategies were the proportion of the total number of coping strategies identified by the individual that were coded as a particular strategy. Higher scores for a strategy indicated that individuals were more likely to identify the particular strategy over other strategies. Information about coping strategies was collected as a preliminary exploration of the links between friendship problems and various types of adjustment. For example, experiencing friendship problems might lead college students to use a variety of coping strategies. Use of various strategies might then contribute to feelings of social support. Alternatively, feelings of social support could lead to the use of strategies that may either hinder or enhance relationships with friends. 
Coding for Coping Strategies. Categories of coping strategies were similar to those used by Strough, Patrick, and Swenson (2002). The coding scheme included nine categories of coping strategies. Categories included cognitive self-regulation (Kappa $=1.00)$, emotion self-regulation $($ Kappa $=1.00)$, behavioral self-regulation $($ Kappa $=.91)$, regulating/controlling others (not used during training; no Kappa was computed), discussion (Kappa = 1.00), seeking assistance (Kappa $=1.00)$, other $($ Kappa $=1.00)$, nothing $($ Kappa $=1.00)$, and missing (not used for training; Kappa not computed). Individuals listed as many strategies for coping with stress as they wanted to list. The investigator and an undergraduate research assistant assigned a code to each strategy that was listed. The number of strategies that each person listed was determined by counting the items on participants' lists. Coders practiced the procedure together with 15 questionnaires. Discrepancies were resolved by consensus. During the practice coding process, four additional codes were added to characterize participants' responses: exercise (Kappa $=.96)$, use of drugs or alcohol $($ Kappa $=1.00)$, leaving the situation $($ Kappa $=.65)$, and sleeping $($ Kappa $=1.00)$. Each new code reflected a specific type of behavioral self-regulation. Approximately $20 \%$ of the data (i.e., 50 questionnaires) were used to establish reliability over a one-week period. During this time, coders compared responses periodically. After reliability was achieved, each person coded approximately half of the remaining data within another week.

Due to low frequencies, coping strategies were classified into the following eight categories: cognitive or emotion regulation (combination of cognitive and emotional selfregulation; e.g., deciding to not think about the problem; deciding to not worry about it), behavioral regulation (e.g., read a book), relying on other people (combination of regulating/controlling others, discussion, and seeking assistance; e.g., call my mom; ask my 
girlfriend for help), exercise (e.g., go for a run), use substances (e.g., get drunk), leave (e.g., go for a drive to get away), sleep (e.g., take a nap), and other, missing, or nothing.

Friendship Problems Questionnaire. After completing the demographics and adjustment information, participants responded to questions about problems they had with their friends on the Friendship Problems Questionnaire (See Appendix B). The instrument was adapted from a measure of everyday problem solving (Sansone \& Berg, 1993) and measure of early adolescent friendship problems (Owens, 2001).

Each participant recalled a problem or conflict with a friend that occurred within the past year. First, participants explained what happened in the problem. Explanations were approximately a paragraph long. In addition, participants indicated the main cause of the problem, their goals for solving the problem, what was done to attempt to prevent and/or solve the problem, and whether or not the problem was resolved. The descriptions of problems provided information about the kinds of problems that occur for college students and their friends. When asked to describe one friendship problem, participants probably identified problems that they remembered as being significant. Thus, the described problems likely represented issues that were particularly noteworthy for participants.

After describing the problem, participants responded to questions about the outcomes of their friendships following problems. Overall friendship quality following the problem was based on the question, "How good of friends were you after the problem?" $(1=$ not friends; $2=$ OK friends $; 3=$ in the middle $; 4=$ pretty good friends $; 5=$ best friends). Friendship outcome was based on the yes-or-no question, "Are you still friends with this person?"

Participants also responded to questions about the features of their specific friendships as experienced prior to and following problems. Friendship features were assessed in terms of 
responses to questions about support and resources, trust, similarity, shared history, current common experiences, commitment, communication, balance of costs and rewards, personal characteristics and behaviors, expected ease of finding a new friend, and length of friendship. These questions were based on issues that have been identified as being related to friendship or romantic relationship dissolution. Ratings of friendship features before problems were used as predictors of friendship outcomes (i.e., friendship maintenance or dissolution and overall friendship quality) after problems. Although ratings of friendship features after problems were not used in the analyses for the current study, post-problem ratings encouraged participants to consider their pre-problem friendship experiences separately from their post-problem experiences. In addition, post-problem friendship feature ratings will be used in future investigations.

Friendship Endings Questionnaire. Next, participants recalled friendships that ended by responding to items on the Friendship Endings Questionnaire (See Appendix C). The questionnaire was based on a measure used in a similar investigation (Owens, 2001). Each participant explained the events surrounding the break-up of a friendship, the main reason the friendship ended, the goals in the situation, what (if anything) was done to try to avoid the dissolution, and the likelihood that the friendship will resume in the future. Participants rated the importance of the friendship to them and the extent to which the ending of the friendship was their own fault, their friend's faults, or neither person's fault. Participants also rated several features of their friendships before and after the break-ups. The friendship features were the same features assessed with the Problems with Friends Questionnaire (i.e., support and resources, trust, similarity, shared history, current common experiences, commitment, communication, balance of costs and rewards, personal characteristics and behaviors, and 
expected ease of finding a new friend). Information about friendship features associated with terminated friendships will be used in future investigations.

Coding Categories for Friendship Problems and Endings. For the Friendship Problems Questionnaire, causes of friendship problems were placed into one of 10 mutually exclusive and exhaustive categories. Coding categories were derived from previous research (Azmitia et al., 1999; Owens, 2001). Specifically, causes that college students identified in response to the question "What was the main cause of problem?" were coded. In a previous investigation (Owens), overall Kappa coefficients were .78 for friendship problems and .95 for friendship endings. A statement such as, "My friend would not stick up for me when I needed her" or, "He ate all of my food" was categorized as a problem with support and resources $($ Kappa $=.75)$. An example of a trust problem $($ Kappa $=.88)$ was, "She told a whole bunch of people a secret about me." A statement such as, "He and I really don't like to do the same things" or, "We started to like different things" was coded as a problem with similarity $($ Kappa $=.75)$. Common experience problems $($ Kappa $=1.00)$ included statements such as, "We don't get to do things together any more" or, "We don't have classes together this semester." Problems with commitment (Kappa = .78) included statements such as, "He spends all his time with his girlfriend and doesn't care about his friends any more" or, "She doesn't care about being friends any more." Intimate communication problems (Kappa $=.88$ ) were statements such as, "She won't tell me how she is feeling" or "We just don't talk much these days." Problems about specific characteristics of friends such as "He is just really rude" or "She drinks too much" were coded as personal characteristics or behavior problems $($ Kappa $=.87)$. The category of misunderstanding $($ Kappa $=$ .88) was used for responses such as, "We didn't understand each other's point-of-view." Problems were coded as other/unsure (no Kappa; not used in training) if participants described 
problems but did not give enough information to code the problem (e.g., "He did not wake up."), if the problem was not directly related to the friendship (e.g., "She and her roommate had a bad day."), or if participants indicated that the cause of the problem was unknown. Participants' responses were coded as none/blank $(\mathrm{Kappa}=1.00)$ if participants indicated that they never experienced a problem with a friend or if participants did not respond to the question. Due to the low frequency of misunderstanding-related problems, the category of misunderstanding was combined with the intimate communication category. Both original categories were related to communication issues; the resulting category was called communication. In addition, the categories of other/unsure and blank/none were combined, because each category included responses that could not be coded. Thus, eight categories were maintained.

For the Friendship Endings Questionnaire, causes of friendship endings were identified based on responses to the question asking, "What was the main reason the friendship ended?" Participants' responses to the open-ended question were coded to identify specific factors that are related to friendship break-ups. The same eight mutually exclusive and exhaustive categories described previously (i.e., support and resources, trust, similarity, common experiences, commitment, communication, personal characteristics and behaviors, or other/unsure/none/blank) were used. Kappa coefficients for intimate communication and support and resources were 1.00 and .90 , respectively. The trust category had a Kappa coefficient of .92 , and the value for similarity was .76. The Kappa coefficient for common experiences was .94;.85 was the value for commitment. The personal characteristics category had a Kappa coefficient of .89. The Kappa coefficients for misunderstanding could not be computed because no codes were given for that category. Kappa values for other, unsure, none, and blank were all 1.00. 
Coding Procedure. Two individuals, the author and an undergraduate research assistant, completed the coding of the main causes of friendship problems and endings. To code responses, the coders read the descriptions of the problems and situations surrounding friendship dissolution. Coders also read the reported main cause of the problem and the main cause of the friendship ending. Approximately $20 \%$ of the data ( $N=100$ codes) were used to train coders to use the coding scheme; coders worked together to code the training responses. Next, coders coded approximately $25 \%$ more of the data independently. During this time, coders classified the same responses. The coders met regularly for two weeks to discuss the codes until reliability was achieved. When coders' opinions of the classifications differed, the coders came to a consensus. After reliability was achieved, the coders divided the remaining data; each coded half of the remaining participants' descriptions. Independent coding took approximately 2 weeks to complete.

Friendship Features Scales. Friendship features were assessed with the Friendship Problems Questionnaire. Questions were chosen based on friendship features that are related to friendship maintenance and dissolution (see Owens, 2001). Specific questions can be found in Appendix B. Individual questions were combined into scales that represented 11 features of friendships. In a previous investigation (Owens), reliability of friendship features was high ( $\alpha=$ .84 or .85 for all scales). Descriptive and reliability information for each scale is found in Table 1. First, the support and resources scale included Questions 37, 39, 41, 43, 45, 47, 49, 51, 53, and 55. The questions asked how often the friends offered various types of emotional and instrumental support for each other $(1=$ not at all; $5=$ very often $)$. An individual's score for the support and resources scale was the mean of the individual's responses to the 10 questions. Higher scores indicated higher reported levels of support and resources. 
The similarity scale included Questions 57 and 59, which asked how much the friends liked to do the same things and thought the same things were important prior to the problem $(1=$ not at all; $5=$ very $m u c h)$. Scores for the scale were the average of the responses to the two questions. Higher scores indicated greater reported levels of similarity. Shared history was assessed with Questions 61 and 63. The questions asked how often the friends did particularly meaningful activities together prior to the problem $(1=$ never $;=$ almost always $)$. The shared history scale was the average of individuals' responses to the questions. Higher scores indicated greater reported shared history. Participants' mean scores for Questions 65 and 67 made up the current common experiences scale. The questions asked how often participants did things with their friends $(1=$ never $; 5=$ almost always $)$ and how much time they spent with their friends $(1=$ none at all; $5=$ very much) before the problem occurred. Higher scores indicated greater amounts of reported current common experiences.

The commitment scale was comprised of individuals' responses for Questions 31, 33, and 35. The first two questions asked how much the friends tried to make the friendship as good as possible and how much they believed the friendships would continue prior to the problem $(1=$ not at all; 5 = very much). Question 35 asked how likely individuals thought it would have been that they could have found a better friend $(1=$ not at all; $5=$ very much $)$; scores for this item were reversed. An individual's commitment score was his or her mean response to Question 31, Question 33, and the reversed response to Question 35. Overall, higher scores indicated higher levels of reported commitment to friendships.

The scale for communication was comprised of an individual's mean responses to Questions 23, 25, and 27. The questions asked how much the individuals and their friends shared their thoughts, feelings, and personal information with each other $(1=$ not at all; $5=$ all the 
time). Higher scores indicated higher levels of communication. Responses to Questions 77, 79, and 81 were used to construct the personal characteristics and behaviors scale. Questions asked how much individuals liked the kind of people their friends were, liked their friends' behaviors, and enjoyed the excitement their friends provided prior to the problem $(1=$ not at all; $5=$ very much). The personal characteristics and behaviors scale was the mean of the responses to the three questions; higher scores indicated greater approval of a friend's personal characteristics and behaviors.

The balance of costs and rewards scale was computed by subtracting responses to Question 69 from Question 73. The scale score was the difference between what participants got out of their friendships and what they put into their friendships $(1=$ nothing at all; $5=$ very much). Possible score ranged from -4 (i.e., participants put much effort into their friendships but received very little benefit from the friendships) to 4 (i.e., participants put little effort into their friendships but received many benefits from the friendships). Higher scores indicated more rewarding friendships; lower scores indicated more costly friendships.

In addition two single-item scales were included. The friendship feature of trust was assessed with Question 29, which asked how much participants trusted their friends prior to the reported problems $(1=$ not at all; $5=$ very much $)$. Expected ease of finding a new friend was an individual's response to Question 83, which asked how easy it would be to make a new friend if participants were no longer friends with the people they described $(1=$ impossible $; 5=$ extremely easy).

Prevalence of Causes of Problems and Endings. Whereas the Friendship Problems Questionnaire and the Friendship Endings Questionnaire included information about one specific friendship problem and one specific friendship ending, the prevalence questionnaire asked 
participants to provide information about a variety of potential causes of friendship problems and friendship endings for college students. Participants provided information about their experiences with various types of friendship problems (See Appendix D) and reasons for friendship endings (See Appendix E) (e.g., trust; intimacy; support and resources). Potential causes of problems and friendship dissolution were provided on a list. Specifically, participants indicated how often such events (i.e., reasons for problems and endings) have occurred ( $1=$ never $; 5=$ very often $)$ in their friendships and the importance $(1=$ not at all $; 5=$ extremely $)$ of the events. Items on the list corresponded to friendship features that were assessed on the Friendship Problems Questionnaire as well as to problems identified by early adolescents in a similar study (Owens, 2001). This information was used to estimate the extent to which various types of problems and friendship endings occur for college students and to determine the relative importance of the different problems and endings. Participants received a total problem score that indicated how many of the problems occurred often in their friendships (i.e., ratings of 4 or $5 ; 1=$ never $; 2=$ rarely $; 3=$ sometimes $; 4=$ fairly often $; 5=$ very often , maximum total $=17$ ).

In addition to their total problem scores, participants had scores for individual events. Scores for individual events corresponded to participants' numerical responses to the 17 items on each prevalence questionnaire. For the purposes of analyzing the data, some of the 17 items were combined to form a total of 11 events that could lead to friendship problems or dissolution. Combinations were created to be consistent with friendship problems codes and friendship features scales from the Friendship Problems Questionnaire. When questions were combined, an individual's score for the event was his or her mean response to each of the combined items. Reliability information for the scales can be found in Table 2. Questions 1 and 2 both asked about support and resources; the items were combined to indicate support. Question 3 referred to 
violations of trust. Questions 4 and 5 asked participants about not liking the same things and not thinking that the same things were important; the combined responses comprised similarity. Ratings of the frequency and importance of events related to not doing things together and not spending time together (Questions 6 and 7) were combined as an assessment of current common experiences. One question (number 8) referred to not sharing past experiences. Questions 9 and 10 asked about making the friendship as good as possible and overall commitment to the friendship; the questions were combined as a measure of commitment. Questions 11, 12, and 13 asked participants to rate events related to a lack of communication about feelings, thoughts, and personal information. The three questions made up the communication assessment. The remaining questions were not combined with other questions. Question 14 asked about unequal effort in the friendship, Question 15 asked participants to rate disapproval of the friend's behavior, and Question 16 asked about lack of closeness. Finally, Question 17 was a rating of thoughts of making new friends easily. Reliability was computed for each of the multiple-item scales.

Results

\section{Descriptive Information}

Before the research questions were explored, general information about participants' responses was examined. This information was obtained from the Friendship Problems and Friendship Endings Questionnaires; see Tables 3 and 4 for descriptive information.

Problems. Overall, reported problems were of medium importance to participants. There was not a significant difference in the ratings of problem importance for pre-college and college problems. Regarding problem severity, problems were rated as moderate in severity; ratings of severity were not significantly different for the two types of friendships. Participants thought it 
was moderately important to keep the reported friendship when problems occurred, and ratings of the importance of keeping pre-college friends were significantly higher than were ratings of the importance of keeping college friends. On average, pre-college friendship problems occurred between 5 and 8 months before the time of measurement; college friendship problems occurred about 3-6 months before testing. Problems with pre-college friends occurred significantly longer before the time of measurement than did problems with college friends. For pre-college friends, the average length of friendship was about 7 years prior to the problem occurrence. Participants had been friends with their college friends for an average of about 1 year prior to the problems they described.

Endings. Participants also answered questions about friendships that had ended.

Participants may or may not have described a friendship ending with the same person with whom they described a friendship problem. Based on information from the Friendship Endings Questionnaire, participants indicated that it was not particularly important for them to have kept their ended friendships. However, participants indicated that it was more important to keep their pre-college friends than their college friends. Participants indicated how long ago their friendships ended. Pre-college friendships ended about 9-10 months before the time of measurement; college friendships ended about 7-8 months prior to testing. Thus, pre-college friendships ended longer before the time of measurement than did college friendships. For precollege friends, the average length of ended friendships was about 6 years. Participants had been friends with their college friends for an average of about 11 months prior to experiencing friendship dissolution. 
Friendship Maintenance, Dissolution, and Quality Following Problem Occurrence

After preliminary analyses were conducted, the primary research questions were addressed. The main purpose of the study was to predict friendship outcome (i.e., friendship maintenance or dissolution; friendship quality) following problems from pre-problem features. Friendship Quality Following Problems

Multiple regression analyses were conducted to examine the ability of each friendship feature (i.e., support and resources, trust, similarity, shared history, current common experiences, commitment, communication, balance of costs and rewards, personal characteristics and behaviors, expected ease of finding a new friend, and length of the friendship) to predict overall friendship quality following a problem with a pre-college and a college friend. Overall friendship quality was assessed by the question, "How good of friends were you after the problem?" $(1=$ not friends; $5=$ best friends). Participants who indicated that they had dissolved their friendships were not included in the analyses. Analyses were conducted separately for participants who completed pre-college or college items first to determine if order effects were present. Results of regression analyses were essentially the same for each order. Thus, order of questionnaire completion did not appear to influence participants' responses. Furthermore, year in school did not have an impact on responses when second and third year students were considered separately.

Pre-college. For pre-college friendships, the set of predictors predicted a significant amount of the variance in the quality of friendships following problems with friends $(F(11,147)$ $=6.98, p<.001)\left(\right.$ See Table 5). The adjusted $R^{2}$ value for the multiple regression for pre-college friendships was .289. Four factors were significant individual predictors of friendship quality. Similarity $(\beta=.31, p<.01)$, commitment $(\beta=.27, p=.02)$, expected ease of finding a new 
friend $(\beta=-.40, p<.001)$, and length of friendship $(\beta=.15, p=.03)$ each accounted for a significant portion of the variance in friendship quality following problems. That is, participants who reported greater similarity with their friend before the problem occurred reported higher quality friendships following problems. College students who experienced commitment in their pre-college friendships indicated that they had high quality friendships following problems. Participants who reported that it would be more difficult to find new friends if their friendships ended reported higher quality friendships following friendship problems. Friendships that were longer in duration prior to the problem also were higher in quality following the problem.

College. For college friendships, the set of predictors also predicted a significant amount of the variance in the quality of friendships following problems with friends $(F(11,141)=5.64$, $p<.001$ ) (See Table 6). The adjusted $R^{2}$ value for the multiple regression for college friendships was .251. There were five factors that were significant individual predictors of friendship quality. Commitment $(\beta=.44, p<.01)$ and a balance of costs and rewards $(\beta=.16, p=.05)$ each accounted for a significant portion of the variance in friendship quality. In addition, expected ease of finding a new friend $(\beta=-.27, p<.001)$, length of friendship $(\beta=.16, p=.04)$, and trust $(\beta=-.29, p=.03)$ were significant individual predictors of friendship quality following problems. Participants who reported more commitment, more rewarding friendships, lower likelihood of finding new friends, longer friendships, and less trust before the problem occurred reported higher quality friendships following problems with college friends.

Comparisons of pre-college and college predictors. After multiple regression analyses were conducted for pre-college and college friendships, comparisons in Beta weights for predictors in each type of friendship were made (see Howell, 1997). No significant differences in 
Beta values were found. Thus, none of the predictors significantly differed in terms of predicting pre-college versus college friendship quality.

Friendship Maintenance or Dissolution Following Problems

Logistic regression analyses were conducted to determine whether or not each of the friendship features was related to a dichotomous friendship outcome after a problem occurred. Friendship outcome was assessed by the yes-or-no question, "Are you still friends with the person?" The 11 predictors included: support and resources, trust, similarity, shared history, current common experiences, commitment, communication, balance of costs and rewards, personal characteristics and behaviors, expected ease of finding a new friend, and length of the friendship.

Pre-college. The equation using the 11 predictors was significant for pre-college friendships $\left(\chi^{2}(11, N=194)=46.75, p<.001\right)$ and correctly classified $79.4 \%$ of the respondents (92.5\% of maintained friendships; $38.3 \%$ of dissolved friendships); see Table 7 . The Nagelkerke $R^{2}$ value was .32 , indicating that the set of predictors accounted for about $32 \%$ of the variance in friendship dissolution. This finding indicates that, as a set, the predictors reliably distinguish between pre-college friendships that end and friendships that do not end following friendship problems. According to Wald criterion, current common experiences and expected ease of finding a new friend reliably predicted whether or not friendships ended $(z=5.09, p=.02$ and $z$ $=15.41, p<.001$, respectively)

The odds ratios (O.R.) indicated that the predictors differed in predictive utility (See Table 7). Specifically, each incremental increase (1 to 5) in current common experiences was associated with a $21.7 \%$ increase in the likelihood of friendship dissolution. Also, increasing one 
increment in expected ease of making new friends was associated with a $22.9 \%$ increase in the likelihood of pre-college friendship dissolution.

College. A logistic regression also was conducted to determine whether the same set of friendship features predicted friendship maintenance or dissolution for college friendships. Overall, the set of predictors reliably distinguished between college friendships that ended or did not end and accounted for a significant portion of the variance in friendship dissolution, $\chi^{2}(11, N$ $=191)=53.01, p<.001$, Nagelkerke $R^{2}=.38$ (see Table 8$)$. The predictors correctly classified $82.7 \%$ of respondents ( $94.1 \%$ of maintained friendships and $38.5 \%$ of dissolved friendships). Wald criterion indicated that support and resources $(z=4.31, p=.04)$, communication, $(z=7.22$, $p=.01)$, a balance of costs and rewards $(z=6.26, p=.01)$, and expected ease of making a new friend $(z=13.83, p<.001)$ reliably predicted whether or not college friendships ended following problems.

Based on odds ratios, each incremental increase in support and resources was associated with a 56.9\% decrease in the likelihood of friendship dissolution, and each incremental increase in communication was associated with a $26.4 \%$ increase in the likelihood of friendship dissolution. In addition, each incremental increase in the balance of costs and rewards was associated with a $57.5 \%$ decrease in the likelihood of friendship dissolution. Finally, each incremental increase in expected ease of finding a new friend was associated with a $27.8 \%$ decrease in the likelihood of college friendship dissolution after problems.

\section{Model Comparison}

A path analysis was conducted to further examine the associations between friendship features and friendship outcomes. Friendship outcomes (the dependent variable) were assessed by the question, "How good of friends are you?" The predictors included: support and resources, 
trust, similarity, shared history, current common experiences, commitment, communication, balance of costs and rewards, personal characteristics and behaviors, expected ease of finding a new friend, and length of the friendship. The purpose of the analysis was to compare the overall models for pre-college and college friendships. Results of the path analysis indicated that the overall models for pre-college friendships and college friendships did not significantly differ in their prediction of friendship quality following problem occurrence. That is, models were essentially the same when the paths for predictors of pre-college and college friendship quality were constrained to be equivalent, $\chi^{2}(34, N=232)=44.61, p=.11$, and when the paths had no constraints, $\chi^{2}(23, N=232)=37.65, p=.03$; the difference between the models was not significant, $\chi^{2}$ difference $(11, N=232)=6.96, p>.05$.

\section{Causes of Friendship Dissolution}

Another aim of the study was to investigate the reasons college students identify for ending their pre-college and college friendships. Figure 1 illustrates the percentage of participants who identified each reason for experiencing pre-college and college friendship dissolution.

Pre-college. College students were most likely to report ending their friendships with pre-college friends as a result of a lack of common experiences (19.1\%), commitment (18.3\%), or similarity (17.4\%). Lack of trust (12.4\%), insufficient support and resources $(5.0 \%)$, disapproval of personal characteristics $(5.0 \%)$, and poor communication $(2.5 \%)$ also led to friendship dissolution. An additional $20.3 \%$ of participants indicated that they had not had a precollege friendship end.

College. Regarding the ending of college friendships, $37.8 \%$ of participants reported that they had not ended a college friendship. A lack of common experiences led to $15.8 \%$ of reported 
endings of college friendships. Issues related to trust (10.4\%), similarity (9.5\%), commitment (9.1\%), and personal characteristics $(8.3 \%)$ also contributed to college friendship endings. Issues related to inadequate support and resources or communication were identified by $7.5 \%$ and $1.7 \%$ of participants, respectively.

\section{Causes of Friendship Problems}

In addition to causes of friendship dissolution, causes of problems with friends were explored. Percentages of participants who identified each cause of friendship problem also are illustrated in Figure 1. Relative frequencies of reported causes of problems with friends differed from relative frequencies of causes of friendship endings.

Pre-college. For pre-college friends, the most commonly identified cause of problems was a lack of commitment to the friendship (24.9\%). Problems with support and resources were common in pre-college friendships (19.1\%), followed by problems related to similarity (12.4\%), trust $(11.2 \%)$, communication $(7.9 \%)$, personal characteristics $(6.6 \%)$, and common experiences (4.6\%). An additional $13.3 \%$ of participants indicated that they had no problems with pre-college friends.

College. For college friends, reported problems were most likely to be related to support and resources $(24.5 \%)$ or personal characteristics $(21.2 \%)$. Problems with commitment, trust, and communication accounted for $12.0 \%, 11.2 \%$, and $10.4 \%$, respectively. Lack of similarity contributed to $6.2 \%$ of problems with college friends, and $0.4 \%$ of the participants identified a problem related to common experiences. Also, $14.1 \%$ of participants reported having had no problems with college friends. 


\section{Pre-college and College Causes of Problems and Endings}

To further explore the reasons college students identified for experiencing friendship problems and endings, a series of 2 (type of friend: pre-college; college) x 2 (category of cause: present; absent) chi-square analyses were conducted for each of the 8 causes of friendship problems and causes of friendship dissolution. The purpose of the analyses was to explore similarities and differences in the likelihood of each cause of problems or endings for pre-college and college friends. Almost all of the chi-square analyses included empty cells; thus, results of the analyses could not be reliably computed. Results of one chi-square analysis with adequate cell sizes were statistically significant. Participants were more likely to report that their precollege friendships ended (19.1\%) as a result of a lack of common experiences as compared to their college friendships $(15.8 \%), X^{2}(1, N=241)=4.56, p=.03$.

\section{Gender Comparisons of Friendship Problems and Endings}

Chi-square analyses also were computed to compare the prevalence of each cause of problems with friends and each cause of friendship termination between males and females. Each

analysis was a 2 (gender: male; female) x 2 (category of cause: present; absent) comparison. These analyses were conducted separately for pre-college and college friends. Only one significant gender difference was found for analyses with adequate cell sizes. Specifically, $35.4 \%$ of males reported a problem with support with a college friend, but only $17.2 \%$ of females described a support problem with a college friend, $X^{2}(1, N=241)=10.32, p=.001$.

\section{Prevalence of Friendship Problems}

Another purpose of the current study was to explore how often college students experienced specific events in terms of friendship problems and friendship dissolution. To examine the prevalence of several specific friendship problems, a 2 (friendship type: pre-college, 
college) x 2 (gender) repeated measures multivariate analysis of variance was performed on the 11 dependent variables (i.e., reported prevalence of each type of problem). Prevalence ratings were obtained from participants' indications of how often various listed potential causes of problems occurred $(1=$ never; $5=$ very often $)$ in their friendships. Rated problems included those related to support, trust, similarity, current common experiences, lack of shared past experiences, commitment, communication, unequal effort, disapproval of the friend's behavior, closeness, and thoughts of making new friends.

Results indicated a main effect for problem frequency, $F(10,199)=16.82, p=.001, \eta^{2}=$ .46. This effect was modified by a significant interaction between problem frequency and friendship type, $F(10,199)=1.88, p=.05, \eta^{2}=.09$. See Table 9 for means. Follow-up pairedsamples $t$-tests indicated that problems related to commitment were reported as being more frequent in pre-college friendships than in college friendships, $t(229)=2.28, p=.02$. In addition, disapproval of a friend's behaviors was reported more often for pre-college friends than for college friends, $t(230)=2.07, p=.04$. Problems related to emotional closeness also were reported as being more frequent for pre-college friends than for college friends, $t(230)=2.95, p$ $<.01$.

\section{Prevalence of Friendship Endings}

As an examination of the prevalence of reasons for friendship endings, a 2 (friendship type: pre-college, college) x 2 (gender) repeated measures multivariate analysis of variance was performed on the 11 rated frequencies of reasons for experiencing friendship dissolution (i.e., event types: support, trust, similarity, current common experiences, lack of shared past experiences, commitment, communication, unequal effort, disapproval of the friend's behavior, closeness, and thoughts of making new friends) (see Table 10). A main effect was present for 
friendship type, $F(1,190)=23.60, p<.001, \eta^{2}=.11$. Overall, ratings of the prevalence of friendship endings were higher for pre-college friendships than for college friendships. In addition, there was a main effect for event frequency, $F(10,181)=29.07, p<.001, \eta^{2}=.62$. That is, some events were rated as being more prevalent in terms of ending friendships. This effect was modified by interactions of event frequency and gender, $F(10,181)=2.17, p=.02, \eta^{2}$ $=.11$ and event frequency and friendship type, $F(10,181)=1.96, p=.04, \eta^{2}=.10$.

Follow-up univariate ANOVA tests were conducted to examine the gender by event frequency interaction. For each follow-up test, gender was the independent variable; dependent variables were mean ratings of each potential cause of friendship ending collapsed across friendship type. No specific gender differences in frequency of friendship endings could be localized.

To localize the gender differences, follow-up tests of within-subjects deviation contrasts were conducted. Results indicated several gender differences and similarities in the frequency with which various events contributed to friendship dissolution (see Figure 2). Support was rated as leading to friendship dissolution infrequently by both males, $F(1,53)=9.02, p<.01$, and females, $F(1,53)=23.01, p<.001$. Issues related to a lack of shared history also were rated as contributing to friendship dissolution infrequently for males, $F(1,53)=30.32, p<.001$, and females, $F(1,53)=93.56, p<.001$. In addition, communication was reported to have led to few friendship endings for either males, $F(1,53)=4.54, p=.04$, or females, $F(1,53)=4.09, p=.05$. Both males, $F(1,53)=38.60, p<.001$, and females, $F(1,53)=18.51, p<.001$, indicated that similarity contributed to many dissolved friendships. Several gender differences also existed. First, males indicated that events related to current common experiences were particularly likely to lead to friendship dissolution, $F(1,53)=6.23, p=.02$; this was not the case for females. 
However, females indicated that their friendships were relatively likely to end due to events related to trust, $F(1,53)=6.81, p=.01$, commitment, $F(1,53)=8.35, p=.01$, unequal friendship effort, $F(1,53)=4.65, p=.04$, and closeness, $F(1,53)=8.85, p<.01$. Similar results were not found for males.

Two-tailed paired-samples $t$-tests were conducted to examine the interaction of event frequency and friendship type. Results indicated that pre-college friendships were reported to end more frequently than were college friendships for a variety of reasons. First, ending friendships because of support issues was more common for pre-college friends than for college friends, $t(198)=4.24, p<.001$. Pre-college friendships also were more likely to end as a result of problems related to similarity than were college friendships, $t(199)=3.48, p=.001$. Precollege friendships were reported to end more frequently due to a lack of current common experiences, $t(200)=5.52, p<.001$, commitment, $t(200)=4.58, p<.001$, and intimate communication-related events, $t(199)=3.32, p=.001$, than were college friendships. Similarly, ending friendships because of friends' unequal effort in the relationship was rated as more prevalent for pre-college friends than for college friends, $t(200)=4.39, p<.001$. Friendship dissolution as a result of a lack of closeness, $t(200)=4.39, p<.001$, and thoughts of making new friends, $t(194)=2.48, p=.01$, were rated as causing friendship dissolution for pre-college friends more often than for college friends.

\section{Importance of Friendship Problems}

To explore reported ratings of the importance of various friendship problems, a 2 (gender) x 2 (friendship type) MANOVA was conducted. There were no statistically significant results at the multivariate level, so a series of 2 (gender) x 2 (friendship type) repeated measures ANOVAs was conducted for exploratory purposes (see Table 11). Results should be interpreted 
with caution, because results of the MANOVA test were not significant. Dependent variables were the rated importance of each of the 11 types of events as problems (i.e., support, trust, similarity, current common experiences, lack of shared past experiences, commitment, communication, unequal effort, disapproval of the friend's behavior, closeness, and thoughts of making new friends). Ratings were based on a 5-point Likert-scale ( $1=$ not at all; $5=$ extremely).

Results indicated three main effects for friendship type. First, problems related to current common experiences were rated as more important for pre-college friends than for college friends, $F(1,163)=11.64, p=.001, \eta^{2}=.07$. Also, problems with commitment were rated as being more important for pre-college friends than for college friends, $F(1,134)=9.56, p=.002$, $\eta^{2}=.07$. Third, ratings of the importance of closeness problems were higher for pre-college friendships than for college friendships, $F(1,160)=19.41, p<.001, \eta^{2}=.11$. There were no significant interactions between friendship type and gender. Importance of Events for Ending Friendships

A repeated measures MANOVA was conducted to assess the relative importance of 11 events (i.e., support, trust, similarity, current common experiences, lack of shared past experiences, commitment, communication, unequal effort, disapproval of the friend's behavior, closeness, and thoughts of making new friends easily) in determining friendship dissolution in terms of gender and friendship type (see Table 12). A significant main effect was present for the importance of various events in leading to friendship dissolution, $F(10,33)=5.63, p<.001, \eta^{2}=$ .63. The effect was modified by a significant three-way interaction of event, friendship type, and gender, $F(10,33)=2.22, p=.04, \eta^{2}=.40$. Follow-up repeated measures MANOVAs were conducted to examine the effects of gender and friendship type on the importance of each event in predicting friendship dissolution. A significant interaction between gender and friendship type 
was present for shared past experiences, $F(1,62)=5.14, p=.03, \eta^{2}=.08$. Specifically, not sharing past experiences was rated as more important in determining friendship ending for females' pre-college friends $(M=2.57, S D=1.29)$ than for college friends $(M=2.19, S D=$ $1.07), t(42)=2.39, p=.02$. There were no significant differences in the reported importance of not sharing past experiences for males.

\section{Pre-College Friendship Problems and Adjustment}

In addition to an examination of the prevalence of various friendship problems, the current study included an assessment of the association between frequency of friendship problems and adjustment outcomes. The purpose of this portion of the investigation was to provide information about the links between frequent experiences with friendship problems and other aspects of college students' lives. Ratings of the frequency of each problem were based on a 5 -point rating scale of problem prevalence $(1=$ never; $5=$ very often $)$. Intercorrelations of problem frequency can be found in Table 13. Several adjustment scores were used. Frequency of feeling lonely $(M=2.26, S D=.91$; range $=1-5)$, feeling homesick $(M=1.90, S D=.83$; range $=1-5$ ) feeling socially supported (i.e., having someone to count on to help you or to talk to) ( $M$ $=4.23, S D=.90 ;$ range $=1.5-5)$, seeking help from an instructor for a class $(M=2.99, S D=$ 1.09 ; range $=1-5)$ and seeking help from a friend for a class $(M=2.97, S D=1.18$; range $=1$ 5) were based on a 5-point frequency rating scale ( $1=$ never; $5=$ almost always $)$. In addition, participants indicated how often they drank alcohol per week $(M=1.57$ days, $S D=1.32$; range $=$ $0-6)$, the typical number of alcoholic beverages they consumed at a time $(M=4.75, S D=4.03$; range $=0-30)$, and the frequency of consuming 5 or more alcoholic drinks at once per month $(M$ $=3.97, S D=5.12$; range $=0-26$ ). Participants also indicated their grade point averages on a 4 point scale $(M=3.01, S D=.55$; range $=1.50-4.00)$. Positive adjustment was indicated by low 
scores for loneliness, homesickness, and alcohol use and by high scores for social support, seeking help, and grade point average. Intercorrelations for adjustment items are illustrated in Table 14. Strategies for coping with stress also were assessed as an aspect of adjustment; intercorrelations of various coping strategies are found in Table 15. Potential associations among coping strategies and other adjustment measures (see Table 16) and among coping strategies and frequency of friendship problems also were explored.

Total number of frequent problems. The hypothesis that college students who experience relatively few problems with their friends would demonstrate higher levels of adjustment was addressed. The total number of any type of problems experienced often with friends was the number of problems with ratings of 4 or 5 for the frequency of particular problems occurring ( 1 $=$ never $; 2=$ rarely $; 3=$ sometimes $; 4=$ fairly often $; 5=$ very often ; maximum total $=17$ ). Adjustment was assessed based on responses to questions about loneliness, homesickness, perceived social support, academic support, alcohol use, academic performance, and use of coping strategies. Correlations between the total number of problems experienced often and the measures of adjustment were correlated. The mean number of problems participants reported was 2.70 with their pre-college friends $(S D=3.29$; range $=0-15)$. For ratings of pre-college friends, results indicate that feelings of loneliness and total number of frequently experienced problems were significantly correlated, $r(234)=.25, p<.001$. Participants who reported experiencing more problems with their pre-college friends also reported that they were lonely more often as compared to other participants. In general, high frequency ratings for problem occurrence were associated with high proportions of using cognitive or emotional regulation strategies to cope with stress, $r(234)=.13, p=.04$. There were no significant correlations 
between the total number of problems experienced often with pre-college friends and other measures of adjustment.

Frequency of specific problems, loneliness, and support. For pre-college friendship ratings, correlations between frequencies of specific problems and adjustment measures also were conducted. Reports of frequent loneliness were associated with frequent problems with shared past experiences, $r(237)=.14, p=.03$, commitment, $r(237)=.23, p<.001$, communication, $r(237)=.13, p=.04$, unequal effort in friendships, $r(237)=.17, p=.01$, disapproval of pre-college friends' behaviors, $r(237)=.14, p=.04$, and thinking about making new friends, $r(235)=.13, p=.04$. That is, college students who reported that they often had problems with their pre-college friends because of not sharing past experiences, not having enough commitment, lacking communication, friends putting unequal effort into their friendships, not approving of friends' behaviors, or thinking about making new friends also reported that they were lonely often.

Regarding perceptions of social support (i.e., having someone to count on or talk to when necessary), frequencies of several types of problems were significantly correlated. Specifically, social support was associated with frequent problems with instrumental and emotional support, $r(239)=-.16, p=.02$, shared past experiences, $r(239)=-.20, p<.01$, commitment, $r(239)=-.15$, $p=.02$, and unequal friendship effort, $r(239)=-.13, p=.04$. College students who indicated that they frequently experienced these problems with their pre-college friends also reported that they did not feel that they would have someone to count on or someone to talk to if needed.

Frequency of specific problems and coping strategies. Individuals' ratings of the frequency of specific problems with pre-college friends were associated with strategies for coping with stress. Specifically, individuals who frequently experienced problems with a lack of 
similarity also used a small proportion of coping strategies involving other people, $r(237)=-.14$, $p=.03$. Experiencing problems with pre-college friends due to a lack of shared past experiences, $r(237)=.20, p<.01$, or commitment to the friendship, $r(237)=.15, p=.02$, was associated with being relatively likely to use cognitive or emotional regulation to cope with stress. In addition, frequency of problems with disapproval of pre-college friends' behaviors was correlated with relative infrequency of using drugs or alcohol to cope with stress, $r(237)=-.13, p=.04$.

Frequency of specific problems and alcohol use. In terms of alcohol use, individuals who reported frequently having problems related to a lack of closeness with their pre-college friends also reported consuming alcohol on few days per week, $r(235)=-.14, p=.04$. Likewise, frequently experiencing similarity problems was negatively correlated with the number of days per week on which alcohol was consumed, $r(235)=-.19, p<.01$. Frequency of similarity problems also was associated with the frequency of consuming 5 or more drinks at a time, $r(232)$ $=-.21, p=.001$. That is, individuals who had more problems related to dissimilarity in activity preference consumed alcohol less often and in smaller quantities as compared to individuals with fewer problems with similar interests.

Frequency of specific problems and academics. Individuals who reported more problems related to a lack of support had lower grade point averages, $r(236)=-.18, p=.01$. Frequent similarity problems with friends also was associated with grade point average, $r(236)=.17, p=$ .01. College students who often experienced problems related to support with pre-college friends had relatively low grade point averages; students who frequently experienced problems with similarity had relatively high grade point averages. 


\section{College Friendship Problems and Adjustment Measures}

Total number of frequent problems. Ratings of the frequency of specific types of friendship problems for college friends were examined in relation to adjustment measures in the same way that pre-college friendship problems were considered. For college friendships, individuals experienced a mean of 2.42 problems frequently $(S D=2.90$; range $=0-13)$. An examination of the correlations between total number of frequently experienced problems and adjustment measures revealed that individuals who experienced many problems with their college friends frequently also reported feeling lonely, $r(225)=.22, p=.001$, and homesick, $r(227)=.17, p=.01$, frequently. In addition, participants who indicated that they experienced relatively more problems with college friends reported feeling less socially supported, $r(227)=$ $.22, p=.001$.

Frequency of specific problems, loneliness, and support. Correlations also indicated several significant associations among frequency of specific problem experiences and adjustment measures. Ratings of loneliness were associated with ratings of the frequency of problems with college friends due to support, $r(230)=.13, p=.04$, similarity, $r(228)=.15, p=.02$, common experiences, $r(230)=.23, p<.001$, commitment, $r(230)=.14, p=.03$, unequal effort in friendships, $r(229)=.14, p=.04$, and closeness, $r(231)=.21, p=.001$. College students who reported having many problems because of a lack of support, a lack of similarity, too few common experiences, little commitment, unequal friendship effort, or a lack of closeness with respect to their college friends also reported that they felt lonely often. In addition, frequent feelings of homesickness were associated with problems with college friends due to communication, $r(233)=.15, p=.03$, and closeness, $r(233)=.14, p=.03$. 
Furthermore, college students' ratings of social support were associated with frequency of problems with college friends due to instrumental and emotional support, $r(232)=-.25, p<$ .001 , similarity, $r(230)=-.17, p<.01$, common experiences, $r(232)=-.17, p=.01$, commitment, $r(230)=-.18, p=.01$, disapproval of friends' behaviors, $r(233)=-.16, p=.02$, closeness, $r(233)$ $=-.16, p=.02$, and sharing past experiences, $r(232)=-.16, p=.01$. Each of these problems was associated with feeling unsupported.

Frequency of specific problems and coping strategies. The types of strategies that college students use to deal with stress also are related to the types of problems they frequently experience with their friends. Specifically, college students who reported that they frequently had problems related to similarity with college friends also reported relatively infrequent use of coping strategies involving other people, $r(228)=-.20, p<.01$. Also, individuals who had high frequencies of trust problems were less likely to involve others in coping with stress, $r(232)=$ $.15, p=.02$, and more likely to use drugs or alcohol to cope with stress, $r(232)=.23, p<.001$. Frequency of specific problems and alcohol use. Only one type of friendship problem with college friends was associated with alcohol use. People who reported frequent similarity problems also indicated that they were less likely to consume alcohol five times per month, $r(224)=-.15, p=.03$.

Frequency of specific problems and academics. Grade point average was related to some types of friendship problems for college friends. Specifically, frequency ratings for problems with similarity, $r(227)=.24, p<.001$, common experiences, $r(229)=.14, p=.03$, and thinking about making new friends were associated with grade point average, $r(229)=-.14, p=.04$. College students who often had problems with similarity or common experiences had relatively 
high grade point averages, and students who had many problems related to thinking of making new friends had relatively low grade point averages.

\section{Discussion}

The main purpose of the investigation was to assess the association between pre-problem friendship features of pre-college and college friends and post-problem friendship maintenance or dissolution and quality. Overall, pre-college friendships seem to be more fragile and susceptible to problems than are college friendships. For the most part, the same friendship features predict post-problem friendship outcomes for pre-college and college friendships, and pre-college friends are more likely to experience a variety of friendship problems and endings than are college friends. Findings suggest that college students do not end friendships for the same reasons that they report having problems with friends. For example, common experiences were identified often as causes of friendship dissolution for both pre-college and college friendships but rarely as causes of friendship problems. Results also suggest that students who experience many problems with their friends tend to be lonelier and feel less socially supported as compared to individuals who experience fewer problems. Together, the results suggest that college students' friendships end for the same reasons that other types of relationships (e.g., early adolescents' friendships; romantic relationships) end. Findings illustrate the importance of considering pre-college and college friendships separately in terms of research on college friends. Findings from this study are useful for people who work with students during the transition to college. The information can assist college students and personnel in identifying problems people normally experience during the transition to college. Efforts can be made to enhance college friendships given the susceptibility of pre-college friendships to problems and dissolution. 
Friendship Features 53

\section{Friendship Quality Following Problems}

College students who thought that it would be easy to make new friends had relatively low quality friendships following problems with both pre-college and college friends. This finding is consistent with research on romantic relationships (e.g., Simpson, 1987) suggesting that people who expect that they will be able to form new relationships are more likely to end their romantic relationships as compared to people who think that forming new relationships would be difficult. Early adolescents also report lower friendship quality when they expected that making new friends would be easy (Owens, 2001). In general, it appears that individuals who think that they could easily replace partners in relationships (i.e., friendships and romantic relationships) tend to have low quality relationships, especially when problems occur. Thus, the expectation of being able to form new relationships seems to predict friendship quality for individuals across different age groups and types of relationships.

Length of friendship also predicted friendship quality following problems for both precollege and college friends. Longer friendships also were higher in quality, and newer friendships were lower in quality after problems. The finding is similar to other research, which suggests that friendships (Owens, 2001) and romantic relationships (e.g., Felmlee et al., 1990) are more likely to end if they are shorter in duration. Perhaps friends learn to resolve differences in the context of longer relationships. As a result, longer friendships tend to be higher in quality following problems. On the other hand, newer friends may be less equipped to solve their problems while maintaining high quality friendships. The importance of friendship length in predicting friendship quality suggests that relationship quality is not exclusively the result of interpersonal dynamics (e.g., support; commitment). Instead, friendship qualities that are not directly interpersonal in nature (i.e., length) can be predictive of friendship quality. Furthermore, 
length of friendship may serve as a marker for other variables. Length of friendship was correlated with several other friendship features in the current study. It is possible that longlasting friendships include high levels of commitment, for example.

For both pre-college and college friendships, friends who reported more commitment to their friendships also reported higher friendship quality following problems. This finding is consistent with Fehr's (1999) work that highlights the crucial role of commitment in friendship maintenance. Friends who are highly committed to each other may strive to keep friendship quality high after problems occur. On the other hand, uncommitted friends may not particularly care what happens in their relationships following problems. Regardless of other features of a given friendship, if friends are not dedicated to their relationships, they may not work to make their friendships as good as possible.

For pre-college friendships, students who indicated that they were more similar to their friends had higher quality friendships following problems as compared to students who reported that they were less similar to their friends. Based on previous research (e.g., Clements et al., 1997), similarity was not expected to predict friendship quality for well-established friendships such as pre-college friendships. In the present study, similarity likely was associated with precollege friendship outcomes because of a decrease in perceived similarity. Specifically, college students who believed that they had been similar to each other prior to beginning college but were no longer similar to each other likely had low quality friendships after problems. Perhaps the friends would have been more interested in resolving differences if they had felt that they were still similar to each other or if they had become more similar to each other over time.

Overall friendship quality for college friends was predicted by a positive ratio of rewards and costs. That is, friendships that were experienced as including more rewards than costs were 
higher in quality following problems as compared to friendships that were more costly. This finding is consistent with Rusbult's (1980) finding that costs should not outweigh rewards in good friendships. Thus, college students might maintain high quality friendships with people whose friendships they experience as rewarding. On the other hand, friendships that already are high in quality may become rewarding to individuals. This idea is consistent with Berg's (1984) finding that friendships are more rewarding over time.

Finally, quality of college friendships following problems depended on pre-problem levels of trust. Specifically, students who reported low levels of trust with their college friends reported high quality friendships after problems occurred. This finding was unexpected. As Jones (1991) suggests, trust is a crucial aspect of good college friendships. It was expected that because trust is so important to college students, college students might not work to enhance friendships that lack trust. However, the opposite was found. It is possible that in this study college students who did not trust their friends prior to experiencing problems actually began to trust their friends more as they resolved their problems. Perhaps the friends worked together to resolve their differences and, in turn, developed higher quality friendships.

\section{Friendship Dissolution Following Problems}

In addition to predicting friendship quality following problems, expected ease of finding a new friend also predicted whether or not pre-college and college friendships ended after problems. This finding also is consistent with research on romantic relationships. For example, Simpson (1987) reported that people who thought it would be easy to find new romantic partners were more likely to terminate relationships than were those who felt it would be difficult to form new relationships. Previous research suggests that early adolescent friendships also are likely to end following problems when friends think that it would be easy to find new friends (Owens, 
2001). College students who thought that new friends would be easy to make probably chose to form new relationships instead of working to maintain troubled friendships with specific individuals. On the other hand, individuals who thought that it would be hard to make new friends likely chose to maintain existing relationships, even if problems occurred. Expected ease of finding a new friend predicted both friendship quality and dissolution. Friendships in which individuals believed they could easily make new friends often dissolve; when the friendships are maintained, friendship quality is low. Thus, the expectation of entering new relationships is an especially important factor in determining friendship outcomes when problems occur.

For pre-college friends, greater frequency of current common experiences was predictive of friendship dissolution when problems occurred. This finding was unexpected. Based on previous research (e.g., Fehr, 1999), sharing many experiences was hypothesized to predict friendship maintenance. It is possible that friends who shared many experiences with pre-college friends experienced a clashing of pre-college and college friendship networks. That is, individuals who saw their pre-college friends often were also forming friendships with people they met during college. Perhaps pre-college friends and college friends were dissimilar; as a result, problems occurred. Perhaps college students did not feel that their pre-college friends fit into their circles of college friends. On the other hand, college students who reported seeing their pre-college friends infrequently may not have experienced the clashing of friendship networks; thus, pre-college friendships with few shared experiences were maintained. Current common experiences were not predictive of friendship quality but were predictive of dissolution. Issues with current common experiences probably are difficult to resolve. As a result, friendship dissolution occurs instead of maintenance of low quality friendships. 
For college friendships, low levels of pre-problem support and resources predicted friendship dissolution following problems. Individuals who felt that their college friends provided little emotional or instrumental support did not maintain their friendships. Similarly, a balance of costs and rewards was predictive of friendship outcome. Specifically, costly friendships were more likely to end after problems. Together, these findings suggest that college students are more likely to maintain friendships that provide some benefit (i.e., support, resources, or general benefits) than friendships without such benefits. This idea is consistent with the current finding that costly friendships were lower in post-problem friendship quality and with Rusbult's (1980) finding that friendships were likely to end when friends felt that they put too much effort into the friendship compared to the benefits they received from the friendship. Results of an investigation of early adolescent friendships indicated that a balance of costs and rewards did not predict friendship maintenance or dissolution (Owens, 2001). Differences in results could be a result of differences in samples. Rusbult's sample was an adult sample, and the current sample was a college sample. Perhaps individuals do not evaluate the costliness of their friendships until after early adolescence. College students seem to focus on equality in relationships, but early adolescents seem to focus more on the types of people their friends are (Owens), regardless of equality. Thus, equality might become more important than friends' individual characteristics throughout adolescence.

Finally, pre-problem communication with college friends predicted friendship maintenance or dissolution. High levels of intimate communication predicted friendship dissolution after problems. However, based on previous research (e.g., Jones, 1991), it was expected that high levels of communication would predict high friendship quality. It is possible that college students did not feel comfortable if their friends chose to disclose too much personal 
information to them early in their relationships (e.g., Baxter, 1990). Thus, sharing high levels of personal information may have led to a decreased interest in the friendship and therefore increased likelihood of friendship dissolution.

Summary. In general, expected ease of making new friends predicted friendship quality, maintenance, and dissolution for pre-college and college friends; it was the only variable to significantly predict all of the outcomes. Regardless of other relationship dynamics, people seem to prefer to replace friends instead of resolving conflicts. Commitment and length of friendship predicted friendship quality for pre-college and college friends. Students who were dedicated to the continuity of their friendships and whose friendships were long-lasting tended to have high quality friendships following problems. Perhaps individuals who have relatively large investments in their relationships are most likely to work to maintain high quality relationships; invested friends also may have learned to not allow problems to reduce their relationship quality. A balance of costs and rewards predicted friendship quality, maintenance, and dissolution following college friends' problems. College students seem to place a great deal of importance on the benefits they receive from their new friends when they make decisions about postproblem friendship experiences. Similar findings have been found for romantic relationships and for early adolescent friendships with one exception. A balance of costs and rewards did not predict friendship outcomes for early adolescent friendships. Assessment of relationship costliness may not take place until individuals reach college age. Predictors of friendship outcomes were essentially the same for males and females. Even though friendship features may differ for males and females (e.g., Dwyer \& Cummings, 2001; Grabill \& Kerns, 2000), it appears that male and female friends experience friendship problems and dissolution for the same reasons. 
Friendship Features 59

\section{Causes of Friendship Problems and Dissolution}

Findings suggest that, overall, college students do not necessarily end friendships for the same reasons that they have problems with friends. For example, when college students were asked to tell what caused their friendships to end, a lack of common experiences was the most common reported cause of terminated friendships for both pre-college and college friends. However, few college students reported that a lack of common experiences was the cause of problems with pre-college or college friends. Thus, friendships appear to end when college students do not have opportunities to do things together. Findings of the current study also indicate that pre-problem current common experiences predict post-problem friendship dissolution but not post-problem friendship quality. Therefore, if one's friend moved to a different dormitory, chose a different major, or lived at home while his or her friends were away at college, the friendship was likely to dissolve. However, friends rarely reported having problems due to a lack of common experiences, perhaps because a lack of common experiences instead led to relationship dissolution. This finding is consistent with previous research (Owens, 2001), which suggested that early adolescents are likely to identify friendship dissolution as a result of a lack of common experiences but are unlikely to identify friendship problems related to a lack of common experiences. Furthermore, in the present study friendship dissolution as a result of too few common experiences was identified more often for pre-college friends than for college friends. This finding is likely a result of the fact that pre-college friends do not see each other as often as do college friends.

Support and resources was the reported cause of many more friendship problems than friendship endings for both pre-college friends and college friends. It is likely that this finding is related to the ease with which support and resources issues could be resolved. For example, 
friends could easily resolve the problem of roommates not paying utility bills by establishing firm rules for the ways in which bill paying should occur. It is likely that many college students experience problems with support and resources with their friends, because they are in new environments in which their friends may not know how to be supportive. Friends need to learn how to provide appropriate support and resources. Discussing boundaries and expectations may help college student friends to support each other more appropriately. Providing new college students with information about living on their own and with roommates could be a useful activity to help to reduce the numbers of problems that college students have with their new friends.

In addition, many college students reported that they had never experienced dissolution of one of the types of friendships. On the other hand, almost all participants indicated that they had experienced problems with pre-college and college friends. This supports research showing that friendships generally are stable but that friends tend to experience many disagreements (Hays, 1985). It is also possible that friendship dissolution had yet to occur for many of the participants because of the relatively short amount of time that had passed since they began college. Although most participants' friendships were stable during their first few years of college, it is possible that their friendships will dissolve some time in the future. Some students might experience friendship dissolution later in college; perhaps some second and third year college students did not have enough time to make and lose new friends. Others might dissolve college friendships after leaving college.

Prevalence and Importance of Causes of Problems

In addition to the problems that college students identified when they were asked to describe a specific problem that had occurred in their friendships, it is important to consider the 
overall prevalence of various types of problems. This portion of the study was exploratory; specific hypotheses were not made. An examination of college students' rating of the prevalence of 11 types of friendship problems suggests that pre-college friends are more likely to experience problems due to commitment, disapproval of a friend's personal characteristics, and emotional closeness than are college friends. In addition, problems related to current common experiences, commitment, and emotional closeness also were rated as being more important in terms of precollege friendships than for college friendships. Overall, pre-college friendship problems occurred more frequently and were more important as compared to college friendship problems. Commitment and emotional closeness were both more frequent and more important for precollege friends.

Problems related to a lack of commitment probably occur more often for pre-college friends, because pre-college friends need to make more of an effort to stay in touch with each other (e.g., Fehr, 1999). Whereas college friends may see each other every day, pre-college friends must make telephone calls or maintain communication via e-mail in order to demonstrate commitment to their friendships. Because more effort is needed on the part of pre-college friends, more problems are likely to arise. Commitment problems also were rated as being more important in pre-college friendships as compared to college friendships. The problems likely are of particular importance to the outcome of a friendship, because a lack of commitment signals indifference to the friendship. Thus, problems with commitment are destructive to friendship quality and stability. For college friends, commitment problems may occur relatively infrequently and may be relatively unimportant as a result of frequent interactions. It might not be necessary for college friends to engage in behaviors that specifically demonstrate friendship commitment. 
College students reported that they were more likely to have problems due to a lack of emotional closeness with pre-college friends than with college friends. A lack of emotional closeness is especially likely to lead to problems for pre-college friends who felt that they were closer prior to beginning college. During the transition to college, the friends might have felt that they had grown apart and that they no longer shared the same close bond that they previously had shared. College friends, in contrast, may not expect as much emotional closeness as do precollege friends. As a result, problems with a lack of emotional closeness may not occur for college friends. Problems with emotional closeness also were rated as being more important for pre-college friendships than for college friendships. This finding probably is due to the lack of physical contact pre-college friends have with each other. In the absence of physical closeness, emotional closeness is of great importance. When problems occur with emotional closeness, the friends may have difficulty in sustaining a high quality friendship.

Disapproval of a friend's personal characteristics or behaviors was rated as occurring more frequently for pre-college than for college friends. Pre-college friends who used to approve of their friends' behaviors but who no longer approve of their friends' behaviors probably were particularly likely to have problems with personal characteristics. For example, college students who perceive that their friends changed a great deal after high school graduation might experience the changes as problematic. However, college friends did not have the opportunity to know what their friends' characteristics were like prior to college. As a result, changes in personal characteristics during the transition to college would not lead to problems. Alternatively, college friends simply might have very similar behaviors at the beginning of their friendships. It is possible that students who attend the same college are quite similar to each 
other, for example. As a result, disapproval of a friend's personal characteristics would be rather unlikely to occur.

Current common experiences likely are rated as more important for pre-college friends because pre-college friends typically experience fewer common daily experiences than do college friends (e.g., Fehr, 1999; Felmlee et al., 1990). The lack of daily experiences likely leads individuals to friendship problems. College students may spend time thinking about the time they are not able to spend with pre-college friends. When they are asked about the importance of a variety of problems with friends, college students might focus on the prominent issue of current common experiences.

\section{Prevalence and Importance of Causes of Friendship Endings}

Overall, college students rated events that could lead to friendship dissolution as being more prevalent in their pre-college friendships than in their college friendships. Specifically, events related to support, similarity, current common experiences, commitment, communication, unequal effort, closeness, and thoughts of making new friends were rated as being more likely to lead to the break-up of pre-college friendships than to the break-up of college friendships. In addition, events related to shared history were rated as being more important in leading to the dissolution of females' pre-college friendships than in leading to the dissolution of females' college friendships. In general, pre-college friendships are more likely to dissolve.

Pre-college friendships are more susceptible to dissolution for a variety of reasons. The lack of physical proximity can lead to friendships ending for pre-college friends (e.g., Fehr, 1999; Felmlee et al., 1990); college friends likely are less affected by proximity because they see each other relatively often. For pre-college friends, however, lack of proximity causes a decrease in common experiences (e.g., Fehr). In addition, friends who do not see each other often may not 
fully understand how to support each other. Lack of proximity also may also lead to problems with commitment and communication. That is, friends may need to put extra effort into maintaining their relationships and keeping open lines of communication. It is possible that friends will perceive unequal effort in their friendships when they are differently committed to their relationships (e.g., Rusbult, 1980).

Upon entering college, individuals have the opportunity to explore activities and ideas that they had not considered before college. The transition to college is both an exciting and an anxiety-provoking experience (Paul \& Kelleher, 1995). As individuals grow through the new experiences they have in college, they may begin to form values and interests that differ from earlier interests or the interests of their pre-college friends. As a result, pre-college friends may experience a lack of perceived similarity with previously similar friends. Friends typically are similar to each other (e.g., Akers et al., 1998), and friends who feel that they are not similar also may not feel that they are emotionally close to each other. When friends do not believe that they are similar or emotionally close to each other, they also may consider making new friends. Perhaps they wish to make friends who share similar interests and beliefs. College friendships, on the other hand, are less susceptible to friendship dissolution as a result of changes that occurred following high school. Because college students did not know what their friends were like prior to beginning college, their friendship outcomes (i.e., maintenance or dissolution) typically will not be based on changes in similarity across the transition to college. Instead, college students may form new friendships with people to whom they are similar.

Some gender differences in terms of frequency of causes of friendship dissolution were found. Males' frequency of dissolution because of current common experiences was relatively high. Females, in contrast, had high ratings for trust, commitment, unequal friendship effort, and 
closeness. These findings are consistent with previous research suggesting that males' and females' friendship experiences differ (e.g., Field et al., 1995; Hartup, 1993). In this study, gender differences were found for frequency ratings of causes of friendship endings but not for other comparisons. Thus, the current study indicates that further research is needed in terms of gender differences in friendship problems and endings.

Summary. When differences were present in the prevalence or importance of various events in determining friendship problems and endings, ratings were higher for pre-college than for college friendships. Overall, then, pre-college friendships are more susceptible to problems and dissolution. Higher susceptibility to problems and endings could be the result of changes in physical proximity to friends or to changes in personality and values during the transition to college. The finding that pre-college friendships are more likely than college friendships to end as a result of many specific types of events might be a function of time. That is, pre-college friends simply might have had more time to experience friendship problems and dissolution because pre-college friendships were longer in duration. It is possible that college friends will experience more problems as time passes.

\section{Friendship Problems and Adjustment}

In general, experiencing many friendship problems was associated with feeling lonely often. This finding is consistent with previous research in which college women who were more satisfied with their friendships also were less lonely (Ponzetti \& Cate, 1989). Individuals with many friendship problems might either see their friends infrequently or might not be comforted by the presence of their friends. It is possible that friends who experience many problems avoid contact with each other or that a lack of contact leads to problems. It also is possible that friends with many problems see each other often but do not feel a particularly strong bond; friends may 
feel that there is something missing in the friendship. Thus, individuals with many friendship problems report being lonely often. Loneliness is fairly common during the transition to college (Larose \& Boivin, 1998), and students who have good friends are less likely to experience psychological problems as a result of loneliness (Fisher \& Hood, 1987). Thus, students who have many problems with friends are particularly vulnerable to feelings of loneliness and may be at risk for psychological disturbances.

In addition, college students who experience many problems with their friends generally feel more homesick and less socially supported as compared to students with fewer problems with college friends. As Fehr (1999) explains, friends typically support each other. When problems occur often, perhaps individuals who have many college friendship problems do not feel that they can count on their friends. It is possible that experiencing numerous friendship problems simply leads college students to feel that others are not looking out for their best interests. As a result, they feel that they do not have the support of others. Feeling socially supported by friends is of particular importance to college students, because they often do not have regular contact with family members. Furthermore, students who frequently experienced problems with college friends, especially problems related to communication and closeness, also reported feeling homesick often. Such students probably thought that they could avoid the problems and feel more accepted if they were at home.

In addition to overall frequency of problems, specific types of problems were associated with college students' loneliness. College students who reported having many problems with commitment and unequal effort in their pre-college or college friendships also reported feeling lonely often. Frequency ratings for several other specific problems with either pre-college or college friends were associated with loneliness as well. Apparently being accepted by others is 
important to college students; overall, college students seemed to feel lonely when they did not feel accepted by their friends (e.g., their friends were not committed to the friendships). In a similar investigation, a common problem early adolescents identified was feeling excluded from the peer group (Owens \& Strough, 2002). Other research suggests that group membership is a fundamental human desire (e.g., Baumeister \& Leary, 1995). Thus, there appears to be some continuity in the importance of feeling accepted by others across age groups.

For pre-college and college friendships, students reported that they felt little social support when they experienced many problems related to instrumental or emotional support, past shared experiences, or commitment. It is likely that socially supportive relationships develop over time; perhaps friends learn how to be supportive of each other. Over time shared experiences accumulate and commitment presumably is high if friendships continue. Therefore, when problems with commitment and shared experiences occur, social support generally is low.

Some types of problems also are associated with college students' use of various coping strategies to deal with stress. Past research suggests that college friendships are associated with effective coping strategies (Dwyer \& Cummings, 2001). In the present study, students who experienced many similarity problems with their pre-college or college friends were unlikely to rely on others to help them deal with stress. It is likely that individuals who do not feel similar to their friends will not wish to ask their friends for advice when stressful events occur; they may assume that their friends will not offer suitable suggestions. Similarly, individuals who reported having many problems with trusting their college friends were less likely to rely on others during stressful times. Talking to others about problems can be an effective way to cope with stress (e.g., Paul \& Kelleher, 1995). However, individuals who have many trust problems likely do not trust that others will give good advice or fear that their friends will share their problems with 
other people. Instead of relying on others to cope with stress, individuals who had many trust problems with their college friends turned to drugs or alcohol to deal with stress. It is possible that the individuals turned to substances in the absence of having a trusting person to help with their stress. This is consistent with findings that alcohol use was more likely to be used as a coping strategy when college students did not have close, intimate friendships (Hussong et al., 2001). Alternatively, the consistent use of substances could lead to problems with trust in friendships. The use of alcohol to cope with stress is not considered to be a positive coping strategy (e.g., Hussong et al.). Students who keep their problems to themselves and do not ask for help might not be able to effectively reduce their stress.

Alcohol use also was correlated with other types of friendship problems. College students who reported having many problems with similarity with pre-college or college friends also reported drinking alcohol infrequently. It is likely that many problems with similarity center on alcohol consumption. For example, college students who choose to not drink alcohol may perceive that they have few similarities with students who choose to drink. Many people have expectations that alcohol use is a normative activity during the college years. As a result, students who do not drink alcohol may not perceive that they are similar to other students. On a related note, individuals who experienced many problems with personal characteristics with precollege friends also reported that they were less likely use drugs or alcohol to cope with stress. Experiencing many emotional closeness problems or similarity problems with pre-college friends was associated with less alcohol consumption per week. Again, problems related to pre-college friends' personal characteristics, closeness, and similarity often might be the result of differences in opinions about substance use. Perhaps students who grew apart from their pre-college friends did so as a result of different decisions about substance use. 
Finally, academic outcomes were associated with some types of friendship problems. Specifically, students who had many similarity problems with their pre-college or college friends also reported having relatively high grade point averages. Individuals also had higher grade point averages when they had many problems with current common experiences with college friends. Perhaps students who felt dissimilar to their friends or who did not engage in common activities with their friends chose to focus on academic pursuits instead. On the other hand, it is possible that students who did well in their coursework felt that they were not similar to other students or did not have time to engage in common activities with other students. College students who had many problems with pre-college friendship support and resources had relatively low grade point averages. Perhaps the students felt that they did not have someone outside of the college atmosphere to encourage them to do their best in school. Previous research suggests that students who have supportive social networks are more likely to seek help with school when necessary (Larose et al., 1999). Perhaps seeking help contributes to grade point average. Low grade point averages also were reported by students who often had problems due to thinking about making new college friends. Perhaps these students were generally frustrated with their situations. They did not do well in their courses and were not particularly pleased with their group of friends.

Summary. The problems that college students have with their friends and other areas of students' lives can affect each other. For the most part, experiencing fewer problems with friends seems to be associated with better adjustment outcomes (i.e., low levels of loneliness, low levels of homesickness, and high levels of social support). Associations among specific types of friendship problems and adjustment outcomes differ. For example, frequent problems with commitment and unequal friendship effort are associated with increased loneliness. At the same time, other problems are associated with positive outcomes. For example, problems with 
similarity are associated with high grade point average and infrequent alcohol consumption. Together, results suggest that problems with friends do not occur in isolation. Instead, problems are only a part of college students' experiences. Additional research should further explore the potential costs and benefits of having problems with friends in terms of general adjustment. It also should be noted that the magnitude of many of the correlations was small and that many of the causes of problems were correlated with each other. More research is needed to determine if the correlations in the current study would be replicated with different sample sizes and if individual problems were considered separately.

\section{Limitations and Future Directions}

One limitation of the current study is the retrospective self-report nature of the data. College students reported information about friendship problems and break-ups that occurred several months before they completed the questionnaires. Participants may not have remembered all of the events that surrounded their friendship problems or endings or may not have reported events accurately. It is possible that participants described their friendships as they were experienced at the time of the study instead of the way in which the friendships were experienced at the time of the friendship problems. Participants also might have reconstructed their memories to be consistent with their current self-schemas (e.g., Ross, 1989). Future research should be conducted in a prospective manner so that friendship features can be assessed before problems occur in friendships. College students could rate the qualities of their friendships when they begin college. The same students could describe their friendships at a later time (presumably after problems occurred). The association between friendship features and outcomes could be better understood. 
In addition, when participants were asked to indicate how often various problems occurred in their friendships, they might have focused only on recent events instead of considering their overall friendship experiences. Again, prospective research should be conducted so that individuals could indicate each time a problem occurs. That is, participants could use a diary to record each friendship problem they experience as the problems occur. Knowing exactly how often various problems take place in friendships would give researchers a more complete picture of friendship problems.

Regarding friendship problems and outcomes, it is impossible to determine whether friendship quality following problems was the direct result of the problem an individual chose to describe. For example, if a participant described a problem with trust and indicated that her friendship ended, the current methodology does not allow for the conclusion that trust directly caused the friendship to end. Future research should address whether described problems directly caused friendship outcomes.

The sample was fairly homogenous in that most participants were Caucasian and had parents who had obtained high levels of education. It would be beneficial for future research to identify students from different backgrounds to determine if all college students experience friendship problems and friendship dissolution in the same ways. Previous research has not addressed this issue, so it is unclear if cultural differences would emerge in studies of friendship. Furthermore, almost one-third of the participants had transferred to a different college prior to completing the study. It is unclear if the participants' reasons for transferring were related to their friendship experiences. Future research should explore the potential differences in the friendships of transfer students and non-transfer students. 
The current study was conducted at a large university. In the future, similar studies should be conducted to explore whether or not friendship problems and endings are similar in other types of settings. For example, researchers could determine if students at smaller schools where most students know each other have the same patterns in their friendship relationships. Fraternities and sororities are other contexts in which individuals know each other well; thus, it would be interesting to identify patterns of friendship problems and endings for students who are members of Greek organizations.

Another aspect of friendship relationships that could be explored is the potential impact of romantic partners. Specifically, researchers could identify ways in which the presence of a romantic partner can lead to friendship problems and friendship dissolution. Some research indicates that friends have both positive and negative effects on romantic relationships (e.g., Felmlee, 2001). Future research could examine the impact of romantic partners on friendships as well.

In the current investigation college students described friendships with friends they had prior to beginning college (i.e., pre-college friends) and new friends they had made in college (i.e., college friends). However, this study did not examine problems individuals had with their pre-college friends who attended college with them. It is likely that friendship problems and endings will differ for friends who attend college with pre-college friends as compared to typical pre-college or college friends. Specifically, pre-college friends who remain friends in college might be more likely to experience friendship problems and endings. This could be a result of students expecting that their pre-college friends will be good companions in college; however, as individuals change in college their friendships also are likely to change. Problems are likely to occur when expectations are not met. Future research should address this topic. 
It should also be noted that friendship dissolution is not necessarily detrimental to college students. For example, if friendships are not supportive for individuals or if individuals tend to experience negative academic outcomes with their friends, then it can be beneficial to terminate the friendships. Future researchers could further explore the consequences of friendship dissolution for various types of friendships.

\section{Implications}

Findings of the current study contribute to knowledge about college students' friendships in several ways. First, there are similarities in friendship problems and dissolution across different age groups and types of relationships (i.e., friendships and romantic relationships). Results also indicate that distinctions need to be made between pre-college friendships and college friendships in studies of college students' friendship experiences. That is, the outcomes of the two types of friendships are affected by different factors. In addition, pre-college friendships seem to be more vulnerable to problems and dissolution than are college friendships. Given that pre-college friendships are susceptible to problems and endings, it is important to further understand the dynamics of college friendships. As individuals make the transition from high school to college, they might need extra support in forming and maintaining new college friendships. Because having friends is associated with positive outcomes and pre-college friendships may decline in quality for a variety of reasons, new college friends can provide needed support for college students. College orientation programs could use information about changes in friendship networks to help new students to build new friendships as well as maintain existing pre-college friendships. 


\section{References}

Aboud, F. E., \& Mendelson, M. J. (1996). Determinants of friendship selection and quality: Developmental perspectives. In W. M. Bukowski, A. F. Newcomb, \& W. W. Hartup (Eds.), The company they keep: Friendship in childhood and adolescence (pp. 87112). New York: Cambridge University Press.

Akers, J. F., Jones, R. M., \& Coyl, D. D. (1998). Adolescent friendship pairs: Similarities in identity status development, behaviors, attitudes, and intentions. Journal of Adolescent Research, 13, 178-201.

Auhagen, A. E. (1996). Adult friendship. In A. E. Auhagen, \& M. von Salisch (Eds.), The Diversity of Human Relationships (pp. 229-247). New York: Cambridge University Press.

Azmitia, M., Lippman, D. L., \& Ittel, A. (1999). On the relation of personal experience to early adolescents' reasoning about best friendship deterioration. Social Development, 8 , 275-291.

Baumeister, R. F., \& Leary, M. R. (1995). The need to belong: Desire for interpersonal attachments as a fundamental human motivation. Psychological Bulletin, 117, 497-529.

Baxter, L. (1990). Dialectical contradictions in relationship development. Journal of Social and Personal Relationships, 7, 69-88.

Berg, J. H. (1984). Development of friendship between roommates. Journal of Personality and Social Psychology, 46, 346-356.

Bogat, G. A., Caldwell, R. A., Rogosch, F. A., \& Kriegler, J. A. (1985). Differentiating specialists and generalists within college students' social support networks. Journal of Youth and Adolescence, 14, 23-35. 
Brissette, I., Scheier, M. F., \& Carver, C. S. (2002). The role of optimism in social network development, coping, and psychological adjustment during a life transition. Journal of Personality and Social Psychology, 82, 102-111.

Clements, M. L., Cordova, A. D., Markman, H. J., \& Laurenceau, J. (1997). The erosion of marital satisfaction over time and how to prevent it. In R. J. Sternberg \& M. Hojjat (Eds.), Satisfaction in Close Relationships (pp. 335-355). New York: Guilford Press.

Devlin, A. S. (1996). Survival skills training during freshman orientation: Its role in college adjustment. Journal of College Student Development, 37, 324-334.

Dwyer, A. L., \& Cummings, A. L. (2001). Stress, self-efficacy, social support, and coping strategies in university students. Canadian Journal of Counselling, 35, 208-220.

Fehr, B. (1999). Stability and commitment in friendships. In J. M. Adams, \& W. H. Jones (Eds.), Handbook of interpersonal commitment and relationship stability (pp.259280). New York: Kluwer Academic/Plenum Publishers.

Felmlee, D. H. (2001). No couple is an island: A social network perspective on dyadic stability. Social Forces, 79, 1259-1287.

Felmlee, D., Sprecher, S., \& Bassin, E. (1990). The dissolution of intimate relationships: A hazard model. Social Psychology Quarterly, 53, 13-30.

Field, T., Lang, C., Yando, R., \& Bendell, D. (1995). Adolescents' intimacy with parents and friends. Adolescence, 30, 133-140.

Fischer, S., \& Hood, B. M. (1987). The stress of the transition to university: A longitudinal study of psychological disturbance, absent-mindedness and vulnerability to homesickness. British Journal of Psychology, 78, 425-441.

Grabill, C. M., \& Kerns, K. A. (2000). Attachment style and intimacy in friendship. Personal 
Relationships, 7, 363-378.

Hartup, W. W. (1993). Adolescents and their friends. New directions for child development, 60, 3-22.

Hartup, W. W., French, D. C., Laursen, B., Johnston, M. K., \& Ogawa, J. R. (1993).

Conflict and friendship relations in middle childhood: Behavior in a closed-field situation. Child Development, 64, 445-454.

Hays, R. B. (1985). A longitudinal study of friendship development. Journal of Personality and Social Psychology, 48, 909-924.

Helsen, M., Vollebergh, W., \& Meeus, W. (2000). Social support from parents and friends and emotional problems in adolescence. Journal of Youth and Adolescence, 29, 319-335.

Henderson, M., \& Furnham, A. (1982). Similarity and attraction: The relationship between personality, beliefs, skills, needs and friendship choice. Journal of Adolescence, 5, 111123.

Hill, C. T., \& Stull, D. E. (1981). Sex differences in effects of social and value similarity in same-sex friendship. Journal of Personality and Social Psychology, 41, 488-502.

House, J. S., Landis, K. R., \& Umberson, D. (1988). Social relationships and health. Science, $241,540-544$.

Howell, D. C. (1997). Statistical Methods for Psychology (5 ${ }^{\text {th }}$ ed.). Belmont, CA: Wadsworth. Hussong, A. M., Hicks, R. E., Levy, S. A., \& Curran, P. J. (2001). Specifying the relations between affect and heavy alcohol use among young adults. Journal of Abnormal Psychology, 110, 449-461.

Jones, D. C. (1991). Friendship satisfaction and gender: An examination of sex differences in 
contributors to friendship satisfaction. Journal of Social and Personal Relationships, 8, $167-185$.

Lakey, B., \& Heller, K. (1988). Social support from a friend, perceived support, and social problem solving. American Journal of Community Psychology, 16, 811-824.

Larose, S., Bernier, A., Soucy, N., \& Duchesne, S. (1999). Attachment style dimensions, network orientation and the process of seeking help from college teachers. Journal of Social and Personal Relationships, 16, 225-247.

Larose, S., \& Boivin, M. (1998). Attachment to parents, social support expectations, and socioemotional adjustment during the high school-college transition. Journal of Research on Adolescence, 8, 1-27.

Lea, M., \& Duck, S. (1982). A model for the role of similarity of values in friendship development. British Journal of Social Psychology, 21, 301-310.

Newcomb, A. F., \& Bagwell, C. L. (1995). Children's friendship relations: A metaanalytic review. Psychological Bulletin, 117, 306-347.

Owens, R. A. (2001). Friendship features associated with early adolescent friendship maintenance and dissolution. Unpublished master's thesis, West Virginia University, Morgantown.

Owens, R. A., \& Strough, J. (2002). Friendship features associated with early adolescent friendship maintenance and dissolution. Manuscript submitted for publication.

Paul, E. L., \& Brier, S. (2001). Friendsickness in the transition to college: Precollege predictors and college adjustment correlates. Journal of Counseling and Development, 79, 77-89.

Paul, E. L., \& Kelleher, M. (1995). Precollege concerns about losing and making friends in 
college: Implications for friendship satisfaction and self-esteem during the college transition. Journal of College Student Development, 36, 513-521.

Ponzetti, J. J., \& Cate, R. M. (1988). The relationship of personal attributes and friendship variables in predicting loneliness. Journal of College Student Development, 29, 292-298.

Raja, S. N., McGee, R., \& Stanton, W. R. (1992). Perceived attachments to parents and peers and psychological well-being in adolescence. Journal of Youth and Adolescence, $21,471-485$.

Rawlins, W. K., \& Holl, M. (1987). The communicative achievement of friendship during adolescence: Predicaments of trust and violation. Western Journal of Speech Communication, 51, 345-363.

Ross, M. (1989). Relation of implicit theories to the construction of personal histories. Psychological Review, 96, 341-357.

Rubin, K. H., Bukowski, W., \& Parker, J. G. (1998). Peer interactions, relationships, and groups. In W. Damon (Series Ed.) \& N. Eisenberg (Vol. Ed.), Handbook of child psychology: Vol. 3. Social, emotional, and personality development ( $5^{\text {th }}$ ed., pp. 619-700). New York: Wiley.

Rusbult, C. E. (1980). Satisfaction and commitment in friendships. Representative Research in Social Psychology, 11, 96-105.

Sansone, C., \& Berg, C. A. (1993). Adapting to the environment across the life span: Different process or different inputs? International Journal of Behavioral Development, 16, 215241.

Scholte, R. H. J., van Lieshout, C. F. M., \& van Aken, M. A. G. (2001). Perceived relational 
support in adolescence: Dimensions, configurations, and adolescent adjustment. Journal of Research on Adolescence, 11, 71-94.

Selman, R. L., \& Schultz, L. H. (1990). Making a friend in Youth: Developmental theory and pair therapy. Chicago: University of Chicago.

Simpson, J. A. (1987). The dissolution of romantic relationships: Factors involved in relationship stability and emotional distress. Journal of Personality and Social Psychology, 53, 683692.

Sprecher, S., \& Fehr, B. (1998). The dissolution of close relationships. In J. H. Harvey (Ed.), Perspectives on Loss (pp. 99-112). Philadelphia: Edwards Brothers.

Stensrud, J. R. (1986). The influence of organizational and environmental factors on the development of college friendships. College Student Journal, 20, 99-103.

Strough, J., Patrick, J. H., \& Swenson, L. M. (2002). Strategies for solving everyday problems faced by grandparents: The role of experience. In B. Hayslip \& J. H. Patrick (Eds.), Working with Custodial Grandparents. (pp. 257-275).

Strough, J., Swenson, L. M., Owens, R. A., \& Pickard, J. Developmental tasks from adolescence through early adulthood. Manuscript submitted for publication.

Tolson, J. M., \& Urberg, K. A. (1993). Similarity between adolescent best friends. Journal of Adolescent Research, 8, 274-288.

Uchino, B. N., Uno, D., \& Holt-Lunstad, J. (1999). Social support, physiological processes, and health. Current Directions in Psychological Science, 8, 145-148.

U.S. Bureau of the Census. (1987). Classified index of industry and occupation: Final edition 1980. (Census Population Report PHC 80-R4). Washington, D.C.: Author.

Urberg, K. A., Degirmencioglu, S. M., \& Tolson, J. M. (1998). Adolescent friendship selection 
and termination: The role of similarity. Journal of Social and Personal Relationships, 15, 703-710.

Werner, C., \& Parmelee, P. (1979). Similarity of activity preferences among friends: Those who play together stay together. Social Psychology Quarterly, 42, 62-66.

Weinstock, J. S., \& Bond, L. A. (2000). Conceptions of conflict in close friendships and ways of knowing among young college women: A developmental framework. Journal of Social and Personal Relationships, 17, 687-696.

Winn, K. I., Crawford, D. W., \& Fischer, J. L. (1991). Equity and commitment in romance versus friendship. Journal of Social Behavior and Personality, 6, 301-314.

Wright, P. H., \& Keple, T. W. (1981). Friends and parents of a sample of high school juniors: An exploratory study of relationship intensity and interpersonal rewards. Journal of Marriage and the Family, 43, 559-570. 


\section{Appendix A}

\section{Background Information}

Today's date

Are you a male or a female? male female

How old are you?

What is your birthdate? Month Day Year

Do you consider yourself to be: (Please check one)

$\begin{array}{ll}\text { White/Caucasian } & \text { Black/African American } \\ & \text { Hispanic }\end{array}$

What is your parents' marital status?

$\begin{array}{ll}\text { Married } & \text { Divorced or Separated } \quad \text { Other }\end{array}$

What is your father's occupation?

What is the highest level of education your father attained?

What is your mother's occupation?

What is the highest level of education your mother attained?

For how many years have you been in college?

Have you ever attended a different college? Yes No

If yes, for how many years have you attended your current college?

Approximately how far is your hometown from your college? hours minutes

Approximately how many times do you visit your hometown per semester? 
Which of the following best describes your current living arrangement?

residence hall with family members

apartment or house with same-sex students apartment or house with opposite-sex students with a boyfriend or girlfriend other (please explain)

What is your romantic relationship status? single dating married

If you are dating or married, for how many months have you been in the relationship?

Please list the types of activities in which you participate outside of class (For example, work, sports, fraternity or sorority, etc.):

If you are employed, how many hours do you work in a typical week?

\section{ADJUSTMENT ASSESSMENT:}

\section{LONELINESS}

How often do you feel lonely?

$$
1=\text { never } \quad 2=\text { occasionally } \quad 3=\text { in the middle } \quad 4=\text { often } \quad 5=\text { almost always }
$$

How often do you feel homesick? 


$$
1=\text { never } \quad 2=\text { occasionally } \quad 3=\text { in the middle } 4=\text { often } \quad 5=\text { almost always }
$$

When you need help with something, how often can you count on someone to help you?

$$
1=\text { never } \quad 2=\text { occasionally } \quad 3=\text { in the middle } 4=\text { often } \quad 5=\text { almost always }
$$

When you are having a bad day, how often can you count on having someone to talk to about your problems?

$$
1=\text { never } \quad 2=\text { occasionally } 3=\text { in the middle } 4=\text { often } \quad 5=\text { almost always }
$$

\section{ACADEMICS}

What is your current college grade point average?

If you are having difficulty in a class, how often would you ask for help from the instructor or a tutor?

$$
1=\text { never } \quad 2=\text { occasionally } \quad 3=\text { in the middle } 4=\text { often } \quad 5=\text { almost always }
$$

How often do your friends help you with school work or encourage you to get help from someone else when you have difficulty in a class?

$$
1=\text { never } \quad 2=\text { occasionally } \quad 3=\text { in the middle } 4=\text { often } \quad 5=\text { almost always }
$$

\section{ALCOHOL CONSUMPTION}

On approximately how many days do you consume alcohol per week?

How many alcoholic drinks do you typically consume at one time?

How many times per month do you consume more than 4 drinks at a time?

How many times per month do you consume more than 5 drinks at a time?

\section{COPING WITH STRESS}

When you are feeling stressed, what are you most likely to do? 
Please list the first names of the friends you have had since before you began college who do not attend college with you. Also, please tell if each friend is a male or a female and how good of friends you are. Use the following rating scale:

$1=\mathrm{OK}$ friend

Name
$2=$ pretty good friends

Male or Female
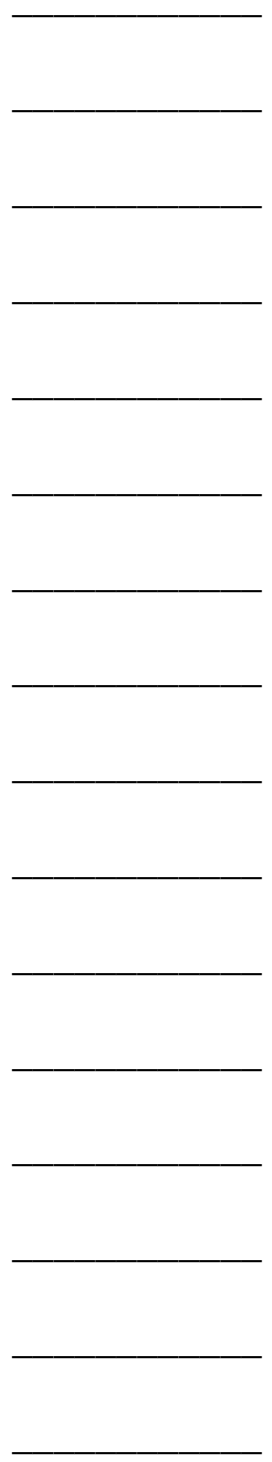

3 = best friends

Rating 
Please list the first names of the friends you have had since before you began college who attend the same college as you do. Also, please tell if each friend is a male or a female and how good of friends you are. Use the following rating scale:

$1=\mathrm{OK}$ friend

Name
$2=$ pretty good friends

Male or Female

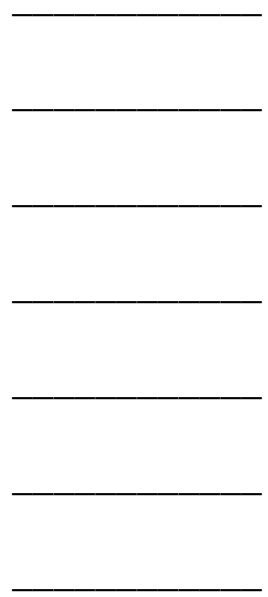

\section{Male or Female}

$3=$ best friends

Rating

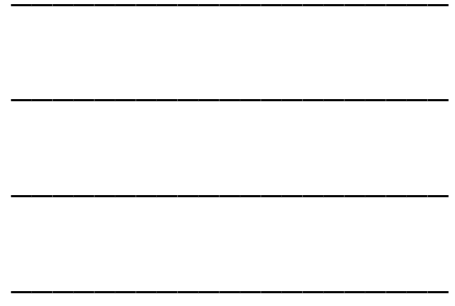

Rating


Please list the first names of the friends you have made since you began college. Also, please tell if each friend is a male or a female and how good of friends you are. Use the following rating scale:

$1=\mathrm{OK}$ friend

Name

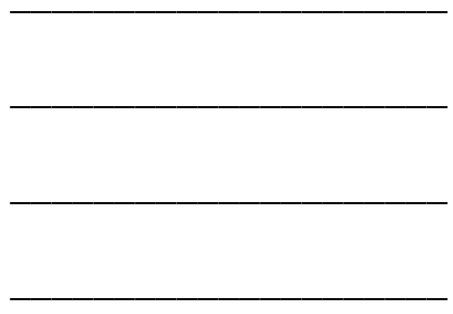

$2=$ pretty good friends $\quad 3=$ best friends

Male or Female

Rating

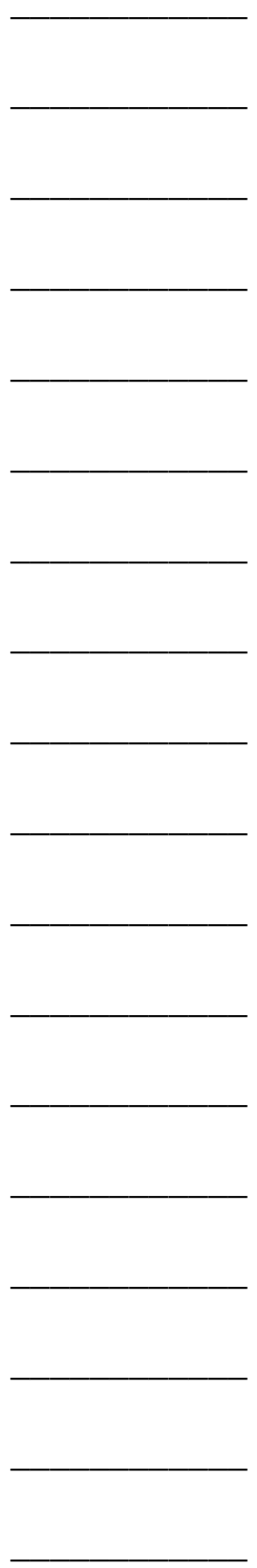


Please list the first names of the friends you had in high school who are no longer your friends. Also, please tell if each person is a male or a female and how good of friends you were. Use the following rating scale:

$1=\mathrm{OK}$ friend $\quad 2=$ pretty good friends $\quad 3=$ best friends

Name

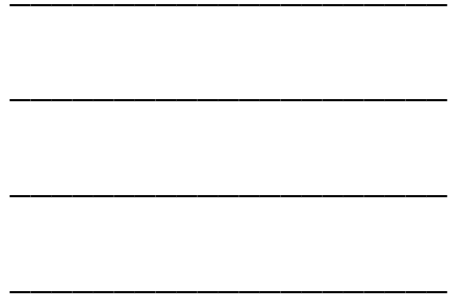

Male or Female

Rating 
Appendix B

Friendship Problems Questionnaire

THESE ARE THE 2 SETS OF DIRECTIONS FOR THE PRE-COLLEGE AND COLLEGE QUESTIONNAIRES.

\section{Problems With Pre-College Friends}

Please think about a problem (disagreement/hassle/argument/conflict) you had with a friend within the last year. Think of a problem you had while you were in college with a friend you knew before you started college. The problem should be with a friend who does not attend college with you. If you are a male, think about a problem with a male. If you are a female, think about a problem with a female. You may think of a problem you had with someone who is still your friend or with someone who is not your friend anymore.

\section{Problems With College Friends}

Please think about a problem (disagreement/hassle/argument/conflict) you had with a friend within the last year. Think of a problem you had while you were in college with a friend you met in college. If you are a male, think about a problem with a male. If you are a female, think about a problem with a female. You may think of a problem you had with someone who is still your friend or with someone who is not your friend anymore.

What are this friend's initials?

1. Explain everything that happened in the problem. Give many details, because you are explaining the problem to someone who doesn't know anything about it. 
2. In this situation, what was the one main problem?

3. In this situation, what was the main cause of the problem?

4. When the problem happened, what was your goal? In other words, what did you want to happen?

5. How well do you think you met this goal?

$\begin{array}{lcccc}1 & 2 & 3 & 4 & 5 \\ \text { not well } & \text { a little bit } & \text { in the middle } & \text { pretty well } & \text { very well } \\ \text { at all } & \text { well } & & \end{array}$

6. How long ago did this problem happen? (Circle one)

$\begin{array}{lllllllll}\text { Less than } & \text { about one } & 2-4 & 1 \text { or } 2 & 3 \text { or } 4 & 5 \text { or } 6 & 7 \text { or } 8 & 9 \text { or } 10 & 11 \text { or } 12 \\ 1 \text { week } & \text { week } & \text { weeks } & \text { months } & \text { months } & \text { months } & \text { months } & \text { months } & \text { months }\end{array}$

7. When did you meet this friend?

8. Where did you meet this friend? 
9. How important was it to you to keep this friendship?

$\begin{array}{llccc}1 & 2 & 3 & 4 & 5 \\ \text { not at all } & \text { a little bit } & \text { in the middle } & \text { pretty } & \text { very } \\ \text { important } & \text { important } & & \text { important } & \text { important }\end{array}$

10. How important was the problem?

$\begin{array}{lcccc}1 & 2 & 3 & 4 & 5 \\ \text { not at all } & \text { a little bit } & \text { in the middle } & \text { pretty } & \text { very } \\ \text { important } & \text { important } & & \text { important } & \text { important }\end{array}$

11. How serious was the problem?

$\begin{array}{llccc}1 & 2 & 3 & 4 & 5 \\ \text { not at all } & \text { a little bit } & \text { in the middle } & \text { pretty } & \text { very } \\ \text { serious } & \text { serious } & & \text { serious } & \text { serious }\end{array}$

12. Are you still friends with the person? (Please check one.)

Yes

No

13. What did you do to solve the problem? Please give as many details as you remember.

14. Did you expect the problem to happen or was it a surprise?

$\begin{array}{lcccc}1 & 2 & 3 & 4 & 5 \\ \text { did not expect } & \begin{array}{c}\text { expected it } \\ \text { at all }\end{array} & \text { in the middle } & \begin{array}{c}\text { expected } \\ \text { quite a bit }\end{array} & \begin{array}{c}\text { completely } \\ \text { expected }\end{array}\end{array}$

15. If you answered 2 or above to question 14, did you do anything to try to stop the problem from happening?

Yes

No

16. If you answered Yes to question 15, what did you do to try to stop the problem from happening? 
17. If you answered No to question 15 , why didn't you do anything to try to stop the problem from happening?

18. Overall, how well do you think you solved the problem?

$\begin{array}{lcccc}1 & 2 & 3 & 4 & 5 \\ \text { not well } & \text { a little bit } & \text { in the middle } & \text { pretty well } & \text { very well } \\ \text { at all } & \text { well } & & \end{array}$

19. How much of the problem was your fault?

$\begin{array}{ccccl}1 & 2 & 3 & 4 & 5 \\ \text { none } & \text { a little bit } & \text { in the middle } & \text { pretty much } & \text { all }\end{array}$

20. How much of the problem was your friend's fault?

$\begin{array}{ccccl}1 & 2 & 3 & 4 & 5 \\ \text { none } & \text { a little bit } & \text { in the middle } & \text { pretty much } & \text { all }\end{array}$

21. How much of the problem was not your fault or your friend's fault?

$\begin{array}{ccccl}1 & 2 & 3 & 4 & 5 \\ \text { none } & \text { a little bit } & \text { in the middle } & \text { pretty much } & \text { all }\end{array}$

22. How long had you and your friend been friends before the problem happened? Circle the number of years you had been friends.

$\begin{array}{lllllllllllllll}\begin{array}{l}\text { Less than } \\ 1 \text { year }\end{array} & 1 & 2 & 3 & 4 & 5 & 6 & 7 & 8 & 9 & 10 & 11 & 12 & 13 & \begin{array}{c}\text { More than } \\ 13 \text { years }\end{array} \\ \end{array}$

23. Before the problem, how much did you and your friend tell each other how you were feeling?

$\begin{array}{lcccc}1 & 2 & 3 & 4 & 5 \\ \text { not at all } & \text { sometimes } & \text { in the middle } & \text { quite a bit } & \text { all the time }\end{array}$


24. After the problem, how much did you and your friend tell each other how you were feeling?

$\begin{array}{lcccc}1 & 2 & 3 & 4 & 5 \\ \text { not at all } & \text { sometimes } & \text { in the middle } & \text { quite a bit } & \text { all the time }\end{array}$

25. Before the problem, how much did you and your friend tell each other what you were thinking?

$\begin{array}{lcccc}1 & 2 & 3 & 4 & 5 \\ \text { not at all } & \text { sometimes } & \text { in the middle } & \text { quite a bit } & \text { all the time }\end{array}$

26. After the problem, how much did you and your friend tell each other what you were thinking?

$\begin{array}{lcccc}1 & 2 & 3 & 4 & 5 \\ \text { not at all } & \text { sometimes } & \text { in the middle } & \text { quite a bit } & \text { all the time }\end{array}$

27. Before the problem, how much did you and your friend share private or secret information with each other?
1
2
3
4
5
not at all sometimes in the middle quite a bit all the time

28. After the problem, how much did you and your friend share private or secret information with each other?

$\begin{array}{lcccc}1 & 2 & 3 & 4 & 5 \\ \text { not at all } & \text { sometimes } & \text { in the middle } & \text { quite a bit } & \text { all the time }\end{array}$

29. How much did you trust your friend before the problem?

$\begin{array}{lcccc}1 & 2 & 3 & 4 & 5 \\ \text { not at all } & \text { a little bit } & \text { in the middle } & \text { pretty much } & \text { very much }\end{array}$

30. How much did you trust your friend after the problem?

$\begin{array}{lcccc}1 & 2 & 3 & 4 & 5 \\ \text { not at all } & \text { a little bit } & \text { in the middle } & \text { pretty much } & \text { very much }\end{array}$


31. Before the problem happened, how much did you and your friend try to make your friendship as good as it could be?

$\begin{array}{lcccc}1 & 2 & 3 & 4 & 5 \\ \text { not at all } & \text { a little bit } & \text { in the middle } & \text { pretty much } & \text { very much }\end{array}$

32. After the problem happened, how much did you and your friend try to make your friendship as good as it could be?

$\begin{array}{lcccc}1 & 2 & 3 & 4 & 5 \\ \text { not at all } & \text { a little bit } & \text { in the middle } & \text { pretty much } & \text { very much }\end{array}$

33. Before the problem, how much did you and your friend believe that your friendship would continue?

$\begin{array}{ccccc}1 & 2 & 3 & 4 & 5 \\ \text { not at all } & \text { a little bit } & \text { in the middle } & \text { pretty much } & \text { very much }\end{array}$

34. After the problem, how much did you and your friend believe that your friendship would continue?

$\begin{array}{ccccc}1 & 2 & 3 & 4 & 5 \\ \text { not at all } & \text { a little bit } & \text { in the middle } & \text { pretty much } & \text { very much }\end{array}$

35. Before the problem, how likely did you feel it would be that you could find a better friend?

$\begin{array}{ccccc}1 & 2 & 3 & 4 & 5 \\ \text { not at all } & \text { a little bit } & \text { in the middle } & \text { pretty much } & \text { very much }\end{array}$

36. After the problem, how likely did you feel it would be that you could find a better friend?

$\begin{array}{ccccc}1 & 2 & 3 & 4 & 5 \\ \text { not at all } & \text { a little bit } & \text { in the middle } & \text { pretty much } & \text { very much }\end{array}$

37. How much did you help your friend emotionally before the problem?

$\begin{array}{lcccc}1 & 2 & 3 & 4 & 5 \\ \text { not at all } & \text { a little bit } & \text { in the middle } & \text { pretty much } & \text { very much }\end{array}$

38. How much did you help your friend emotionally after the problem?

$\begin{array}{lcccc}1 & 2 & 3 & 4 & 5 \\ \text { not at all } & \text { a little bit } & \text { in the middle } & \text { pretty much } & \text { very much }\end{array}$


39. How much did your friend help you emotionally before the problem?

$\begin{array}{lcccc}1 & 2 & 3 & 4 & 5 \\ \text { not at all } & \text { a little bit } & \text { in the middle } & \text { pretty much } & \text { very much }\end{array}$

40. How much did your friend help you emotionally after the problem?

$\begin{array}{lcccc}1 & 2 & 3 & 4 & 5 \\ \text { not at all } & \text { a little bit } & \text { in the middle } & \text { pretty much } & \text { very much }\end{array}$

41. Before the problem happened, how often did you spend time with your friend when he or she needed support?

$\begin{array}{lcccc}1 & 2 & 3 & 4 & 5 \\ \text { not at all } & \text { a little bit } & \text { in the middle } & \text { pretty often } & \text { very often }\end{array}$

42. After the problem happened, how often did you spend time with your friend when he or she needed support?

$\begin{array}{lcccc}1 & 2 & 3 & 4 & 5 \\ \text { not at all } & \text { a little bit } & \text { in the middle } & \text { pretty often } & \text { very often }\end{array}$

43. Before the problem happened, how often did your friend spend time with you when you needed support?

$\begin{array}{lcccc}1 & 2 & 3 & 4 & 5 \\ \text { not at all } & \text { a little bit } & \text { in the middle } & \text { pretty often } & \text { very often }\end{array}$

44. After the problem happened, how often did your friend spend time with you when you needed support?

$\begin{array}{lcccc}1 & 2 & 3 & 4 & 5 \\ \text { not at all } & \text { a little bit } & \text { in the middle } & \text { pretty often } & \text { very often }\end{array}$

45. How much did your friend help you complete tasks or projects before the problem?

$\begin{array}{lcccc}1 & 2 & 3 & 4 & 5 \\ \text { not at all } & \text { a little bit } & \text { in the middle } & \text { pretty much } & \text { very much }\end{array}$

46. How much did your friend help you complete tasks or projects after the problem?

$\begin{array}{lcccc}1 & 2 & 3 & 4 & 5 \\ \text { not at all } & \text { a little bit } & \text { in the middle } & \text { pretty much } & \text { very much }\end{array}$


47. How much did you help your friend complete tasks or projects before the problem?

$\begin{array}{lcccc}1 & 2 & 3 & 4 & 5 \\ \text { not at all } & \text { a little bit } & \text { in the middle } & \text { pretty much } & \text { very much }\end{array}$

48. How much did you help your friend complete tasks or projects after the problem?

$\begin{array}{lcccc}1 & 2 & 3 & 4 & 5 \\ \text { not at all } & \text { a little bit } & \text { in the middle } & \text { pretty much } & \text { very much }\end{array}$

49. Before the problem happened, how often did you give or loan your friend money when he or she needed it?
1
2
3
4
5
not at all
a little bit
in the middle
pretty often
very often

50. After the problem happened, how often did you give or loan your friend money when he or she needed it?

$\begin{array}{lcccc}1 & 2 & 3 & 4 & 5 \\ \text { not at all } & \text { a little bit } & \text { in the middle } & \text { pretty often } & \text { very often }\end{array}$

51. Before the problem happened, how often did your friend give or loan you money when you needed it?

$\begin{array}{lcccc}1 & 2 & 3 & 4 & 5 \\ \text { not at all } & \text { a little bit } & \text { in the middle } & \text { pretty often } & \text { very often }\end{array}$

52. After the problem happened, how often did your friend give or loan you money when you needed it?

$\begin{array}{lcccc}1 & 2 & 3 & 4 & 5 \\ \text { not at all } & \text { a little bit } & \text { in the middle } & \text { pretty often } & \text { very often }\end{array}$

53. Before the problem happened, how often did you give or let your friend borrow things such as books, clothes, or other items?
1
2
3
4
5
not at all
a little bit
in the middle
pretty often
very often

54. After the problem happened, how often did you give or let your friend borrow things such as books, clothes, or other items?
1
2
3
4
5
not at all
a little bit
in the middle
pretty often
very often 
55. Before the problem happened, how often did your friend give you or let you borrow things such as books, clothes, or other items?

$\begin{array}{lcccc}1 & 2 & 3 & 4 & 5 \\ \text { not at all } & \text { a little bit } & \text { in the middle } & \text { pretty often } & \text { very often }\end{array}$

56. After the problem happened, how often did your friend give you or let you borrow things such as books, clothes, or other items?

$\begin{array}{lcccc}1 & 2 & 3 & 4 & 5 \\ \text { not at all } & \text { a little bit } & \text { in the middle } & \text { pretty often } & \text { very often }\end{array}$

57. Before the problem, how much did you and your friend like to do the same things?

$\begin{array}{lcccc}1 & 2 & 3 & 4 & 5 \\ \text { not at all } & \text { a little bit } & \text { in the middle } & \text { pretty much } & \text { very much }\end{array}$

58. After the problem, how much did you and your friend like to do the same things?

$\begin{array}{lcccc}1 & 2 & 3 & 4 & 5 \\ \text { not at all } & \text { a little bit } & \text { in the middle } & \text { pretty much } & \text { very much }\end{array}$

59. Before the problem, how much did you and your friend believe that the same things were important?

$\begin{array}{ccccc}1 & 2 & 3 & 4 & 5 \\ \text { not at all } & \text { a little bit } & \text { in the middle } & \text { pretty much } & \text { very much }\end{array}$

60. After the problem, how much did you and your friend believe that the same things were important?
12
not at all a little bit
3
4
5
in the middle pretty much very much

61. Before the problem, how often did you and your friend do things together that affected or changed the kind of person you are?

$\begin{array}{lcccc}1 & 2 & 3 & 4 & 5 \\ \text { never } & \text { a little bit } & \text { in the middle } & \text { pretty often } & \text { almost always }\end{array}$

62. After the problem, how often did you and your friend do things together that affected or changed the kind of person you are?

$\begin{array}{lcccc}1 & 2 & 3 & 4 & 5 \\ \text { never } & \text { a little bit } & \text { in the middle } & \text { pretty often } & \text { almost always }\end{array}$


63. Before the problem, how often did you and your friend do things together that were particularly meaningful or important?

$\begin{array}{lcccc}1 & 2 & 3 & 4 & 5 \\ \text { never } & \text { a little bit } & \text { in the middle } & \text { pretty often } & \text { almost always }\end{array}$

64. After the problem, how often did you and your friend do things together that were particularly meaningful or important?

$\begin{array}{lcccc}1 & 2 & 3 & 4 & 5 \\ \text { never } & \text { a little bit } & \text { in the middle } & \text { pretty often } & \text { almost always }\end{array}$

65. Before the problem, how often did you and your friend do things together?

$\begin{array}{lllll}1 & 2 & 3 & 4 & 5\end{array}$

never a little bit in the middle pretty often almost always

66. After the problem, how often did you and your friend do things together?

$\begin{array}{lcccc}1 & 2 & 3 & 4 & 5 \\ \text { never } & \text { a little bit } & \text { in the middle } & \text { pretty often } & \text { almost always }\end{array}$

67. How much time did you spend with your friend before the problem?

$\begin{array}{lcccc}1 & 2 & 3 & 4 & 5 \\ \text { none at all } & \text { a little bit } & \text { in the middle } & \text { pretty much } & \text { very much }\end{array}$

68. How much time did you spend with your friend after the problem?

$\begin{array}{lcccc}1 & 2 & 3 & 4 & 5 \\ \text { none at all } & \text { a little bit } & \text { in the middle } & \text { pretty much } & \text { very much }\end{array}$

69. Before the problem, how much did you put into the friendship?

$\begin{array}{ccccc}1 & 2 & 3 & 4 & 5 \\ \text { nothing at all } & \text { a little bit } & \text { in the middle } & \text { pretty much } & \text { very much }\end{array}$

70. After the problem, how much did you put into the friendship?

$\begin{array}{ccccc}1 & 2 & 3 & 4 & 5 \\ \text { nothing at all } & \text { a little bit } & \text { in the middle } & \text { pretty much } & \text { very much }\end{array}$

71. Before the problem, how much did your friend put into the friendship?
1
nothing at all a little bit
3
4
in the middle pretty much very much 
72. After the problem, how much did your friend put into the friendship?

$\begin{array}{ccccc}1 & 2 & 3 & 4 & 5 \\ \text { nothing at all } & \text { a little bit } & \text { in the middle } & \text { pretty much } & \text { very much }\end{array}$

73. Before the problem, how much did you get out of the friendship?

$\begin{array}{ccccc}1 & 2 & 3 & 4 & 5 \\ \text { nothing at all } & \text { a little bit } & \text { in the middle } & \text { pretty much } & \text { very much }\end{array}$

74. After the problem, how much did you get out of the friendship?

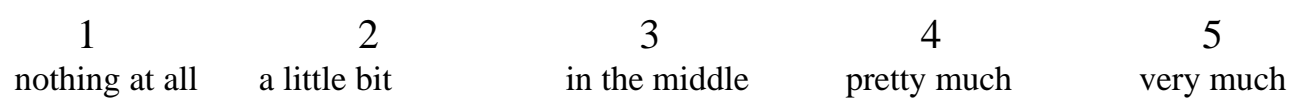

75. Before the problem, how much did your friend get out of the friendship?

$\begin{array}{ccccc}1 & 2 & 3 & 4 & 5 \\ \text { nothing at all } & \text { a little bit } & \text { in the middle } & \text { pretty much } & \text { very much }\end{array}$

76. After the problem, how much did your friend get out of the friendship?

$\begin{array}{ccccc}1 & 2 & 3 & 4 & 5 \\ \text { thing at all } & \text { a little bit } & \text { in the middle } & \text { pretty much } & \text { very much }\end{array}$

77. Before the problem, how much did you like the kind of person your friend was?

$\begin{array}{ccccc}1 & 2 & 3 & 4 & 5 \\ \text { not at all } & \text { a little bit } & \text { in the middle } & \text { pretty much } & \text { very much }\end{array}$

78. After the problem, how much did you like the kind of person your friend was?

$\begin{array}{ccccc}1 & 2 & 3 & 4 & 5 \\ \text { not at all } & \text { a little bit } & \text { in the middle } & \text { pretty much } & \text { very much }\end{array}$

79. Before the problem, how much did you like the way your friend behaved?

$\begin{array}{ccccc}1 & 2 & 3 & 4 & 5 \\ \text { not at all } & \text { a little bit } & \text { in the middle } & \text { pretty much } & \text { very much }\end{array}$

80. After the problem, how much did you like the way your friend behaved?

$\begin{array}{ccccc}1 & 2 & 3 & 4 & 5 \\ \text { not at all } & \text { a little bit } & \text { in the middle } & \text { pretty much } & \text { very much }\end{array}$


81. Before the problem, how much did you enjoy the excitement your friend provided you?

$\begin{array}{ccccc}1 & 2 & 3 & 4 & 5 \\ \text { not at all } & \text { a little bit } & \text { in the middle } & \text { pretty much } & \text { very much }\end{array}$

82. After the problem, how much did you enjoy the excitement your friend provided you?

$\begin{array}{ccccc}1 & 2 & 3 & 4 & 5 \\ \text { not at all } & \text { a little bit } & \text { in the middle } & \text { pretty much } & \text { very much }\end{array}$

83. If you and the friend you described the problem with were no longer friends, how easy would it be to find a new friend?

$\begin{array}{lcccc}1 & 2 & 3 & 4 & 5 \\ \text { impossible } & \text { a little hard } & \text { in the middle } & \text { pretty easy } & \text { extremely easy }\end{array}$

84. How good of friends were you before the problem?

$\begin{array}{lcccc}1 & 2 & 3 & 4 & 5 \\ \text { not friends } & \text { OK friends } & \text { in the middle } & \begin{array}{c}\text { pretty good } \\ \text { friends }\end{array} & \text { best } \\ & & & \text { friends }\end{array}$

85. How good of friends were you after the problem?

$\begin{array}{lcccc}1 & 2 & 3 & 4 & 5 \\ \text { not friends } & \text { OK friends } & \text { in the middle } & \begin{array}{c}\text { pretty good } \\ \text { friends }\end{array} & \begin{array}{c}\text { best } \\ \text { friends }\end{array}\end{array}$

86. If this problem happened again, how likely would you be to remain friends with the person?

$\begin{array}{lcccc}1 & 2 & 3 & 4 & 5 \\ \text { not at all } & \text { a little bit } & \text { in the middle } & \text { pretty likely } & \text { very likely } \\ \text { likely } & \text { likely } & & \end{array}$

87. If problems like the one you described started to happen all the time, how likely would you be to remain friends with the person?

$\begin{array}{lcccc}1 & 2 & 3 & 4 & 5 \\ \text { not at all } & \text { a little bit } & \text { in the middle } & \text { pretty likely } & \text { very likely } \\ \text { likely } & \text { likely } & & \end{array}$

88. How happy did the problem make you feel?

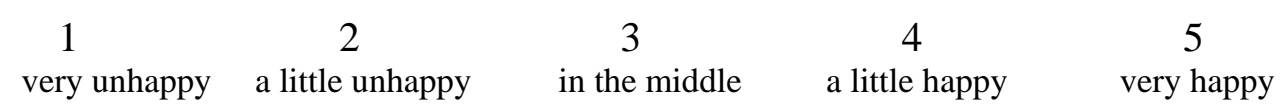


89. How angry did the problem make you feel?

1 (x)

very angry pretty angry

in the middle

4

slightly angry

5

not angry at all

90. How sad did the problem make you feel?

$\begin{array}{ccccc}1 & 2 & 3 & 4 & 5 \\ \text { not at all sad } & \text { a little sad } & \text { in the middle } & \text { pretty sad } & \text { very sad }\end{array}$

91. How stressful was the problem for you?

$\begin{array}{ccccc}1 & 2 & 3 & 4 & 5 \\ \text { not at all stressful } & \text { a little stressful } & \text { in the middle } & \text { pretty stressful } & \text { very stressful }\end{array}$




\section{Appendix C}

Friendship Endings Questionnaire

\section{Friendship Endings for Pre-College Friends}

Please think of a person who used to be your friend but who is not your friend anymore. Think of a friendship you had before college that ended since you entered college. The person should be someone who does not attend college with you. If you are a male, think of a former male friend, and if you are a female, think of a former female friend.

\section{Friendship Endings for College Friends}

Please think of a person who used to be your friend but who is not your friend anymore. Think of a friendship you made in college that has ended. If you are a male, think of a former male friend, and if you are a female, think of a former female friend.

What are this person's initials?

1. What happened that caused your friendship to end? Please give as many details as you can. You are describing this to someone who knows nothing about the friendship.

2. What was the main cause of the friendship ending? 
3. When the friendship ended, what was your goal? In other words, what did you want to happen?

4. How well do you think you met this goal?

$\begin{array}{llcll}1 & 2 & 3 & 4 & 5 \\ \begin{array}{l}\text { not well } \\ \text { at all }\end{array} & \begin{array}{l}\text { a little bit } \\ \text { well }\end{array} & \text { in the middle } & \text { pretty well } & \text { very well }\end{array}$

5. How long ago did the friendship end? (Circle one)

$\begin{array}{llllrrrrrr}\text { Less than } & \text { about one } & 2-4 & 1 \text { or } 2 & 3 \text { or } 4 & 5 \text { or } 6 & 7 \text { or } 8 & 9 \text { or } 10 & 11 \text { or } 12 & \text { more than } \\ 1 \text { week } & \text { week } & \text { weeks } & \text { months } & \text { months } & \text { months } & \text { months } & \text { months } & \text { months } & 1 \text { year }\end{array}$

6. How important was it to you to keep this friendship?

$\begin{array}{lllll}1 & 2 & 3 & 4 & 5 \\ \text { not at all } & \text { a little bit } & \text { in the middle } & \text { pretty }\end{array}$

7. Did you expect the friendship to end or was it a surprise?

$\begin{array}{ccccc}1 & 2 & 3 & 4 & 5 \\ \begin{array}{c}\text { did not expect } \\ \text { at all }\end{array} & \begin{array}{c}\text { expected it } \\ \text { a little bit }\end{array} & \text { in the middle } & \begin{array}{c}\text { expected } \\ \text { quite a bit }\end{array} & \begin{array}{c}\text { completely } \\ \text { expected }\end{array}\end{array}$

8. If you answered 2 or above to question 7 , did you do anything to try to stop the friendship from ending?

Yes_ No

9. If you answered Yes to question 8, what did you do to try to stop the friendship from ending? 
10. If you answered No to question 8 , why didn't you do anything to stop the friendship from ending?

11. How much would you say that ending the friendship was your idea?

$\begin{array}{ccccc}1 & 2 & 3 & 4 & 5 \\ \text { not at all } & \text { not very much } & \text { in the middle } & \text { pretty much } & \text { completely }\end{array}$

12. How much would you say that ending the friendship was your friend's idea?

not at all

$\begin{array}{cccc}2 & 3 & 4 & 5 \\ \text { not very much } & \text { in the middle } & \text { pretty much } & \text { completely }\end{array}$

13. How much would you say that ending the friendship was not your idea or your friend's idea?

$\begin{array}{ccccc}1 & 2 & 3 & 4 & 5 \\ \text { not at all } & \text { not very much } & \text { in the middle } & \text { pretty much } & \text { completely }\end{array}$

14. How long had you and your friend been friends before your friendship ended? Circle the number of years you had been friends.

$\begin{array}{lllllllllllllll}\text { Less than } & 1 & 2 & 3 & 4 & 5 & 6 & 7 & 8 & 9 & 10 & 11 & 12 & 13 & \text { More than }\end{array}$

1 year

13 years

15. Before the friendship ended, how much did you and your friend tell each other how you were feeling?

$\begin{array}{ccccc}1 & 2 & 3 & 4 & 5 \\ \text { not at all } & \text { sometimes } & \text { in the middle } & \text { quite a bit } & \text { all the time }\end{array}$

16. After the friendship ended, how much did you and your friend tell each other how you were feeling?

$\begin{array}{ccccc}1 & 2 & 3 & 4 & 5 \\ \text { not at all } & \text { sometimes } & \text { in the middle } & \text { quite a bit } & \text { all the time }\end{array}$


17. Before the friendship ended, how much did you and your friend tell each other what you were thinking?

$\begin{array}{ccccc}1 & 2 & 3 & 4 & 5 \\ \text { not at all } & \text { sometimes } & \text { in the middle } & \text { quite a bit } & \text { all the time }\end{array}$

18. After the friendship ended, how much did you and your friend tell each other what you were thinking?

$\begin{array}{ccccc}1 & 2 & 3 & 4 & 5 \\ \text { not at all } & \text { sometimes } & \text { in the middle } & \text { quite a bit } & \text { all the time }\end{array}$

19. Before the friendship ended, how much did you and your friend share private or secret information with each other?

$\begin{array}{ccccc}1 & 2 & 3 & 4 & 5 \\ \text { not at all } & \text { sometimes } & \text { in the middle } & \text { quite a bit } & \text { all the time }\end{array}$

20. After the friendship ended, how much did you and your friend share private or secret information with each other?

$\begin{array}{ccccc}1 & 2 & 3 & 4 & 5 \\ \text { not at all } & \text { sometimes } & \text { in the middle } & \text { quite a bit } & \text { all the time }\end{array}$

21. How much did you trust your friend before the friendship ended?

$\begin{array}{ccccc}1 & 2 & 3 & 4 & 5 \\ \text { not at all } & \text { a little bit } & \text { in the middle } & \text { pretty much } & \text { very much }\end{array}$

22. How much did you trust your friend after your friendship ended?

$\begin{array}{ccccc}1 & 2 & 3 & 4 & 5 \\ \text { not at all } & \text { a little bit } & \text { in the middle } & \text { pretty much } & \text { very much }\end{array}$

23. Before your friendship ended, how much did you and your friends try to make your friendship as good as it could be?
1
not at all
2
a little bit
3
in the middle
4
pretty much
5
very much 
24. Before the friendship ended, how much did you and your friend believe that your friendship would continue?

$\begin{array}{ccccc}1 & 2 & 3 & 4 & 5 \\ \text { not at all } & \text { a little bit } & \text { in the middle } & \text { pretty much } & \text { very much }\end{array}$

25. Before the friendship ended, how likely did you feel it would be that you could find a better friend?
1
2
a little bit
3
in the middle
4
pretty much
5
very much

26. After the friendship ended, how likely did you feel it would be that you could find a better friend?
1
not at all
2
a little bit
3
in the middle
4
pretty much
5
very much

27. How much did you help your friend emotionally before the friendship ended?

$\begin{array}{ccccc}1 & 2 & 3 & 4 & 5 \\ \text { not at all } & \text { a little bit } & \text { in the middle } & \text { pretty much } & \text { very much }\end{array}$

28. How much did you help your friend emotionally after the friendship ended?
1
not at all
2
3
in the middle
4
pretty much
5
very much

29. How much did your friend help you emotionally before the friendship ended?

$\begin{array}{ccccc}1 & 2 & 3 & 4 & 5 \\ \text { not at all } & \text { a little bit } & \text { in the middle } & \text { pretty much } & \text { very much }\end{array}$

30. How much did your friend help you emotionally after the friendship ended?
not at all
2
a little bit
3
the middle
4
5
pretty much
very much

31. Before the friendship ended, how often did you spend time with your friend when he or she needed support?

$\begin{array}{ccccc}1 & 2 & 3 & 4 & 5 \\ \text { not at all } & \text { a little bit } & \text { in the middle } & \text { pretty much } & \text { very much }\end{array}$


32. After the friendship ended, how often did you spend time with your friend when he or she needed support?

$\begin{array}{ccccc}1 & 2 & 3 & 4 & 5 \\ \text { not at all } & \text { a little bit } & \text { in the middle } & \text { pretty much } & \text { very much }\end{array}$

33. Before the friendship ended, how often did your friend spend time with you when you needed support?

$\begin{array}{ccccc}1 & 2 & 3 & 4 & 5 \\ \text { not at all } & \text { a little bit } & \text { in the middle } & \text { pretty much } & \text { very much }\end{array}$

34. After the friendship ended, how often did your friend spend time with you when you needed support?

$\begin{array}{ccccc}1 & 2 & 3 & 4 & 5 \\ \text { not at all } & \text { a little bit } & \text { in the middle } & \text { pretty much } & \text { very much }\end{array}$

35. How much did your friend help you complete tasks or projects before the friendship ended?

$\begin{array}{ccccc}1 & 2 & 3 & 4 & 5 \\ \text { not at all } & \text { a little bit } & \text { in the middle } & \text { pretty much } & \text { very much }\end{array}$

36. How much did your friend help you complete tasks or projects after the friendship ended?

$\begin{array}{ccccl}1 & 2 & 3 & 4 & 5 \\ \text { not at all } & \text { a little bit } & \text { in the middle } & \text { pretty much } & \text { very much }\end{array}$

37. How much did you help your friend complete tasks or projects before the friendship ended?

$\begin{array}{ccccc}1 & 2 & 3 & 4 & 5 \\ \text { not at all } & \text { a little bit } & \text { in the middle } & \text { pretty much } & \text { very much }\end{array}$

38. How much did you help your friend complete tasks or projects after the friendship ended?

$\begin{array}{ccccc}1 & 2 & 3 & 4 & 5 \\ \text { not at all } & \text { a little bit } & \text { in the middle } & \text { pretty much } & \text { very much }\end{array}$

39. Before the friendship ended, how often did you give or loan your friend money when he or she needed it? 
not at all

a little bit

in the middle

pretty much

very much

40. After the friendship ended, how often did you give or loan your friend money when he or she needed it?
1
not at all
2
a little bit
in the middle
$\quad 4$
pretty much
5
very much

41. Before the friendship ended, how often did your friend give or loan you money when you needed it?
1
not at all
2
little bit
3
in the middle
4
pretty much
5
very much

42. After the friendship ended, how often did your friend give or loan you money when you needed it?
1
not at all
2
a little bit
3
in the middle
4
pretty much
5
very much

43. Before the friendship ended, how often did you give or let your friend borrow things such as books, clothes, or other items?
1
2
a little bit
3
in the middle
4
pretty often
5
very often

44. After the friendship ended, how often did you give or let your friend borrow things such as books, clothes, or other items?
1
not at all
2
a little bit
3
in the middle
4
pretty often
5
very often

45. Before the friendship ended, how often did your friend give you or let you borrow things such as books, clothes, or other items?
1
2
a little bit
3
in the middle
4
pretty often
5
very often

46. After the friendship ended, how often did your friend give you or let you borrow things such as books, clothes, or other items?
1
not at all
2
a little bit
3
the middle
4
pretty often
5
very often 
47. Before your friendship ended, how much did you and your friend like to do the same things?

$\begin{array}{clcll}1 & 2 & 3 & 4 & 5 \\ \text { not at all } & \text { a little bit } & \text { in the middle } & \text { pretty much } & \text { very much }\end{array}$

48. After your friendship ended, how much did you and your friend like to do the same things?

$\begin{array}{ccccc}1 & 2 & 3 & 4 & 5 \\ \text { not at all } & \text { a little bit } & \text { in the middle } & \text { pretty much } & \text { very much }\end{array}$

49. Before the friendship ended, how much did you and your friend believe that the same things were important?

$\begin{array}{ccccc}1 & 2 & 3 & 4 & 5 \\ \text { not at all } & \text { a little bit } & \text { in the middle } & \text { pretty much } & \text { very much }\end{array}$

50. After the friendship ended, how much did you and your friend believe that the same things were important?
1
2
3
4
5
not at all a little bit
in the middle
pretty much
very much

51. Before the friendship ended, how often did you and your friend do things together that affected or changed the kind of person you are?
1
2
3
4
5
never a little bit in the middle pretty often almost always

52. After the friendship ended, how often did you and your friend do things together that affected or changed the kind of person you are?

$\begin{array}{lcccc}1 & 2 & 3 & 4 & 5 \\ \text { never } & \text { a little bit } & \text { in the middle } & \text { pretty often } & \text { almost always }\end{array}$

53. Before the friendship ended, how often did you and your friend do things together that were particularly meaningful or important?
1
2
3
4
5
never
a little bit
in the middle
pretty often
almost always 
54. After the friendship ended, how often did you and your friend do things together that were particularly meaningful or important?

$\begin{array}{lcccc}1 & 2 & 3 & 4 & 5 \\ \text { never } & \text { a little bit } & \text { in the middle } & \text { pretty often } & \text { almost always }\end{array}$

55. Before your friendship ended, how often did you and your friend do things together?

$\begin{array}{lcccc}1 & 2 & 3 & 4 & 5 \\ \text { never } & \text { a little bit } & \text { in the middle } & \text { pretty often } & \text { almost always }\end{array}$

56. After your friendship ended, how often did you and your friend do things together?

$\begin{array}{lcccc}1 & 2 & 3 & 4 & 5 \\ \text { never } & \text { a little bit } & \text { in the middle } & \text { pretty often } & \text { almost always }\end{array}$

57. How much time did you spend with your friend before your friendship ended?

$\begin{array}{lcccc}1 & 2 & 3 & 4 & 5 \\ \text { none at all } & \text { a little bit } & \text { in the middle } & \text { pretty much } & \text { very much }\end{array}$

58. How much time did you spend with your friend after your friendship ended?

$\begin{array}{lcccc}1 & 2 & 3 & 4 & 5 \\ \text { none at all } & \text { a little bit } & \text { in the middle } & \text { pretty much } & \text { very much }\end{array}$

59. Before your friendship ended, how much did you put into the friendship?

$\begin{array}{ccccc}1 & 2 & 3 & 4 & 5 \\ \text { nothing at all } & \text { a little bit } & \text { in the middle } & \text { pretty much } & \text { very much }\end{array}$

60. Before the friendship ended, how much did your friend put into the friendship?

$\begin{array}{ccccc}1 & 2 & 3 & 4 & 5 \\ \text { nothing at all } & \text { a little bit } & \text { in the middle } & \text { pretty much } & \text { very much }\end{array}$

61. Before your friendship ended, how much did you get out of the friendship?

$\begin{array}{ccccc}1 & 2 & 3 & 4 & 5 \\ \text { nothing at all } & \text { a little bit } & \text { in the middle } & \text { pretty much } & \text { very much }\end{array}$

62. Before your friendship ended, how much did your friend get out of the friendship?

$\begin{array}{ccccc}1 & 2 & 3 & 4 & 5 \\ \text { nothing at all } & \text { a little bit } & \text { in the middle } & \text { pretty much } & \text { very much }\end{array}$


63. Before your friendship ended, how much did you like the kind of person your friend was?

$\begin{array}{ccccc}1 & 2 & 3 & 4 & 5 \\ \text { not at all } & \text { a little bit } & \text { in the middle } & \text { pretty much } & \text { very much }\end{array}$

64. After your friendship ended, how much did you like the kind of person your friend was?

$\begin{array}{ccccc}1 & 2 & 3 & 4 & 5 \\ \text { not at all } & \text { a little bit } & \text { in the middle } & \text { pretty much } & \text { very much }\end{array}$

65. Before the friendship ended, how much did you like the way your friend behaved?

$\begin{array}{ccccc}1 & 2 & 3 & 4 & 5 \\ \text { not at all } & \text { a little bit } & \text { in the middle } & \text { pretty much } & \text { very much }\end{array}$

66. After the friendship ended, how much did you like the way your friend behaved?

$\begin{array}{ccccc}1 & 2 & 3 & 4 & 5 \\ \text { not at all } & \text { a little bit } & \text { in the middle } & \text { pretty much } & \text { very much }\end{array}$

67. Before the friendship ended, how much did you enjoy the excitement your friend provided you?

$\begin{array}{ccccc}1 & 2 & 3 & 4 & 5 \\ \text { not at all } & \text { a little bit } & \text { in the middle } & \text { pretty much } & \text { very much }\end{array}$

68. After your friendship ended, how easy was it for you to find a new friend?

$\begin{array}{lcccc}1 & 2 & 3 & 4 & 5 \\ \text { impossible } & \text { pretty hard } & \text { in the middle } & \text { pretty easy } & \text { extremely easy }\end{array}$

69. How good of friends were you before your friendship ended?

$\begin{array}{lcccc}1 & 2 & 3 & 4 & 5 \\ \text { not friends } & \text { OK friends } & \text { in the middle } & \text { pretty good } & \text { best } \\ & & & \text { friends } & \text { friends }\end{array}$

70. Did you and your friend become friends again after your friendship ended?

Yes No

71. If you answered No to question 21, do you think that you will become friends again in the future?

Yes No 
72. How happy did ending the friendship make you feel?

$\begin{array}{lcccc}1 & 2 & 3 & 4 & 5 \\ \text { very unhappy } & \text { a little unhappy } & \text { in the middle } & \text { a little happy } & \text { very happy }\end{array}$

73. How angry did ending the friendship make you feel?

$\begin{array}{lcccc}1 & 2 & 3 & 4 & 5 \\ \text { very angry } & \text { pretty angry } & \text { in the middle } & \text { slightly angry } & \text { not angry at all }\end{array}$

74. How sad did ending the friendship make you feel?

$\begin{array}{lcccc}1 & 2 & 3 & 4 & 5 \\ \text { not sad at all } & \text { a little sad } & \text { in the middle } & \text { pretty sad } & \text { very sad }\end{array}$

75. How stressful was ending the friendship for you?

$\begin{array}{ccccc}1 & 2 & 3 & 4 & 5 \\ \text { not at all stressful } & \text { a little stressful } & \text { in the middle } & \text { pretty stressful } & \text { very stressful }\end{array}$


Appendix D

Prevalence and Importance of Problems

\section{Which Problems Occur Most Often?}

Please indicate how often you have had problems with friends you knew before college due to each of the following reasons while you were in college. Also indicate how important each problem would be in your friendships. Please think about only same-gender friendships.

\section{Which Problems Occur Most Often?}

Please indicate how often you have had problems with friends you met in college due to each of the following reasons. Also indicate how important each problem would be in your friendships. Please think about only same-gender friendships.

\section{1. not helping or supporting each other emotionally}

How often has this type of problem occurred in your friendships?

$$
1=\text { never } \quad 2=\text { rarely } \quad 3=\text { sometimes } \quad 4=\text { fairly often } \quad 5=\text { very often }
$$

If you have experienced this type of problem, how important is this type of problem in your friendships?

$$
1=\text { not at all } \quad 2=\text { slightly } \quad 3=\text { in the middle } \quad 4=\text { very } \quad 5=\text { extremely }
$$

If you have not experienced this type of problem, how important would you expect this type of problem be in your friendships?

$$
1=\text { not at all } 2=\text { slightly } \quad 3=\text { in the middle } 4=\text { very } \quad 5=\text { extremely }
$$

2. not helping or supporting each other when you need money or other things

How often has this type of problem occurred?

$$
1=\text { never } \quad 2=\text { rarely } \quad 3=\text { sometimes } \quad 4=\text { fairly often } \quad 5=\text { very often }
$$

If you have experienced this type of problem, how important is this type of problem?

$$
1=\text { not at all } \quad 2=\text { slightly } \quad 3=\text { in the middle } 4=\text { very } \quad 5=\text { extremely }
$$

If you have not experienced this type of problem, how important would you expect this type of problem be in your friendships? 


$$
1=\text { not at all } 2=\text { slightly } \quad 3=\text { in the middle } 4=\text { very } \quad 5=\text { extremely }
$$

\section{3. violations of trust}

How often has this type of problem occurred?

$$
1=\text { never } \quad 2=\text { rarely } \quad 3=\text { sometimes } \quad 4=\text { fairly often } \quad 5=\text { very often }
$$

If you have experienced this type of problem, how important is this type of problem?

$$
1=\text { not at all } \quad 2=\text { slightly } \quad 3=\text { in the middle } \quad 4=\text { very } \quad 5=\text { extremely }
$$

If you have not experienced this type of problem, how important would you expect this type of problem be in your friendships?

$$
1=\text { not at all } 2=\text { slightly } \quad 3=\text { in the middle } \quad 4=\text { very } \quad 5=\text { extremely }
$$

\section{4. not liking to do the same things}

How often has this type of problem occurred?

$$
1=\text { never } \quad 2=\text { rarely } \quad 3=\text { sometimes } \quad 4=\text { fairly often } \quad 5=\text { very often }
$$

If you have experienced this type of problem, how important is this type of problem?

$$
1=\text { not at all } \quad 2=\text { slightly } \quad 3=\text { in the middle } 4=\text { very } \quad 5=\text { extremely }
$$

If you have not experienced this type of problem, how important would you expect this type of problem be in your friendships?

$$
1=\text { not at all } \quad 2=\text { slightly } \quad 3=\text { in the middle } \quad 4=\text { very } \quad 5=\text { extremely }
$$

\section{5. not thinking the same things are important}

How often has this type of problem occurred?

$$
1=\text { never } \quad 2=\text { rarely } \quad 3=\text { sometimes } \quad 4=\text { fairly often } \quad 5=\text { very often }
$$

If you have experienced this type of problem, how important is this type of problem?

$$
1=\text { not at all } \quad 2=\text { slightly } \quad 3=\text { in the middle } \quad 4=\text { very } \quad 5=\text { extremely }
$$

If you have not experienced this type of problem, how important would you expect this type of problem be in your friendships? 


$$
1=\text { not at all } 2=\text { slightly } \quad 3=\text { in the middle } 4=\text { very } \quad 5=\text { extremely }
$$

\section{6. not doing things together}

How often has this type of problem occurred?

$$
1=\text { never } \quad 2=\text { rarely } \quad 3=\text { sometimes } \quad 4=\text { fairly often } \quad 5=\text { very often }
$$

If you have experienced this type of problem, how important is this type of problem?

$$
1=\text { not at all } \quad 2=\text { slightly } \quad 3=\text { in the middle } \quad 4=\text { very } \quad 5=\text { extremely }
$$

If you have not experienced this type of problem, how important would you expect this type of problem be in your friendships?

$$
1=\text { not at all } \quad 2=\text { slightly } \quad 3=\text { in the middle } \quad 4=\text { very } \quad 5=\text { extremely }
$$

7. not spending enough time together

How often has this type of problem occurred?

$$
1=\text { never } \quad 2=\text { rarely } \quad 3=\text { sometimes } \quad 4=\text { fairly often } \quad 5=\text { very often }
$$

If you have experienced this type of problem, how important is this type of problem?

$$
1=\text { not at all } \quad 2=\text { slightly } \quad 3=\text { in the middle } \quad 4=\text { very } \quad 5=\text { extremely }
$$

If you have not experienced this type of problem, how important would you expect this type of problem be in your friendships?

$$
1=\text { not at all } \quad 2=\text { slightly } \quad 3=\text { in the middle } \quad 4=\text { very } \quad 5=\text { extremely }
$$

\section{8. not sharing past experiences}

How often has this type of problem occurred?

$$
1=\text { never } \quad 2=\text { rarely } \quad 3=\text { sometimes } \quad 4=\text { fairly often } \quad 5=\text { very often }
$$

If you have experienced this type of problem, how important is this type of problem?

$$
1=\text { not at all } \quad 2=\text { slightly } \quad 3=\text { in the middle } 4=\text { very } \quad 5=\text { extremely }
$$

If you have not experienced this type of problem, how important would you expect this type of problem be in your friendships?

$$
1=\text { not at all } \quad 2=\text { slightly } \quad 3=\text { in the middle } 4=\text { very } \quad 5=\text { extremely }
$$


9. not working to make the friendship as good as it could be

How often has this type of problem occurred?

$$
1=\text { never } \quad 2 \text { = rarely } \quad 3=\text { sometimes } \quad 4=\text { fairly often } \quad 5=\text { very often }
$$

If you have experienced this type of problem, how important is this type of problem?

$$
1=\text { not at all } \quad 2=\text { slightly } \quad 3=\text { in the middle } \quad 4=\text { very } \quad 5=\text { extremely }
$$

If you have not experienced this type of problem, how important would you expect this type of problem be in your friendships?

$$
1=\text { not at all } \quad 2=\text { slightly } \quad 3=\text { in the middle } \quad 4=\text { very } \quad 5=\text { extremely }
$$

\section{0. lack of commitment to the friendship}

How often has this type of problem occurred?

$$
1=\text { never } \quad 2=\text { rarely } \quad 3=\text { sometimes } \quad 4=\text { fairly often } \quad 5=\text { very often }
$$

If you have experienced this type of problem, how important is this type of problem?

$$
1=\text { not at all } \quad 2=\text { slightly } \quad 3=\text { in the middle } 4=\text { very } \quad 5=\text { extremely }
$$

If you have not experienced this type of problem, how important would you expect this type of problem be in your friendships?

$$
1=\text { not at all } \quad 2=\text { slightly } \quad 3=\text { in the middle } \quad 4=\text { very } \quad 5=\text { extremely }
$$

\section{1. lack of communication about feelings}

How often has this type of problem occurred?

$$
1=\text { never } \quad 2=\text { rarely } \quad 3=\text { sometimes } \quad 4=\text { fairly often } \quad 5=\text { very often }
$$

If you have experienced this type of problem, how important is this type of problem?

$$
1=\text { not at all } \quad 2=\text { slightly } \quad 3=\text { in the middle } \quad 4=\text { very } \quad 5=\text { extremely }
$$

If you have not experienced this type of problem, how important would you expect this type of problem be in your friendships?

$$
1=\text { not at all } 2=\text { slightly } \quad 3=\text { in the middle } 4=\text { very } \quad 5=\text { extremely }
$$




\section{2. lack of communication about thoughts}

How often has this type of problem occurred?

$$
1=\text { never } \quad 2=\text { rarely } \quad 3=\text { sometimes } \quad 4=\text { fairly often } \quad 5=\text { very often }
$$

If you have experienced this type of problem, how important is this type of problem?

$$
1=\text { not at all } \quad 2=\text { slightly } \quad 3=\text { in the middle } \quad 4=\text { very } \quad 5=\text { extremely }
$$

If you have not experienced this type of problem, how important would you expect this type of problem be in your friendships?

$$
1=\text { not at all } \quad 2=\text { slightly } \quad 3=\text { in the middle } \quad 4=\text { very } \quad 5=\text { extremely }
$$

\section{3. lack of communication about personal information}

How often has this type of problem occurred?

$$
1=\text { never } \quad 2=\text { rarely } \quad 3=\text { sometimes } \quad 4=\text { fairly often } \quad 5=\text { very often }
$$

If you have experienced this type of problem, how important is this type of problem?

$$
1=\text { not at all } \quad 2=\text { slightly } \quad 3=\text { in the middle } \quad 4=\text { very } \quad 5=\text { extremely }
$$

If you have not experienced this type of problem, how important would you expect this type of problem be in your friendships?

$$
1=\text { not at all } \quad 2=\text { slightly } \quad 3=\text { in the middle } \quad 4=\text { very } \quad 5=\text { extremely }
$$

\section{4. unequal effort in the friendship}

How often has this type of problem occurred?

$$
1=\text { never } \quad 2=\text { rarely } \quad 3=\text { sometimes } \quad 4=\text { fairly often } \quad 5=\text { very often }
$$

If you have experienced this type of problem, how important is this type of problem?

$$
1=\text { not at all } \quad 2=\text { slightly } \quad 3=\text { in the middle } \quad 4=\text { very } \quad 5=\text { extremely }
$$

If you have not experienced this type of problem, how important would you expect this type of problem be in your friendships?

$$
1=\text { not at all } \quad 2=\text { slightly } \quad 3=\text { in the middle } \quad 4=\text { very } \quad 5=\text { extremely }
$$

\section{5. disapproval of how the other behaved}


How often has this type of problem occurred?

$$
1=\text { never } \quad 2=\text { rarely } \quad 3=\text { sometimes } \quad 4=\text { fairly often } \quad 5=\text { very often }
$$

If you have experienced this type of problem, how important is this type of problem?

$$
1=\text { not at all } 2=\text { slightly } \quad 3=\text { in the middle } 4=\text { very } 5=\text { extremely }
$$

If you have not experienced this type of problem, how important would you expect this type of problem be in your friendships?

$$
1=\text { not at all } \quad 2=\text { slightly } \quad 3=\text { in the middle } \quad 4=\text { very } \quad 5=\text { extremely }
$$

\section{6. lack of closeness}

How often has this type of problem occurred?

$$
1=\text { never } \quad 2=\text { rarely } \quad 3=\text { sometimes } \quad 4=\text { fairly often } \quad 5=\text { very often }
$$

If you have experienced this type of problem, how important is this type of problem?

$$
1=\text { not at all } \quad 2=\text { slightly } \quad 3=\text { in the middle } \quad 4=\text { very } \quad 5=\text { extremely }
$$

If you have not experienced this type of problem, how important would you expect this type of problem be in your friendships?

$$
1=\text { not at all } \quad 2=\text { slightly } \quad 3=\text { in the middle } 4=\text { very } \quad 5=\text { extremely }
$$

\section{7. thoughts of making new friends easily}

How often has this type of problem occurred?

$$
1=\text { never } \quad 2=\text { rarely } \quad 3=\text { sometimes } \quad 4=\text { fairly often } \quad 5=\text { very often }
$$

If you have experienced this type of problem, how important is this type of problem?

$$
1=\text { not at all } \quad 2=\text { slightly } \quad 3=\text { in the middle } \quad 4=\text { very } \quad 5=\text { extremely }
$$

If you have not experienced this type of problem, how important would you expect this type of problem be in your friendships?

$$
1=\text { not at all } \quad 2=\text { slightly } \quad 3=\text { in the middle } \quad 4=\text { very } \quad 5=\text { extremely }
$$

18. other (Please list any additional types of problems you have had with your friends, rate how often the problems have occurred, and rate the importance of the problems.) 
Appendix E

Prevalence and Importance of Friendship Endings

\section{Why Do Pre-College Friendships End?}

Please indicate how often you have had pre-college friendships end due to each of the following reasons while you were in college.

\section{Why Do College Friendships End?}

Please think about the friends you have made in college. Please indicate how often those friendships have ended due to each of the following reasons.

\section{1. not helping or supporting each other emotionally}

How often have you had friendships end for this reason?

$$
1=\text { never } \quad 2=\text { rarely } \quad 3=\text { sometimes } \quad 4=\text { fairly often } \quad 5=\text { very often }
$$

If you have experienced this type of friendship ending, how important was this issue in determining if your friendships would end?

$$
1=\text { not at all } 2=\text { slightly } \quad 3=\text { in the middle } \quad 4=\text { very } \quad 5=\text { extremely }
$$

If you have not experienced this type of friendship ending, how important would this issue be in determining if your friendships will end?

$$
1=\text { not at all } 2=\text { slightly } 3=\text { in the middle } \quad 4=\text { very } \quad 5=\text { extremely }
$$

2. not helping or supporting each other when you need things or money

How often have you had friendships end for this reason?

$$
1=\text { never } \quad 2=\text { rarely } \quad 3=\text { sometimes } \quad 4=\text { fairly often } \quad 5=\text { very often }
$$

If you have experienced this type of friendship ending, how important was this issue in determining if your friendships would end?

$$
1=\text { not at all } \quad 2=\text { slightly } \quad 3=\text { in the middle } \quad 4=\text { very } \quad 5=\text { extremely }
$$

If you have not experienced this type of friendship ending, how important would this issue be in determining if your friendships will end? 


$$
1=\text { not at all } 2=\text { slightly } \quad 3=\text { in the middle } 4=\text { very } \quad 5=\text { extremely }
$$

\section{3. violations of trust}

How often have you had friendships end for this reason?

$$
1=\text { never } \quad 2=\text { rarely } \quad 3=\text { sometimes } \quad 4=\text { fairly often } \quad 5=\text { very often }
$$

If you have experienced this type of friendship ending, how important was this issue in determining if your friendships would end?

$$
1=\text { not at all } \quad 2=\text { slightly } \quad 3=\text { in the middle } 4=\text { very } \quad 5=\text { extremely }
$$

If you have not experienced this type of friendship ending, how important would this issue be in determining if your friendships will end?

$$
1=\text { not at all } \quad 2=\text { slightly } \quad 3=\text { in the middle } \quad 4=\text { very } \quad 5=\text { extremely }
$$

\section{4. not liking to do the same things}

How often have you had friendships end for this reason?

$$
1=\text { never } \quad 2=\text { rarely } \quad 3=\text { sometimes } \quad 4=\text { fairly often } \quad 5=\text { very often }
$$

If you have experienced this type of friendship ending, how important was this issue in determining if your friendships would end?

$$
1=\text { not at all } \quad 2=\text { slightly } \quad 3=\text { in the middle } \quad 4=\text { very } \quad 5=\text { extremely }
$$

If you have not experienced this type of friendship ending, how important would this issue be in determining if your friendships will end?

$$
1=\text { not at all } 2=\text { slightly } \quad 3=\text { in the middle } \quad 4=\text { very } \quad 5=\text { extremely }
$$

\section{5. not thinking that the same things are important}

How often have you had friendships end for this reason?

$$
1=\text { never } \quad 2=\text { rarely } \quad 3=\text { sometimes } \quad 4=\text { fairly often } \quad 5=\text { very often }
$$

If you have experienced this type of friendship ending, how important was this issue in determining if your friendships would end? 


$$
1=\text { not at all } 2=\text { slightly } \quad 3=\text { in the middle } \quad 4=\text { very } \quad 5=\text { extremely }
$$

If you have not experienced this type of friendship ending, how important would this issue be in determining if your friendships will end?

$$
1=\text { not at all } \quad 2=\text { slightly } \quad 3=\text { in the middle } \quad 4=\text { very } \quad 5=\text { extremely }
$$

\section{6. not doing things together}

How often have you had friendships end for this reason?

$$
1=\text { never } \quad 2=\text { rarely } \quad 3=\text { sometimes } \quad 4=\text { fairly often } \quad 5=\text { very often }
$$

If you have experienced this type of friendship ending, how important was this issue in determining if your friendships would end?

$$
1=\text { not at all } \quad 2=\text { slightly } \quad 3=\text { in the middle } \quad 4=\text { very } \quad 5=\text { extremely }
$$

If you have not experienced this type of friendship ending, how important would this issue be in determining if your friendships will end?

$$
1=\text { not at all } \quad 2=\text { slightly } \quad 3=\text { in the middle } 4=\text { very } \quad 5=\text { extremely }
$$

\section{7. not spending enough time together}

How often have you had friendships end for this reason?

$$
1=\text { never } \quad 2=\text { rarely } \quad 3=\text { sometimes } \quad 4=\text { fairly often } \quad 5=\text { very often }
$$

If you have experienced this type of friendship ending, how important was this issue in determining if your friendships would end?

$$
1=\text { not at all } \quad 2=\text { slightly } \quad 3=\text { in the middle } \quad 4=\text { very } \quad 5=\text { extremely }
$$

If you have not experienced this type of friendship ending, how important would this issue be in determining if your friendships will end?

$$
1=\text { not at all } \quad 2=\text { slightly } \quad 3=\text { in the middle } \quad 4=\text { very } \quad 5=\text { extremely }
$$

\section{8. not sharing past experiences}

How often have you had friendships end for this reason? 


$$
1=\text { never } \quad 2 \text { = rarely } \quad 3=\text { sometimes } \quad 4=\text { fairly often } \quad 5=\text { very often }
$$

If you have experienced this type of friendship ending, how important was this issue in determining if your friendships would end?

$$
1=\text { not at all } \quad 2=\text { slightly } \quad 3=\text { in the middle } \quad 4=\text { very } \quad 5=\text { extremely }
$$

If you have not experienced this type of friendship ending, how important would this issue be in determining if your friendships will end?

$$
1=\text { not at all } \quad 2=\text { slightly } \quad 3=\text { in the middle } \quad 4=\text { very } \quad 5=\text { extremely }
$$

9. not working to make the friendship as good as it could be

How often have you had friendships end for this reason?

$$
1=\text { never } \quad 2=\text { rarely } \quad 3=\text { sometimes } \quad 4=\text { fairly often } \quad 5=\text { very often }
$$

If you have experienced this type of friendship ending, how important was this issue in determining if your friendships would end?

$$
1=\text { not at all } \quad 2=\text { slightly } \quad 3=\text { in the middle } \quad 4=\text { very } \quad 5=\text { extremely }
$$

If you have not experienced this type of friendship ending, how important would this issue be in determining if your friendships will end?

$$
1=\text { not at all } \quad 2=\text { slightly } \quad 3=\text { in the middle } \quad 4=\text { very } \quad 5=\text { extremely }
$$

\section{0. lack of commitment to the friendship}

How often have you had friendships end for this reason?

$$
1=\text { never } \quad 2=\text { rarely } \quad 3=\text { sometimes } \quad 4=\text { fairly often } \quad 5=\text { very often }
$$

If you have experienced this type of friendship ending, how important was this issue in determining if your friendships would end?

$$
1=\text { not at all } \quad 2=\text { slightly } \quad 3=\text { in the middle } \quad 4=\text { very } \quad 5=\text { extremely }
$$

If you have not experienced this type of friendship ending, how important would this issue be in determining if your friendships will end?

$$
1=\text { not at all } \quad 2=\text { slightly } \quad 3=\text { in the middle } 4=\text { very } \quad 5=\text { extremely }
$$




\section{1. lack of communication about feelings}

How often have you had friendships end for this reason?

$$
1=\text { never } \quad 2=\text { rarely } \quad 3=\text { sometimes } \quad 4=\text { fairly often } \quad 5=\text { very often }
$$

If you have experienced this type of friendship ending, how important was this issue in determining if your friendships would end?

$$
1=\text { not at all } \quad 2=\text { slightly } \quad 3=\text { in the middle } \quad 4=\text { very } \quad 5=\text { extremely }
$$

If you have not experienced this type of friendship ending, how important would this issue be in determining if your friendships will end?

$$
1=\text { not at all } \quad 2=\text { slightly } \quad 3=\text { in the middle } \quad 4=\text { very } \quad 5=\text { extremely }
$$

\section{2. lack of communication about thoughts}

How often have you had friendships end for this reason?

$$
1=\text { never } \quad 2=\text { rarely } \quad 3=\text { sometimes } \quad 4=\text { fairly often } \quad 5=\text { very often }
$$

If you have experienced this type of friendship ending, how important was this issue in determining if your friendships would end?

$$
1=\text { not at all } \quad 2=\text { slightly } \quad 3=\text { in the middle } \quad 4=\text { very } \quad 5=\text { extremely }
$$

If you have not experienced this type of friendship ending, how important would this issue be in determining if your friendships will end?

$$
1=\text { not at all } \quad 2=\text { slightly } \quad 3=\text { in the middle } \quad 4=\text { very } \quad 5=\text { extremely }
$$

\section{3. lack of communication about personal information}

How often have you had friendships end for this reason?

$$
1=\text { never } \quad 2=\text { rarely } \quad 3=\text { sometimes } \quad 4=\text { fairly often } \quad 5=\text { very often }
$$

If you have experienced this type of friendship ending, how important was this issue in determining if your friendships would end?

$$
1=\text { not at all } \quad 2=\text { slightly } \quad 3=\text { in the middle } \quad 4=\text { very } \quad 5=\text { extremely }
$$


If you have not experienced this type of friendship ending, how important would this issue be in determining if your friendships will end?

$$
1=\text { not at all } \quad 2=\text { slightly } \quad 3=\text { in the middle } 4=\text { very } \quad 5=\text { extremely }
$$

\section{4. unequal effort in the friendship}

How often have you had friendships end for this reason?

$$
1=\text { never } \quad 2=\text { rarely } \quad 3=\text { sometimes } \quad 4=\text { fairly often } \quad 5=\text { very often }
$$

If you have experienced this type of friendship ending, how important was this issue in determining if your friendships would end?

$$
1=\text { not at all } 2=\text { slightly } \quad 3=\text { in the middle } \quad 4=\text { very } \quad 5=\text { extremely }
$$

If you have not experienced this type of friendship ending, how important would this issue be in determining if your friendships will end?

$$
1=\text { not at all } \quad 2=\text { slightly } \quad 3=\text { in the middle } 4=\text { very } \quad 5=\text { extremely }
$$

\section{5. disapproval of how the other behaved}

How often have you had friendships end for this reason?

$$
1=\text { never } \quad 2=\text { rarely } \quad 3=\text { sometimes } \quad 4=\text { fairly often } \quad 5=\text { very often }
$$

If you have experienced this type of friendship ending, how important was this issue in determining if your friendships would end?

$$
1=\text { not at all } \quad 2=\text { slightly } \quad 3=\text { in the middle } 4=\text { very } \quad 5=\text { extremely }
$$

If you have not experienced this type of friendship ending, how important would this issue be in determining if your friendships will end?

$$
1=\text { not at all } \quad 2=\text { slightly } \quad 3=\text { in the middle } 4=\text { very } \quad 5=\text { extremely }
$$

\section{6. lack of closeness}

How often have you had friendships end for this reason?

$$
1=\text { never } \quad 2 \text { = rarely } \quad 3=\text { sometimes } \quad 4=\text { fairly often } \quad 5=\text { very often }
$$


If you have experienced this type of friendship ending, how important was this issue in determining if your friendships would end?

$$
1=\text { not at all } 2=\text { slightly } \quad 3=\text { in the middle } 4=\text { very } \quad 5=\text { extremely }
$$

If you have not experienced this type of friendship ending, how important would this issue be in determining if your friendships will end?

$$
1=\text { not at all } \quad 2=\text { slightly } \quad 3=\text { in the middle } \quad 4=\text { very } \quad 5=\text { extremely }
$$

\section{7. thoughts of making new friends easily}

How often have you had friendships end for this reason?

$$
1=\text { never } \quad 2=\text { rarely } \quad 3=\text { sometimes } \quad 4=\text { fairly often } \quad 5=\text { very often }
$$

If you have experienced this type of friendship ending, how important was this issue in determining if your friendships would end?

$$
1=\text { not at all } \quad 2=\text { slightly } \quad 3=\text { in the middle } \quad 4=\text { very } \quad 5=\text { extremely }
$$

If you have not experienced this type of friendship ending, how important would this issue be in determining if your friendships will end?

$$
1=\text { not at all } \quad 2=\text { slightly } \quad 3=\text { in the middle } 4=\text { very } \quad 5=\text { extremely }
$$

18. other (Please list any additional reasons your friendships have ended, and rate how often.) 
Table 1

Descriptive Statistics for Friendship Features Before Friendship Problems

\begin{tabular}{lclll}
\hline Friendship Feature & Mean & Standard & Range \\
& \multicolumn{5}{c}{ Deviation } \\
& & & & \\
\hline Support and Resources & 3.55 & .95 & $1-5$ & .93 \\
Pre-college & 3.18 & 1.10 & $1-5$ & .95 \\
College & 3.40 & .77 & $1-5$ & \\
Overall & & &
\end{tabular}

Similarity

$\alpha$

$N \quad t$

(1)

$\begin{array}{llccc}\text { Pre-college } & 3.99 & .86 & 1-5 & .75 \\ \text { College } & 3.50 & 1.03 & 1-5 & .81 \\ \text { Overall } & 3.76 & .75 & 1-5 & \end{array}$

Shared History

$183 \quad 3.93^{*}$

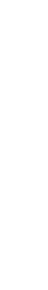


Table 1 (continued)

\begin{tabular}{|c|c|c|c|c|c|c|}
\hline Friendship Feature & Mean & Standard & Range & $\alpha$ & $N$ & $t$ \\
\hline & & Deviation & & & & \\
\hline Commitment & & & & & 187 & $4.56 *$ \\
\hline Pre-college & 4.02 & .85 & $1.33-5$ & .71 & & \\
\hline College & 3.58 & 1.04 & $1-5$ & .83 & & \\
\hline Overall & 3.80 & .63 & $1-5$ & & & \\
\hline Communication & & & & & 187 & $5.36^{*}$ \\
\hline Pre-college & 3.68 & 1.15 & $1-5$ & .88 & & \\
\hline College & 3.10 & 1.24 & $1-5$ & .90 & & \\
\hline Overall & 3.42 & .87 & $1-5$ & & & \\
\hline Personal Characteristics & & & & & 187 & $3.99 *$ \\
\hline Pre-college & 3.99 & .85 & $1.33-5$ & .83 & & \\
\hline College & 3.64 & .96 & $1-5$ & .88 & & \\
\hline Overall & 3.83 & .66 & $1-5$ & & & \\
\hline Costs and Rewards & & & & & 187 & -.28 \\
\hline Pre-college & -.03 & .77 & $-4-+2$ & & & \\
\hline College & -.05 & .74 & $-2-+2$ & & & \\
\hline Overall & -.04 & .55 & $-4-+2$ & & & \\
\hline
\end{tabular}


Table 1 (continued)

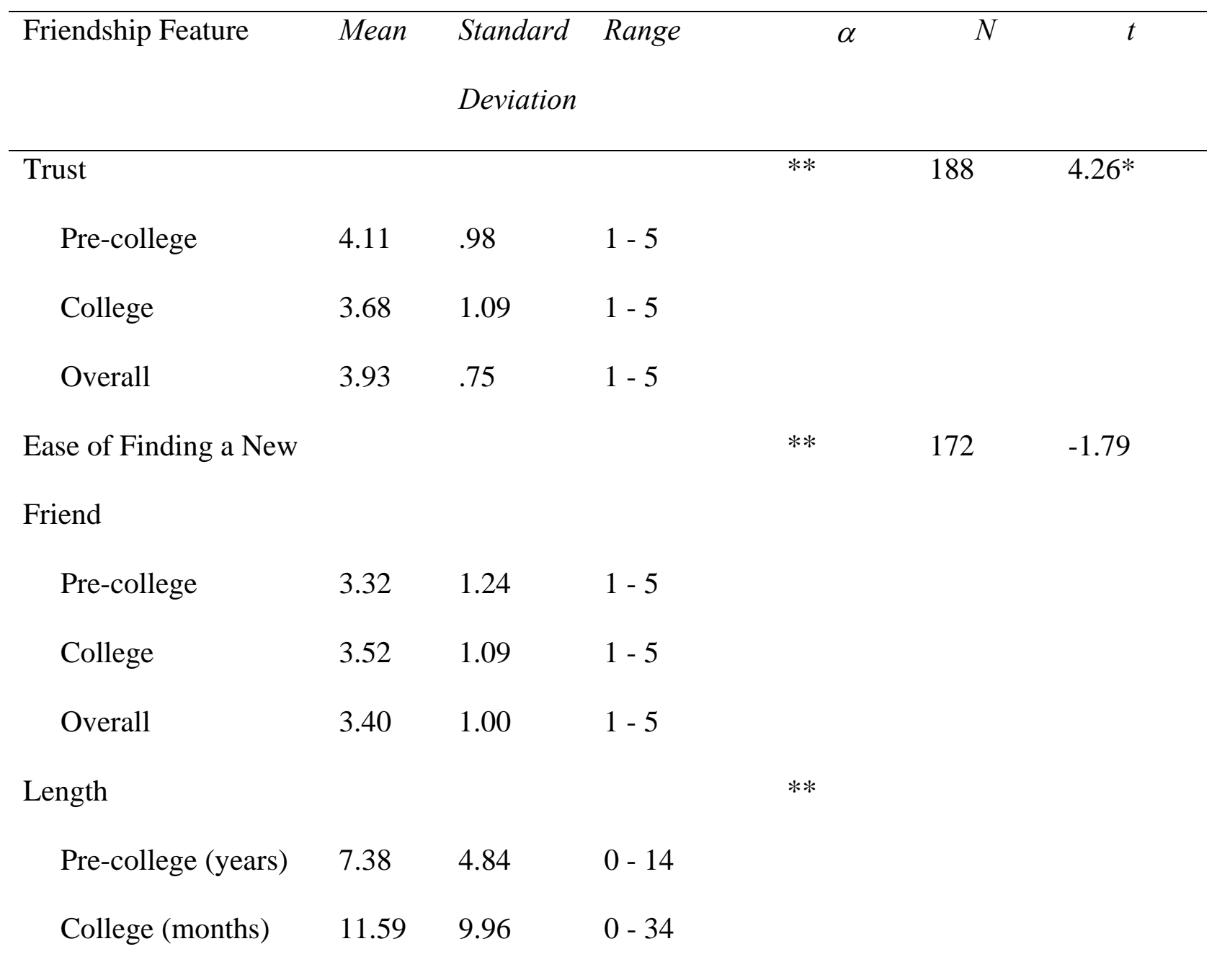

Note. $*$ indicates a significant difference in means, $p<.01$ ** alpha values were not computed for single-item scales 
Table 2

Cronbach's Alpha Levels for Event Prevalence and Importance Scales

\begin{tabular}{|c|c|c|c|c|}
\hline \multirow[t]{2}{*}{ Scale } & Problem & Problem & Ending & Ending \\
\hline & Frequency & Importance & Frequency & Importance \\
\hline \multicolumn{5}{|l|}{ Support } \\
\hline Pre-college & .47 & .48 & .56 & .53 \\
\hline College & .59 & .50 & .57 & .60 \\
\hline \multicolumn{5}{|l|}{ Similarity } \\
\hline Pre-college & .70 & .67 & .82 & .78 \\
\hline College & .74 & .76 & .83 & .77 \\
\hline \multicolumn{5}{|c|}{ Common Experiences } \\
\hline Pre-college & .82 & .80 & .90 & .86 \\
\hline College & .67 & .81 & .88 & .85 \\
\hline \multicolumn{5}{|l|}{ Commitment } \\
\hline Pre-college & .81 & .76 & .78 & .78 \\
\hline College & .77 & .74 & .78 & .81 \\
\hline \multicolumn{5}{|l|}{ Communication } \\
\hline Pre-college & .81 & .79 & .88 & .81 \\
\hline College & .82 & .83 & .89 & .83 \\
\hline
\end{tabular}


Table 3

Descriptive Information for Problems with Friends

\begin{tabular}{|c|c|c|c|c|c|}
\hline Rated Item & Mean & $\begin{array}{l}\text { Standard } \\
\text { Deviation }\end{array}$ & Range & $N$ & $t$ \\
\hline Importance of Problem & & & & 183 & .42 \\
\hline Pre-college & 3.45 & 1.29 & $1-5$ & 212 & \\
\hline College & 3.35 & 1.27 & $1-5$ & 206 & \\
\hline Seriousness of Problem & & & & 183 & 1.68 \\
\hline Pre-college & 3.39 & 1.25 & $1-5$ & 212 & \\
\hline College & 3.16 & 1.28 & $1-5$ & 206 & \\
\hline Importance of Keeping Friend & & & & 183 & $4.63 *$ \\
\hline Pre-college & 4.17 & 1.01 & $1-5$ & 212 & \\
\hline College & 3.62 & 1.32 & $1-5$ & 206 & \\
\hline How Long Ago Problem & & & & 183 & $4.53^{*}$ \\
\hline \multicolumn{6}{|l|}{ Occurred } \\
\hline Pre-college & 6.89 & 2.26 & $1-9$ & 212 & \\
\hline College & 5.83 & 2.39 & $1-9$ & 206 & \\
\hline \multicolumn{6}{|l|}{ Length of Friendship } \\
\hline Pre-college (years) & 7.38 & 4.84 & $0-14$ & 211 & \\
\hline College (months) & 11.59 & 9.96 & $0-34$ & 209 & \\
\hline
\end{tabular}

Note. $*$ indicates a significant difference in means, $p<.01$ 
Table 4

Descriptive Information for Friendship Endings

\begin{tabular}{|c|c|c|c|c|c|}
\hline Rated Item & Mean & $\begin{array}{l}\text { Standard } \\
\text { Deviation }\end{array}$ & Range & $N$ & $t$ \\
\hline Importance of Keeping Friend & & & & 128 & $2.33 *$ \\
\hline Pre-college & 2.86 & 1.23 & $1-5$ & 191 & \\
\hline College & 2.51 & 1.26 & $1-5$ & 148 & \\
\hline How Long Ago Friendship Ended & & & & 129 & $8.20 * *$ \\
\hline Pre-college & 8.96 & 1.71 & $4-10$ & 191 & \\
\hline College & 7.08 & 2.36 & $1-10$ & 149 & \\
\hline \multicolumn{6}{|l|}{ Length of Friendship } \\
\hline Pre-college (years) & 6.02 & 4.34 & $0-14$ & 193 & \\
\hline College (months) & 10.99 & 9.39 & $1-34$ & 149 & \\
\hline
\end{tabular}

Note. * indicates a significant difference in means, $p<.05 ; * *$ indicates a significant difference in means, $p<.001$ 
Table 5

Standardized and Unstandardized Regression Weights for Model Predicting Pre-College Friendship Quality From Friendship Features

\begin{tabular}{|c|c|c|c|c|c|c|c|}
\hline Variables & $B$ & $S E B$ & $\beta$ & $R^{2}$ & $F$ & $d f$ & $p$ \\
\hline Overall Model & & & & .289 & 6.979 & 11,147 & $.000^{*}$ \\
\hline Support and Resources & .096 & .160 & .074 & & & & .548 \\
\hline Similarity & .436 & .151 & .313 & & & & $.004 *$ \\
\hline Shared History & -.135 & .113 & -.114 & & & & .233 \\
\hline Current Common Experiences & -.033 & .131 & -.027 & & & & .800 \\
\hline Commitment & .397 & .167 & .268 & & & & $.019 *$ \\
\hline Communication & -.117 & .105 & -.109 & & & & .278 \\
\hline Costs and Rewards & .052 & .114 & .032 & & & & .649 \\
\hline Personal Characteristics & -.152 & .172 & -.102 & & & & .377 \\
\hline Ease of Finding a New Friend & -.380 & .072 & -.397 & & & & $.000^{*}$ \\
\hline Length of Friendship & .040 & .018 & .153 & & & & $.031 *$ \\
\hline Trust & -.120 & .120 & -.097 & & & & .319 \\
\hline
\end{tabular}

Note. * indicates a significant model or predictor 
Table 6

Standardized and Unstandardized Regression Weights for Model Predicting College Friendship Quality From Friendship Features

\begin{tabular}{|c|c|c|c|c|c|c|c|}
\hline Variables & $B$ & $S E B$ & $\beta$ & $R^{2}$ & $F$ & $d f$ & $p$ \\
\hline Overall Model & & & & .251 & 5.639 & 11,141 & $.000 *$ \\
\hline Support and Resources & .069 & .147 & .065 & & & & .638 \\
\hline Similarity & .070 & .141 & .059 & & & & .619 \\
\hline Shared History & -.012 & .108 & -.012 & & & & .914 \\
\hline Current Common Experiences & .026 & .139 & .024 & & & & .849 \\
\hline Commitment & .521 & .165 & .435 & & & & $.002 *$ \\
\hline Communication & -.159 & .115 & -.171 & & & & .170 \\
\hline Costs and Rewards & .237 & .120 & .155 & & & & $.050 *$ \\
\hline Personal Characteristics & .064 & .149 & .053 & & & & .665 \\
\hline Ease of Finding a New Friend & -.238 & .073 & -.274 & & & & $.001 *$ \\
\hline Length of Friendship & .019 & .009 & .164 & & & & $.037 *$ \\
\hline Trust & -.300 & .134 & -.286 & & & & $.026 *$ \\
\hline
\end{tabular}

Note. $*$ indicates a significant model or predictor 
Table 7

Logistic Regression Analysis Predicting Pre-College Friendship Dissolution from 11 Friendship Features

\begin{tabular}{lccccccc}
\hline Variable & $B$ & $S . E$. & Wald & $d f$ & $p$ & $O . R$. & $95 \%$ CI \\
\hline Support and Resources & -.462 & .378 & 1.495 & 1 & .221 & .630 & $.30-1.32$ \\
Similarity & -.626 & .387 & 2.613 & 1 & .106 & .535 & $.25-1.14$ \\
Shared History & .511 & .290 & 3.111 & 1 & .078 & 1.668 & $.95-2.94$ \\
Current Common Experiences & .775 & .344 & 5.085 & 1 & $.024 *$ & 2.171 & $1.11-4.26$ \\
Commitment & -.624 & .358 & 3.032 & 1 & .082 & .536 & $.27-1.08$ \\
Communication & .086 & .237 & .131 & 1 & .717 & 1.090 & $.69-1.73$ \\
Balance of Costs and Rewards & -.252 & .259 & .944 & 1 & .331 & .777 & $.47-1.29$ \\
Personal Characteristics & -.214 & .380 & .318 & 1 & .573 & .807 & $.38-1.70$ \\
Ease of Finding a New Friend & .826 & .210 & 15.414 & 1 & $.000 *$ & 2.285 & $1.51-3.45$ \\
Length of Friendship & -.051 & .043 & 1.421 & 1 & .233 & .951 & $.88-1.03$ \\
Trust & .262 & .279 & .881 & 1 & .348 & 1.300 & $.75-2.25$ \\
\hline Note * indicates a significant effect $p<.05$. & & & & & & & \\
\hline
\end{tabular}

Note. $*$ indicates a significant effect, $p<.05$. 
Table 8

Logistic Regression Analysis Predicting College Friendship Dissolution from 11 Friendship Features

\begin{tabular}{|c|c|c|c|c|c|c|c|}
\hline Variable & $B$ & S. E. & Wald & $d f$ & $p$ & $O . R$. & $95 \% C I$ \\
\hline Support and Resources & -.842 & .406 & 4.312 & 1 & $.038 *$ & .431 & $.19-.95$ \\
\hline Similarity & -.442 & .358 & 1.521 & 1 & .217 & .643 & $.32-1.30$ \\
\hline Shared History & -.240 & .320 & .560 & 1 & .454 & .787 & $.42-1.48$ \\
\hline Current Common Experiences & .374 & .370 & 1.018 & 1 & .313 & 1.453 & $.70-3.00$ \\
\hline Commitment & -.580 & .406 & 2.037 & 1 & .153 & .560 & $.25-1.24$ \\
\hline Communication & .972 & .362 & 7.221 & 1 & $.007 *$ & 2.643 & $1.30-5.37$ \\
\hline Balance of Costs and Rewards & -.857 & .342 & 6.259 & 1 & $.012 *$ & .425 & $.22-.83$ \\
\hline Personal Characteristics & .058 & .387 & .022 & 1 & .882 & 1.059 & $.50-2.26$ \\
\hline Ease of Finding a New Friend & 1.022 & .275 & 13.828 & 1 & $.000 *$ & 2.780 & $1.62-4.77$ \\
\hline Length of Friendship & .005 & .024 & .041 & 1 & .840 & 1.005 & $.96-1.05$ \\
\hline Trust & .239 & .340 & .494 & 1 & .482 & 1.269 & $.65-2.47$ \\
\hline
\end{tabular}

Note. $*$ indicates a significant effect, $p<.05$. 
Table 9

Means and (Standard Errors) for Friendship Type x Problem Frequency x Gender MANOVA

\begin{tabular}{|c|c|c|c|c|c|c|c|c|c|}
\hline & \multicolumn{3}{|c|}{ Pre-College Friendships } & \multicolumn{3}{|c|}{ College Friendships } & \multicolumn{3}{|c|}{ Total } \\
\hline & Males & Females & Total & Males & Females & Total & Males & Females & Total \\
\hline \multirow[t]{2}{*}{ Support } & 2.25 & 2.16 & 2.19 & 2.30 & 2.05 & 2.14 & 2.27 & 2.11 & 2.19 \\
\hline & $(.09)$ & $(.07)$ & $(.05)$ & $(.09)$ & $(.07)$ & $(.06)$ & $(.07)$ & $(.06)$ & $(.05)$ \\
\hline \multirow[t]{2}{*}{ Trust } & 2.41 & 2.47 & 2.44 & 2.43 & 2.37 & 2.40 & 2.42 & 2.45 & 2.42 \\
\hline & $(.12)$ & $(.10)$ & (08) & $(.12)$ & $(.09)$ & $(.07)$ & $(.10)$ & $(.08)$ & $(.06)$ \\
\hline \multirow[t]{2}{*}{ Similarity } & 2.39 & 2.61 & 2.64 & 2.77 & 2.61 & 2.67 & 2.73 & 2.61 & 2.67 \\
\hline & $(.10)$ & $(.08)$ & $(.06)$ & $(.10)$ & $(.08)$ & $(.06)$ & $(.08)$ & $(.06)$ & $(.05)$ \\
\hline Common & 2.70 & 2.74 & 2.73 & 2.60 & 2.58 & 2.59 & 2.65 & 2.66 & 2.66 \\
\hline Experiences & $(.14)$ & $(.11)$ & $(.09)$ & $(.10)$ & $(.08)$ & $(.06)$ & $(.09)$ & $(.07)$ & $(.06)$ \\
\hline \multirow[t]{2}{*}{ Shared History } & 2.17 & 2.00 & 2.07 & 2.30 & 2.08 & 2.16 & 2.23 & 2.04 & 2.14 \\
\hline & $(.96)$ & (.09) & $(.07)$ & $(.11)$ & $(.09)$ & $(.07)$ & $(.09)$ & $(.07)$ & $(.06)$ \\
\hline \multirow[t]{2}{*}{ Commitment } & 2.31 & 2.48 & $2.42^{\mathrm{a}}$ & 2.28 & 2.27 & $2.27^{\mathrm{a}}$ & 2.30 & 2.38 & 2.34 \\
\hline & $(.10)$ & $(.08)$ & $(.06)$ & $(.10)$ & $(.08)$ & $(.06)$ & $(.08)$ & $(.06)$ & $(.05)$ \\
\hline
\end{tabular}


Table 9 (continued)

\begin{tabular}{|c|c|c|c|c|c|c|c|c|c|}
\hline & \multicolumn{3}{|c|}{ Pre-College Friendships } & \multicolumn{3}{|c|}{ College Friendships } & \multicolumn{3}{|c|}{ Total } \\
\hline & Males & Females & Total & Males & Females & Total & Males & Females & Total \\
\hline \multirow[t]{2}{*}{ Communication } & 2.40 & 2.42 & 2.41 & 2.42 & 2.49 & 2.46 & 2.41 & 2.46 & 2.43 \\
\hline & $(.10)$ & $(.08)$ & $(.06)$ & $(.10)$ & $(.08)$ & $(.06)$ & $(.08)$ & $(.06)$ & $(.05)$ \\
\hline \multirow[t]{2}{*}{ Unequal Effort } & 2.40 & 2.61 & 2.53 & 2.42 & 2.42 & 2.42 & 2.41 & 2.52 & 2.46 \\
\hline & $(.12)$ & (.09) & $(.07)$ & $(.12)$ & $(.09)$ & $(.07)$ & $(.10)$ & $(.08)$ & $(.06)$ \\
\hline Personal & 2.79 & 2.87 & $2.84^{\mathrm{b}}$ & 2.73 & 2.64 & $2.67^{b}$ & 2.76 & 2.76 & 2.76 \\
\hline Characteristics & $(.11)$ & $(.09)$ & $(.07)$ & $(.12)$ & $(.09)$ & $(1.07)$ & $(.10)$ & $(.08)$ & $(.06)$ \\
\hline \multirow[t]{2}{*}{ Closeness } & 2.54 & 2.62 & $2.59^{c}$ & 2.27 & 2.40 & $2.35^{c}$ & 2.41 & 2.51 & 2.46 \\
\hline & $(.12)$ & $(.09)$ & $(.08)$ & $(.11)$ & $(.09)$ & $(.07)$ & $(.09)$ & $(.07)$ & $(.06)$ \\
\hline Thoughts of & 2.44 & 2.53 & 2.50 & 2.38 & 2.33 & 2.35 & 2.41 & 2.43 & 2.42 \\
\hline New Friends & $(.13)$ & $(.11)$ & $(.09)$ & (.13) & $(.10)$ & $(.08)$ & $(.11)$ & (.09) & $(.07)$ \\
\hline
\end{tabular}

Note. Matching letters represent significant interactions, $p<.05$ 
Table 10

Means and (Standard Errors) for Results of Friendship Type $x$ Ending Event Frequency $x$ Gender MANOVA

\begin{tabular}{|c|c|c|c|c|c|c|c|c|c|}
\hline & \multicolumn{3}{|c|}{ Pre-College Friendships } & \multicolumn{3}{|c|}{ College Friendships } & \multicolumn{3}{|c|}{ Total } \\
\hline & Males & Females & Total & Males & Females & Total & Males & Females & Total \\
\hline \multirow[t]{2}{*}{ Support } & 1.88 & 1.99 & $1.95^{\mathrm{a}}$ & 1.77 & 1.70 & $1.72^{\mathrm{a}}$ & $1.83 * *$ & $1.85^{* *}$ & 1.84 \\
\hline & $(.11)$ & $(.08)$ & $(.07)$ & $(.09)$ & $(.07)$ & $(.06)$ & (.09) & $(.07)$ & $(.06)$ \\
\hline \multirow[t]{2}{*}{ Trust } & 2.33 & 2.54 & 2.46 & 2.18 & 2.36 & 2.29 & 2.25 & $2.45^{*}$ & 2.35 \\
\hline & $(.14)$ & $(.11)$ & $(.09)$ & (.14) & $(.11)$ & $(.09)$ & $(.12)$ & $(.09)$ & $(.08)$ \\
\hline \multirow[t]{2}{*}{ Similarity } & 2.34 & 2.24 & $2.28^{\mathrm{b}}$ & 2.08 & 2.00 & $2.03^{\mathrm{b}}$ & $2.21 *$ & $2.12 *$ & 2.17 \\
\hline & $(.12)$ & $(.10)$ & $(.08)$ & $(.12)$ & $(.09)$ & $(.07)$ & $(.10)$ & $(.08)$ & $(.07)$ \\
\hline Common & 2.67 & 2.66 & $2.66^{c}$ & 2.18 & 2.18 & $2.18^{\mathrm{c}}$ & $2.43 *$ & 2.42 & 2.42 \\
\hline Experiences & $(.14)$ & $(.11)$ & $(.09)$ & $(.12)$ & $(.09)$ & $(.08)$ & $(.11)$ & $(.08)$ & $(.07)$ \\
\hline \multirow[t]{2}{*}{ Shared History } & 1.70 & 1.53 & 1.59 & 1.59 & 1.49 & 1.53 & $1.64 * *$ & $1.51 * *$ & 1.58 \\
\hline & $(.10)$ & $(.08)$ & $(.06)$ & $(.10)$ & $(.08)$ & $(.06)$ & $(.08)$ & $(.06)$ & $(.05)$ \\
\hline \multirow[t]{2}{*}{ Commitment } & 2.22 & 2.44 & $2.36^{\mathrm{d}}$ & 2.01 & 2.10 & $2.07^{\mathrm{d}}$ & 2.11 & $2.27^{*}$ & 2.19 \\
\hline & $(.12)$ & $(.09)$ & $(.08)$ & $(.11)$ & $(.09)$ & $(.07)$ & $(.10)$ & $(.08)$ & $(.06)$ \\
\hline
\end{tabular}


Table 10 (continued)

\begin{tabular}{|c|c|c|c|c|c|c|c|c|c|}
\hline & \multicolumn{3}{|c|}{ Pre-College Friendships } & \multicolumn{3}{|c|}{ College Friendships } & \multicolumn{3}{|c|}{ Total } \\
\hline & Males & Females & Total & Males & Females & Total & Males & Females & Total \\
\hline \multirow[t]{2}{*}{ Communication } & 1.93 & 2.05 & $2.00^{\mathrm{e}}$ & 1.72 & 1.89 & $1.82^{\mathrm{e}}$ & $1.82 * *$ & $1.97 * *$ & 1.90 \\
\hline & $(.11)$ & $(.09)$ & $(.07)$ & $(.10)$ & $(. .08)$ & $(.07)$ & $(.10)$ & $(.08)$ & $(.06)$ \\
\hline \multirow[t]{2}{*}{ Unequal Effort } & 2.32 & 2.53 & $2.45^{\mathrm{f}}$ & 2.05 & 2.17 & $2.12^{f}$ & 2.19 & $2.35^{*}$ & 2.27 \\
\hline & $(.14)$ & $(.11)$ & $(.09)$ & $(.13)$ & $(.10)$ & $(.08)$ & $(.12)$ & $(.09)$ & $(.07)$ \\
\hline Personal & 2.26 & 2.28 & 2.27 & 2.18 & 2.28 & 2.24 & 2.22 & 2.28 & 2.25 \\
\hline Characteristics & $(.14)$ & $(.11)$ & $(.09)$ & $(.13)$ & $(.10)$ & $(.08)$ & $(.11)$ & $(.09)$ & $(.07)$ \\
\hline \multirow[t]{2}{*}{ Closeness } & 2.33 & 2.65 & $2.53^{\mathrm{g}}$ & 1.97 & 2.24 & $2.14^{\mathrm{g}}$ & 2.15 & $2.45^{*}$ & 2.30 \\
\hline & $(.15)$ & $(.12)$ & $(.09)$ & $(.13)$ & $(.10)$ & $(.08)$ & $(.12)$ & $(.09)$ & $(.07)$ \\
\hline Thoughts of & 1.92 & 1.87 & $1.89^{\mathrm{h}}$ & 1.81 & 1.65 & $1.71^{\mathrm{h}}$ & 1.86 & 1.76 & 1.81 \\
\hline New Friends & $(.13)$ & $(.10)$ & $(.08)$ & $(.11)$ & $(.09)$ & $(.07)$ & $(.10)$ & $(.08)$ & $(.07)$ \\
\hline
\end{tabular}

Note. Matching letters represent significant interactions, $p<.05 ;$ *indicates relatively high ratings; $* *$ indicates relatively low ratings 
Table 11

Means and (Standard Errors) for Results of Friendship Type x Problem Importance x Gender Repeated Measures ANOVAs

\begin{tabular}{|c|c|c|c|c|c|c|c|c|c|}
\hline & \multicolumn{3}{|c|}{ Pre-College Friendships } & \multicolumn{3}{|c|}{ College Friendships } & \multicolumn{3}{|c|}{ Total } \\
\hline & Males & Females & Total & Males & Females & Total & Males & Females & Total \\
\hline \multirow[t]{2}{*}{ Support } & 2.98 & 3.28 & 3.14 & 3.01 & 3.41 & 3.22 & 3.00 & 3.35 & 3.18 \\
\hline & $(.13)$ & $(.11)$ & $(.10)$ & $(.12)$ & $(.12)$ & $(.11)$ & $(.11)$ & $(.10)$ & $(.09)$ \\
\hline \multirow[t]{2}{*}{ Trust } & 4.25 & 4.60 & 4.46 & 4.16 & 4.50 & 4.36 & 4.21 & 4.55 & 4.40 \\
\hline & $(.12)$ & $(.07)$ & $(.06)$ & $(.12)$ & $(.10)$ & $(.08)$ & $(.10)$ & $(.08)$ & $(.06)$ \\
\hline \multirow[t]{2}{*}{ Similarity } & 3.06 & 3.11 & 3.09 & 2.85 & 3.04 & 2.96 & 2.96 & 3.07 & 3.03 \\
\hline & $(.11)$ & $(.11)$ & $(.09)$ & $(.12)$ & $(.10)$ & $(.08)$ & $(.10)$ & $(.08)$ & $(.07)$ \\
\hline Common & 3.13 & 3.57 & $3.40^{\mathrm{a}}$ & 2.91 & 3.23 & $3.11^{\mathrm{a}}$ & $(3.02)$ & 3.40 & 3.26 \\
\hline Experiences & $(.13)$ & $(.10)$ & $(.09)$ & $(.12)$ & $(.10)$ & $(.09)$ & $(.11)$ & $(.08)$ & $(.06)$ \\
\hline \multirow[t]{2}{*}{ Shared History } & 2.51 & 2.71 & 2.63 & 2.21 & 2.73 & 2.51 & 2.36 & 2.72 & 2.57 \\
\hline & $(.17)$ & $(.12)$ & $(.11)$ & (.16) & $(.12)$ & $(.11)$ & $(.15)$ & $(.10)$ & $(.08)$ \\
\hline \multirow[t]{2}{*}{ Commitment } & 3.40 & 3.94 & $3.73^{b}$ & 3.19 & 3.67 & $3.48^{b}$ & 3.29 & 3.80 & 3.61 \\
\hline & $(.15)$ & $(.09)$ & $(.07)$ & (.14) & $(.10)$ & $(.09)$ & (.13) & (.08) & $(.06)$ \\
\hline
\end{tabular}


Table 11 (continued)

\begin{tabular}{|c|c|c|c|c|c|c|c|c|c|}
\hline & \multicolumn{3}{|c|}{ Pre-College Friendships } & \multicolumn{3}{|c|}{ College Friendships } & \multicolumn{3}{|c|}{ Total } \\
\hline & Males & Females & Total & Males & Females & Total & Males & Females & Total \\
\hline \multirow[t]{2}{*}{ Communication } & 2.98 & 3.58 & 3.36 & 2.94 & 3.46 & 3.27 & 2.96 & 3.52 & 3.32 \\
\hline & $(.15)$ & $(.09)$ & $(.09)$ & $(.15)$ & $(.09)$ & $(.09)$ & $(.14)$ & $(.08)$ & $(.07)$ \\
\hline \multirow[t]{2}{*}{ Unequal Effort } & 3.29 & 3.89 & 3.66 & 3.29 & 3.75 & 3.57 & 3.29 & 3.82 & 3.62 \\
\hline & $(.14)$ & $(.11)$ & $(.10)$ & $(.14)$ & $(.10)$ & $(.09)$ & $(.13)$ & $(.09)$ & $(.08)$ \\
\hline Personal & 3.10 & 3.38 & 3.27 & 3.23 & 3.20 & 3.21 & 3.17 & 3.29 & 3.24 \\
\hline Characteristics & $(.12)$ & $(.10)$ & $(.09)$ & $(.12)$ & $(.10)$ & $(.08)$ & $(.10)$ & $(.09)$ & $(.08)$ \\
\hline \multirow[t]{2}{*}{ Closeness } & 3.30 & 3.78 & $3.60^{c}$ & 2.83 & 3.54 & $3.28^{c}$ & 3.07 & 3.65 & 3.44 \\
\hline & $(.15)$ & $(.11)$ & $(.09)$ & $(.14)$ & $(.11)$ & $(.09)$ & $(.13)$ & $(.10)$ & $(.09)$ \\
\hline Thoughts of & 2.75 & 3.17 & 3.02 & 2.78 & 3.10 & 2.99 & 2.77 & 3.14 & 3.00 \\
\hline New Friends & $(.17)$ & $(.11)$ & $(.10)$ & $(.17)$ & $(.12)$ & $(.10)$ & $(.15)$ & $(.10)$ & $(.09)$ \\
\hline
\end{tabular}

Note. Matching letters represent significant interactions, $p<.05$. 
Table 12

Means and (Standard Deviations) for Results of Friendship Type x Importance of Ending Event x Gender MANOVA

\begin{tabular}{|c|c|c|c|c|c|c|c|c|c|}
\hline & \multicolumn{3}{|c|}{ Pre-College Friendships } & \multicolumn{3}{|c|}{ College Friendships } & \multicolumn{3}{|c|}{ Total } \\
\hline & Males & Females & Total & Males & Females & Total & Males & Females & Total \\
\hline \multirow[t]{2}{*}{ Support } & 3.35 & 3.19 & 3.24 & 3.04 & 3.21 & 3.16 & 3.19 & 3.20 & 3.20 \\
\hline & $(.32)$ & $(.20)$ & $(.19)$ & $(.32)$ & $(.20)$ & $(.19)$ & $(.28)$ & (.18) & $(.17)$ \\
\hline \multirow[t]{2}{*}{ Trust } & 4.46 & 4.26 & 4.32 & 3.92 & 4.16 & 4.09 & 4.19 & 4.21 & 4.20 \\
\hline & $(.29)$ & $(.19)$ & $(.18)$ & $(.36)$ & $(.23)$ & $(.22)$ & $(.31)$ & $(.20)$ & (.19) \\
\hline \multirow[t]{2}{*}{ Similarity } & 3.42 & 3.15 & 3.23 & 3.23 & 2.85 & 2.97 & 3.33 & 3.00 & 3.16 \\
\hline & $(.32)$ & $(.21)$ & $(.19)$ & $(.32)$ & $(.20)$ & $(.19)$ & $(.26)$ & (.17) & (.16) \\
\hline Common & 3.31 & 3.40 & 3.38 & 3.15 & 3.26 & 3.23 & 3.23 & 3.33 & 3.28 \\
\hline Experiences & $(.32)$ & $(.21)$ & $(.19)$ & $(.28)$ & $(.18)$ & $(.17)$ & $(.27)$ & $(.18)$ & $(.16)$ \\
\hline \multirow[t]{2}{*}{ Shared History } & 2.77 & $2.71^{\mathrm{a}}$ & 2.73 & 2.69 & $2.35^{\mathrm{a}}$ & 2.45 & 2.73 & 2.53 & 2.63 \\
\hline & $(.37)$ & $(.24)$ & $(.22)$ & $(.34)$ & $(.22)$ & $(.20)$ & $(.33)$ & $(.21)$ & $(.19)$ \\
\hline \multirow[t]{2}{*}{ Commitment } & 3.62 & 3.71 & 3.68 & 3.73 & 3.47 & 3.55 & 3.67 & 3.59 & 3.63 \\
\hline & $(.29)$ & $(.19)$ & $(.17)$ & $(.29)$ & (.19) & $(.17)$ & $(.27)$ & $(.18)$ & $(.16)$ \\
\hline
\end{tabular}


Table 12 (continued)

\begin{tabular}{|c|c|c|c|c|c|c|c|c|c|}
\hline & \multicolumn{3}{|c|}{ Pre-College Friendships } & \multicolumn{3}{|c|}{ College Friendships } & \multicolumn{3}{|c|}{ Total } \\
\hline & Males & Females & Total & Males & Females & Total & Males & Females & Total \\
\hline \multirow[t]{2}{*}{ Communication } & 3.41 & 3.40 & 3.40 & 3.10 & 3.10 & 3.10 & 3.26 & 3.25 & 3.25 \\
\hline & $(.29)$ & $(.19)$ & $(.18)$ & $(.30)$ & (.19) & (.18) & $(.24)$ & $(.17)$ & $(.16)$ \\
\hline \multirow[t]{2}{*}{ Unequal Effort } & 3.69 & 3.74 & 3.73 & 3.62 & 3.74 & 3.70 & 3.65 & 3.74 & 3.70 \\
\hline & $(.31)$ & $(.20)$ & $(.19)$ & $(.35)$ & $(.23)$ & $(.21)$ & $(.31)$ & $(.20)$ & $(.18)$ \\
\hline Personal & 3.69 & 3.16 & 3.32 & 3.85 & 3.29 & 3.45 & 3.77 & 3.23 & 3.50 \\
\hline Characteristics & $(.36)$ & $(.23)$ & $(.21)$ & $(.32)$ & $(.20)$ & (.19) & $(.28)$ & $(.18)$ & $(.17)$ \\
\hline \multirow[t]{2}{*}{ Closeness } & 3.62 & 3.68 & 3.66 & 3.54 & 3.42 & 3.45 & 3.58 & 3.55 & 3.56 \\
\hline & $(.32)$ & $(.21)$ & $(.19)$ & $(.34)$ & $(.22)$ & $(.20)$ & $(.29)$ & $(.19)$ & $(.17)$ \\
\hline Thoughts of & 3.15 & 2.84 & 2.93 & 2.62 & 2.65 & 2.64 & 2.89 & 2.74 & 2.81 \\
\hline New Friends & $(.36)$ & $(.23)$ & $(.21)$ & $(.34)$ & $(.22)$ & $(.20)$ & $(.31)$ & $(.20)$ & (.18) \\
\hline
\end{tabular}

Note. Matching letters represent significant interactions, $p<.05$. 
Table 13

Intercorrelations Among Ratings of Problem Frequency

\begin{tabular}{|c|c|c|c|c|c|c|c|c|c|c|c|}
\hline & 1 & 2 & 3 & 4 & 5 & 6 & 7 & 8 & 9 & 10 & 11 \\
\hline 1. Trust & 1.00 & $.227 * *$ & $.338 * *$ & $.391 * *$ & $.274 * *$ & $.287 * *$ & $.400 * *$ & $.355 * *$ & $.165^{*}$ & $.391 * *$ & $.344 * *$ \\
\hline 2. Shared History & .060 & 1.00 & $.221 * *$ & $.274 * *$ & $.371 * *$ & $.193 * *$ & $.339 * *$ & $.381 * *$ & $.222 * *$ & $.394 * *$ & $.519 * *$ \\
\hline 3. Unequal Effort & $.308^{* *}$ & $.261 * *$ & 1.00 & $.348 * *$ & $.355^{* *}$ & $.381 * *$ & $.342 * *$ & $.484 * *$ & $.297 * *$ & $.608 * *$ & $.413 * *$ \\
\hline 4. Disapproval/Behavior & $.321 * *$ & $.235^{* *}$ & $.408 * *$ & 1.00 & $.369 * *$ & $.271 * *$ & $.330 * *$ & $.553 * *$ & $.198 * *$ & $.414 * *$ & $.408 * *$ \\
\hline 5. Closeness & $.266^{* *}$ & $.227 * *$ & $.469 * *$ & $.414 * *$ & 1.00 & $.382 * *$ & $.339 * *$ & $.386 * *$ & $.329 * *$ & $.540 * *$ & $.507 * *$ \\
\hline 6. Thoughts/New Friends & $.248 * *$ & $.178 * *$ & $.365^{* *}$ & $.273 * *$ & $.357 * *$ & 1.00 & $.162 *$ & $.340 * *$ & $.265^{* *}$ & $.334 * *$ & $.331 * *$ \\
\hline 7. Support & $.474 * *$ & $.268 * *$ & $.358 * *$ & $.379 * *$ & $.368 * *$ & $.357 * *$ & 1.00 & $.376^{* *}$ & $.285^{* *}$ & $.464 * *$ & $.479 * *$ \\
\hline 8. Similarity & $.254 * *$ & $.222 * *$ & $.377 * *$ & $.498 * *$ & $.440 * *$ & $.331 * *$ & $.356^{* *}$ & 1.00 & $.328 * *$ & $.455^{* *}$ & $.464 * *$ \\
\hline 9. Common Experiences & $.166^{*}$ & $.224 * *$ & $.425 * *$ & $.321 * *$ & $.477 * *$ & $.217 * *$ & $.388 * *$ & $.484 * *$ & 1.00 & $.319 * *$ & $.249 * *$ \\
\hline 10. Commitment & $.415^{* *}$ & $.278 * *$ & $.564 * *$ & $.427 * *$ & $.572 * *$ & $.410 * *$ & $.495 * *$ & $.362 * *$ & $.475 * *$ & 1.00 & $.593 * *$ \\
\hline 11. Communication & $.387 * *$ & $.356^{* *}$ & $.510 * *$ & $.440 * *$ & $.459 * *$ & $.355 * *$ & $.486 * *$ & $.496 * *$ & $.384 * *$ & $.512 * *$ & 1.00 \\
\hline
\end{tabular}

Note. $*$ indicates a significant correlation, $p<.05 ; * *$ indicates a significant correlation, $p<.01$.

Data for pre-college friendships are on the top half of the table; college friendship data are on the bottom half. 
Table 14

Intercorrelations Among Adjustment Items

\begin{tabular}{|c|c|c|c|c|c|c|c|c|c|}
\hline & 1 & 2 & 3 & 4 & 5 & 6 & 7 & 8 & 9 \\
\hline 1. Loneliness & 1.00 & $.224 * *$ & $-.328 * *$ & $-.130 *$ & -.127 & -.088 & -.068 & -.054 & $-.148 *$ \\
\hline 2. Homesickness & & 1.00 & -.052 & -.029 & .040 & -.009 & -.094 & -.078 & -.075 \\
\hline 3. Social Support & & & 1.00 & $.166^{* *}$ & $.340 * *$ & $.137 *$ & -.055 & .003 & .023 \\
\hline 4. Seek an Instructor's Help & & & & 1.00 & $.314^{* *}$ & $.307 * *$ & -.070 & -.087 & -.088 \\
\hline 5. Friend's Academic Help & & & & & 1.00 & .050 & .081 & .035 & .023 \\
\hline 6. Grade Point Average & & & & & & 1.00 & $-.203 * *$ & $-.179 * *$ & $-.223 * *$ \\
\hline 7. Alcohol Consumption per Week & & & & & & & 1.00 & $.527 * *$ & $.752 * *$ \\
\hline 8. Alcoholic Beverages at a Time & & & & & & & & 1.00 & $.596 * *$ \\
\hline 9. 5+ Drinks per Month & & & & & & & & & 1.00 \\
\hline
\end{tabular}

Note. $*$ indicates a significant correlation, $p<.05 ; * *$ indicates a significant correlation, $p<.01$ 
Table 15

Intercorrelations Among Coping Strategies

\begin{tabular}{|c|c|c|c|c|c|c|c|c|}
\hline & 1 & 2 & 3 & 4 & 5 & 6 & 7 & 8 \\
\hline 1. Cognitive/Emotional Regulation & 1.00 & $-.201 * *$ & -.111 & $-.201 * *$ & -.105 & -.011 & -.114 & .045 \\
\hline 2. Behavioral Self-Regulation & & 1.00 & $-.245 * *$ & $-.369 * *$ & $-.174 * *$ & -.084 & -.123 & -.100 \\
\hline 3. Involving Others & & & 1.00 & $-.225^{* *}$ & -.121 & -.066 & $-.168 * *$ & -.101 \\
\hline 4. Exercise & & & & 1.00 & $-.162 *$ & -.092 & $-.161 *$ & $-.148 *$ \\
\hline 5. Alcohol/Drugs & & & & & 1.00 & -.031 & -.097 & -.046 \\
\hline 6. Leaving & & & & & & 1.00 & $-.129 *$ & -.039 \\
\hline 7. Sleeping & & & & & & & 1.00 & -.095 \\
\hline 8. Other/None/Blank & & & & & & & & 1.00 \\
\hline
\end{tabular}

Note. $*$ indicates a significant correlation, $p<.05 ; * *$ indicates a significant correlation, $p<.01$ 
Table 16

Correlations of Coping Strategies and Adjustment Measures

\begin{tabular}{|c|c|c|c|c|c|c|c|c|c|}
\hline & Lonely & Homesick & $\begin{array}{c}\text { Social } \\
\text { Support }\end{array}$ & $\begin{array}{l}\text { Instructor } \\
\text { Help }\end{array}$ & $\begin{array}{l}\text { Friend } \\
\text { Help }\end{array}$ & GPA & $\begin{array}{l}\text { Weekly } \\
\text { Alcohol }\end{array}$ & $\begin{array}{l}\text { Number } \\
\text { Drinks }\end{array}$ & $\begin{array}{c}\text { Monthly } \\
\text { Drinks }\end{array}$ \\
\hline Cognitive/Emotional Regulation & .094 & .079 & $-.151 *$ & .008 & -.049 & -.101 & -.002 & -.030 & -.044 \\
\hline Behavioral Self-Regulation & .068 & .002 & .003 & -.022 & -.013 & .098 & -.019 & -.039 & -.076 \\
\hline Involving Others & .053 & .011 & .087 & -.018 & .012 & -.071 & -.064 & -.096 & -.025 \\
\hline Exercise & $-.137 *$ & -.031 & $.130 *$ & .086 & .055 & .080 & $-.161 *$ & .007 & -.059 \\
\hline Alcohol/Drugs & .003 & -.048 & $-.166^{*}$ & -.064 & -.054 & $-.158 *$ & $.41 * *$ & $.220 * *$ & $.321 * *$ \\
\hline Leaving & .044 & -.079 & .107 & -.006 & $.130 *$ & .039 & .051 & -.033 & -.075 \\
\hline Sleep & -.019 & .089 & -.079 & .061 & .049 & .101 & -.070 & -.011 & -.032 \\
\hline Other/None/Blank & -.039 & -.064 & -.052 & -.036 & -.124 & -.009 & -.020 & .030 & .052 \\
\hline
\end{tabular}

Note. $*$ indicates a significant correlation, $p<.05 ; * *$ indicates a significant correlation, $p<.01$ 


\section{Figure Captions}

Figure 1. Percentage of reported causes of problems and causes of friendship dissolution for precollege and college friends.

Figure 2. Males' and Females' mean ratings of the frequency of causes of friendship dissolution. 


\section{$\square$ PC Problem $\square$ PC Ending $\square$ C Problem $\square$ C Ending}

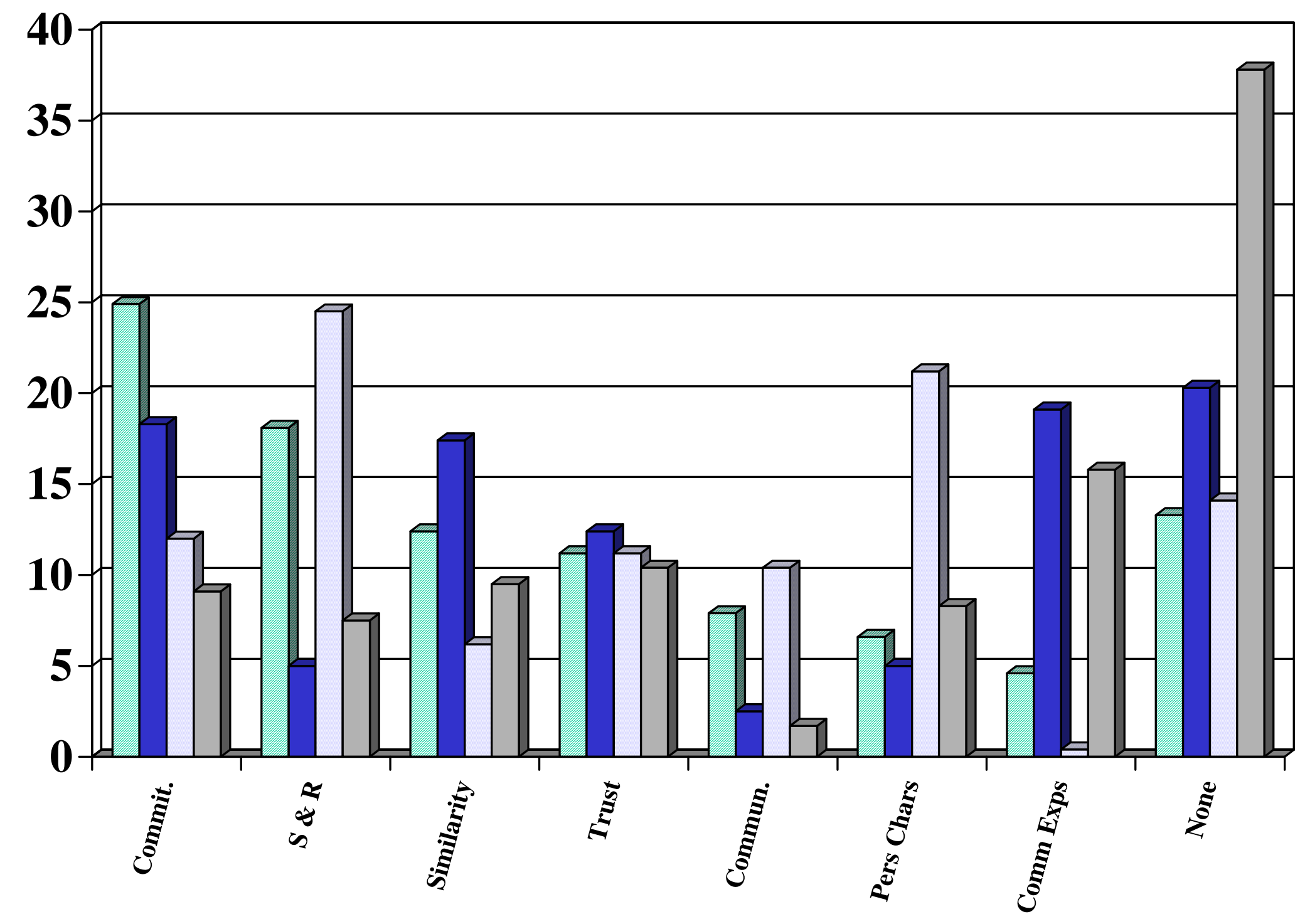




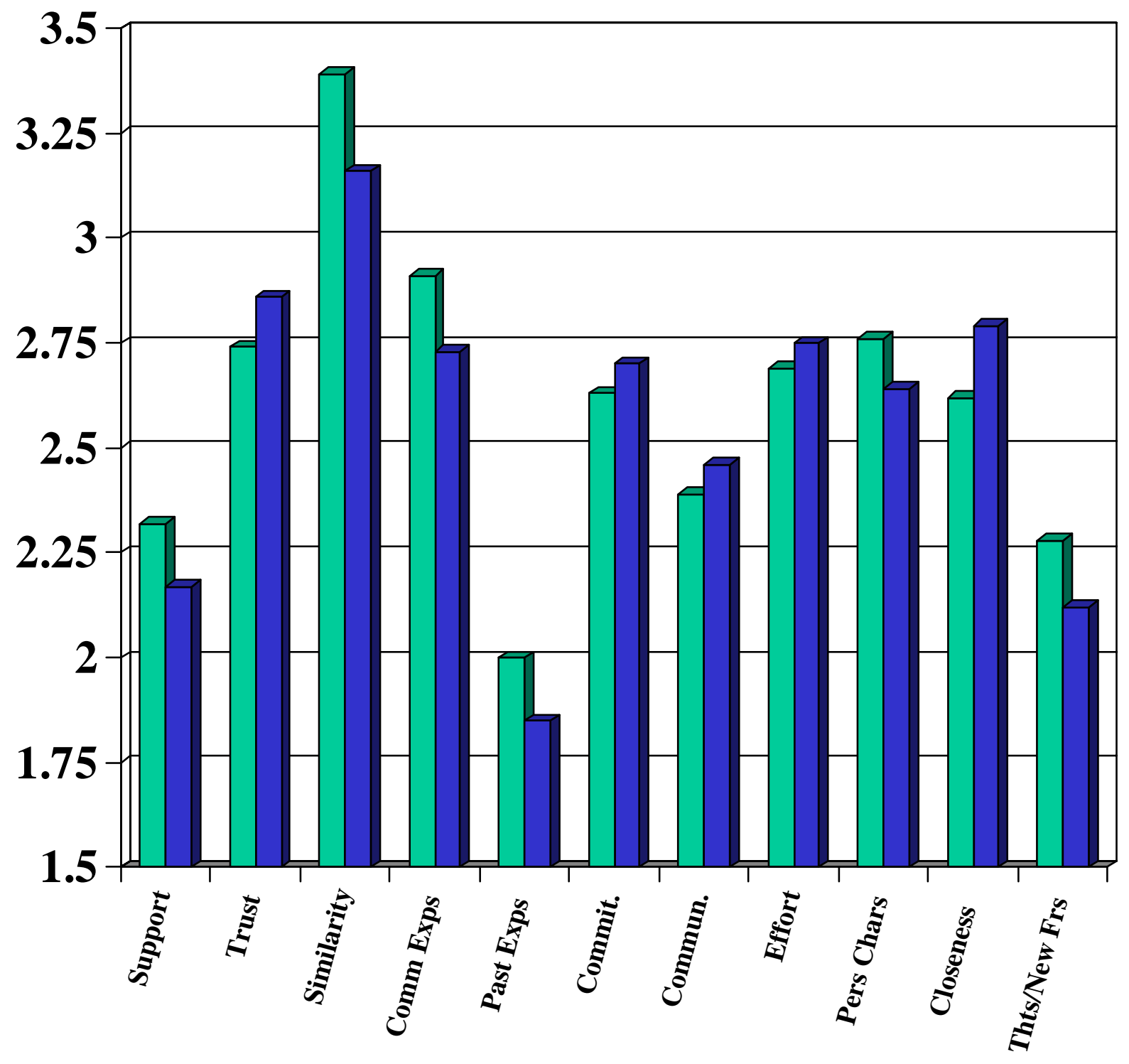

$\square$ Males

$\square$ Females 